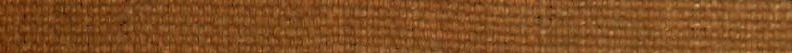

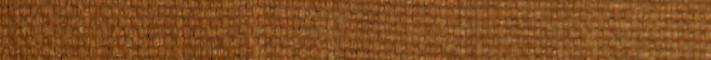
Q6. How

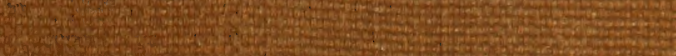
(D. 20.6. C. Q5.

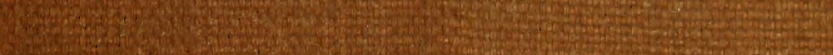
20.7.

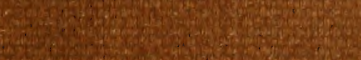

S.

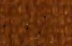

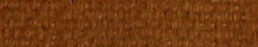
A

SWE (4)

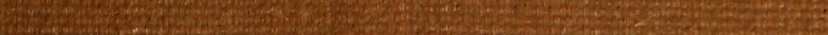
Q. 900

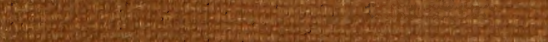
6.

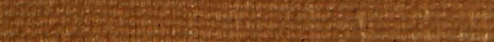
130.

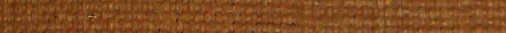
60. How

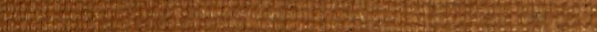

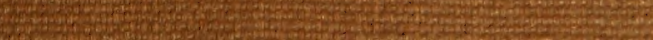




\section{CORNELL UNIVERSITY LIBRAR Y}

BOUGHT WITH THE INCOME OF THE SAGE ENDOWMENT FUND GIVEN IN I89I BY HENRY WILLIAMS SAGE 
a. 



\section{IOH. CHRIST. FABRICII}

PROF. HIST. NAT, OECON, ET CAMERAL. SOC. REE. HAFN. NORW. ET BEROL. SOC.

\section{PHILOSOPHIA ENTOMOLOGICA S I S T E S} SCIENTIAE FVNDAMENTA A DIECTIS

DEFINITIONIBVS, EXEMPLIS, OBSERVATIONIBVS, ADVMBRATIONIBVS.
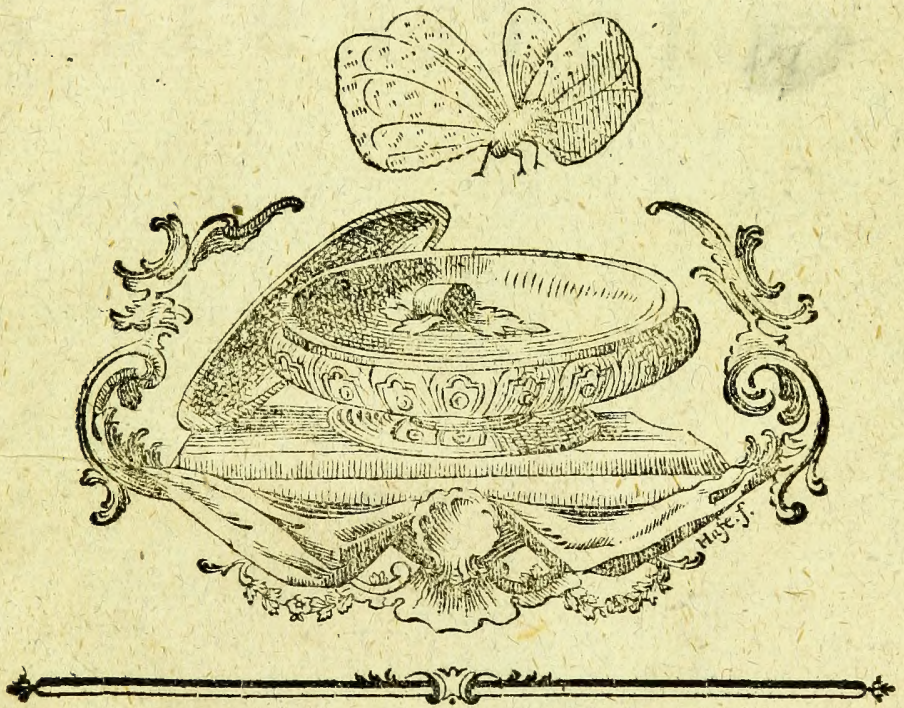

$H A M B V R G I$ et $K I L O N I I$

IMPENSIS CAROL. ERNEST. BOHNII MDCCLXXVIII. 


\section{$9598 \AA 30$ \\ A. 71417}

Hominum commenta delet dies, at Naturat opus peragatur. 
INDVLGENTISSIMO

M V SARVM PATRONO

ILLVSTRISSIMO COMITI

A B E R NSTOR F。

\section{S.}

$x=$ 


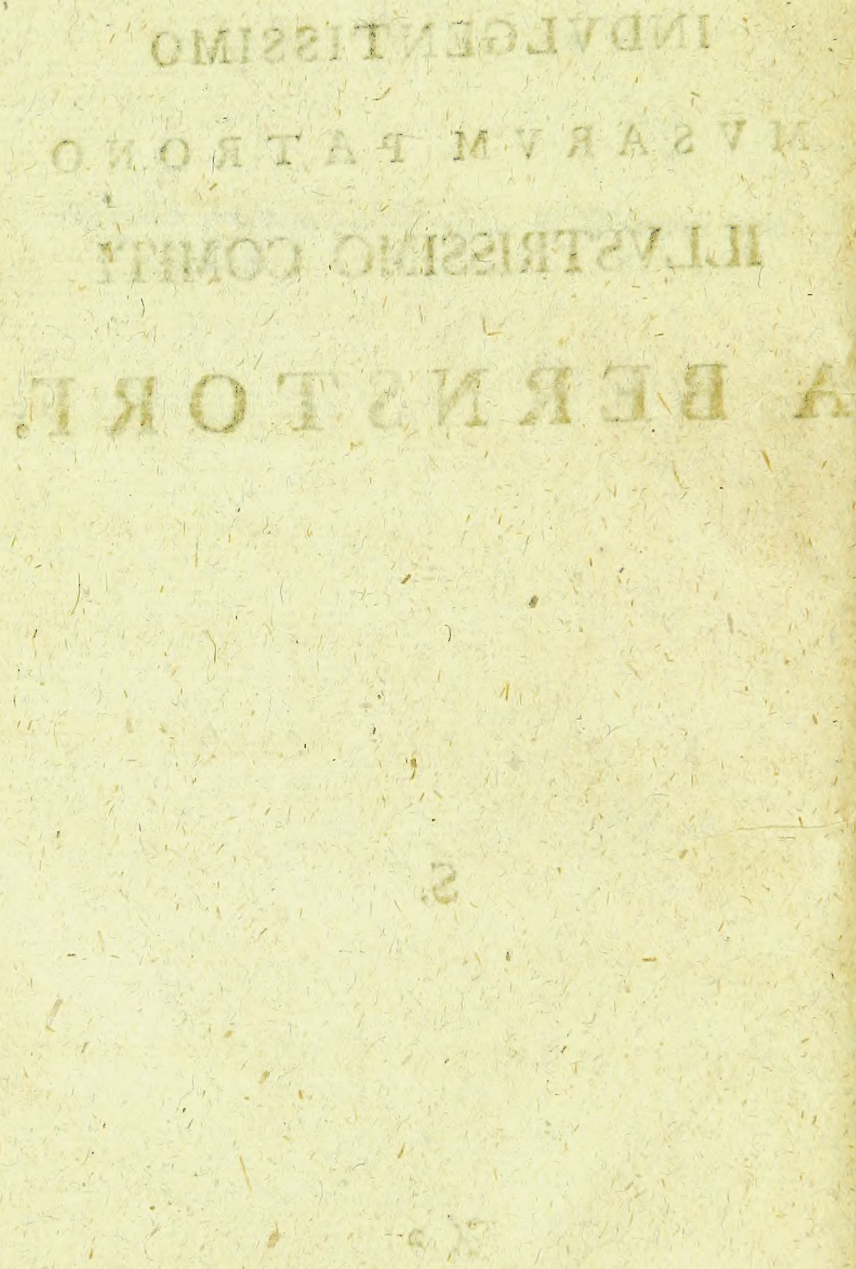




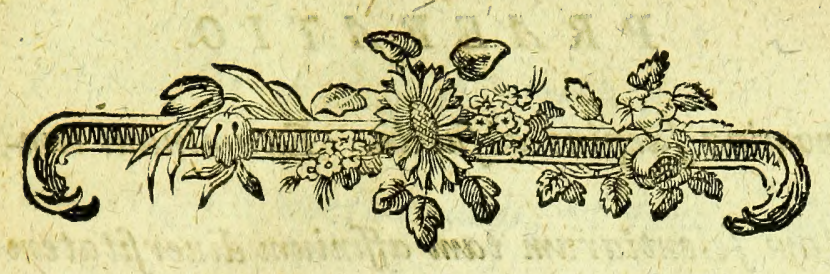

\section{$P R A E F A T I O$.}

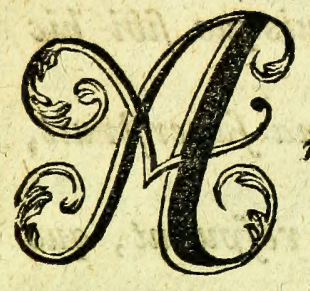

nte iam duodecim annos fundamenta haec entomologica

pofui, vt haberem, quibus fyfema fuper-

fruere poffim. Vidi Botanices praeftantiam inprimis certitudine niti, vidi vacilJantem Entomologiam, claffes Iudicras, genera falja, Species haud determinatas et 


\section{$P R A E F A T I O$.}

gomina faepius abfurda. Examinaui tan-

tam fcientiarum tam affinium diuerfitatem et in illa omnia firma, certa, in hac vero omnia vaga inueni. Certitudinem hanc Botanices regulis fixis bene fabilitis niti ob. feruani, qumn e contrario in Entomologia omnino mullae fancitae. Quisque fibi hic regulas fingit, quibus fyftema fuperftruit, quin phurimi amnino regulas refpunnt, qua ipfo fyftemata fallacia redduntur et tanta orta confufio, vt magis figuris quam fyftemati confidamus.

Botanicorum ideo, imprimis vero praeGeptoris optimi fommi Linnaei, fyftemati- 


\section{PRAEFATIO.}

bus, regulis operam dedi, vt fundamenta folida certitudinis fcientiae cognofcerem et Entomologiae applicarem. Hoc fudio philofophia haec entomologica orta, cui poftea fyftema proprium fuperftruxi.

Continet philofophia haec varias partes, quae omnes ad fientiae theoriam fpeIant, omnes fcientiam firmiorem, certiorem reddunt, vt tandem pedibus infiftat hand vacillantibus.

In Bibliotheca entomotogica pliures fame foriptores enumerare potuiffem, at inter emineratos plures iam fuperwacanei. Non enim eft lettionis farrago, fed obfer. x 4 yationes. 


\section{P R A E F A TIO}

vationes propriae, quae fcientiae heroes praebent.

Partes In fectorum Inftrumentaque cibaria determinare, rite definive et terminologiam firmare operam dedi. Primum eft fyftematis fundamentum, ne charafteres vagi dubiique enadant. Terminologia confufa omnia confunduntur.

Metamorphofin et determinationem.

Laruarum puparumque qualemonque addidi, at miti mullo modo fatisfecit. Multa adhuc tatent, nec nota rite tradita. Forte. inftrumenta cibaria et laruarum charatteres praeftantiffimos praeberent, at hos afsequi 


\section{$P R A E F A T T O$.}

affequi nondum valui. Praeftantiffimos

Entomologos his inprimis operam dare wellem, vt nitor fcientiae magis magisque fulgeat.

Sexus et generationis theoriam continet. Obferuationes huc fpettantes omnes brenitatis cauffa tradere houd potui; cons chufones tantum propofui. Alio toco alio. que opere, $\sqrt{a}$ fata velint, ob fernationes hafce qualescunque fiftam.

Charatteres effentiale fyftematis con tinent. Regulas hic paullo artiores dedi exemplisque illuftrani, qum his tota nitatur fcientia. Entomologis veris in primis 


\section{$P R A E F A T I O$.}

Aremie commendo: charateres amnes iisdem Semper partibus defumendos. Regula enim has hand obferuata chas onmino erit res entomologica.

Nomina Infectorum difincte tradere comonit, Nomina fi pereunt, perit et cognitio rerom: namina $f$ confundantur, confondantur ommia neceffe eft.

Differentiis fixis, rite elaboratis itidem nititur Entomologia, qunim omnis vera cogmitio fpecierum cognitioni fuperftruatur, Probe idea obferuandum, nunquam fpe cient absque differentia rite eruta propo. mendam effe. 


\section{P RAEFATIO.}

Adumbrationes, Oeconomia et $V$ fus ob.

fernationes partim ad fyftema, partim ad naturam fpectantes praebent; Entomo. logiam et incundiorem et vtitiorem red dunt.

His vtere, $L, B$. noftrisque fudiis fom pere perge.

Dab. Kiliae d, xx. Febr. 1778:

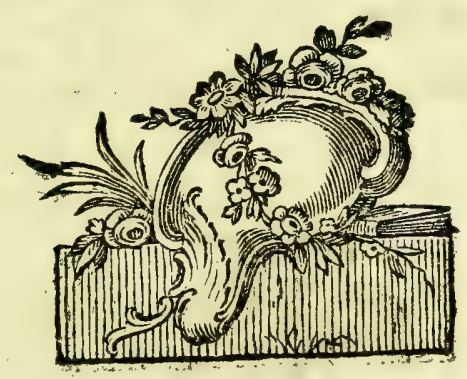




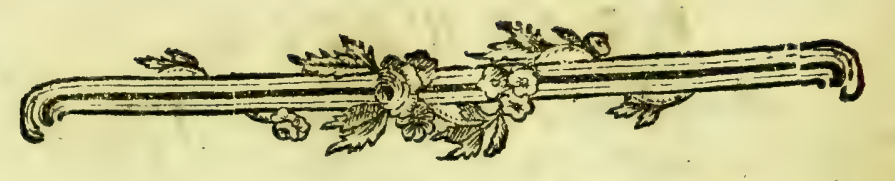

\section{O N S P E C T V S.}

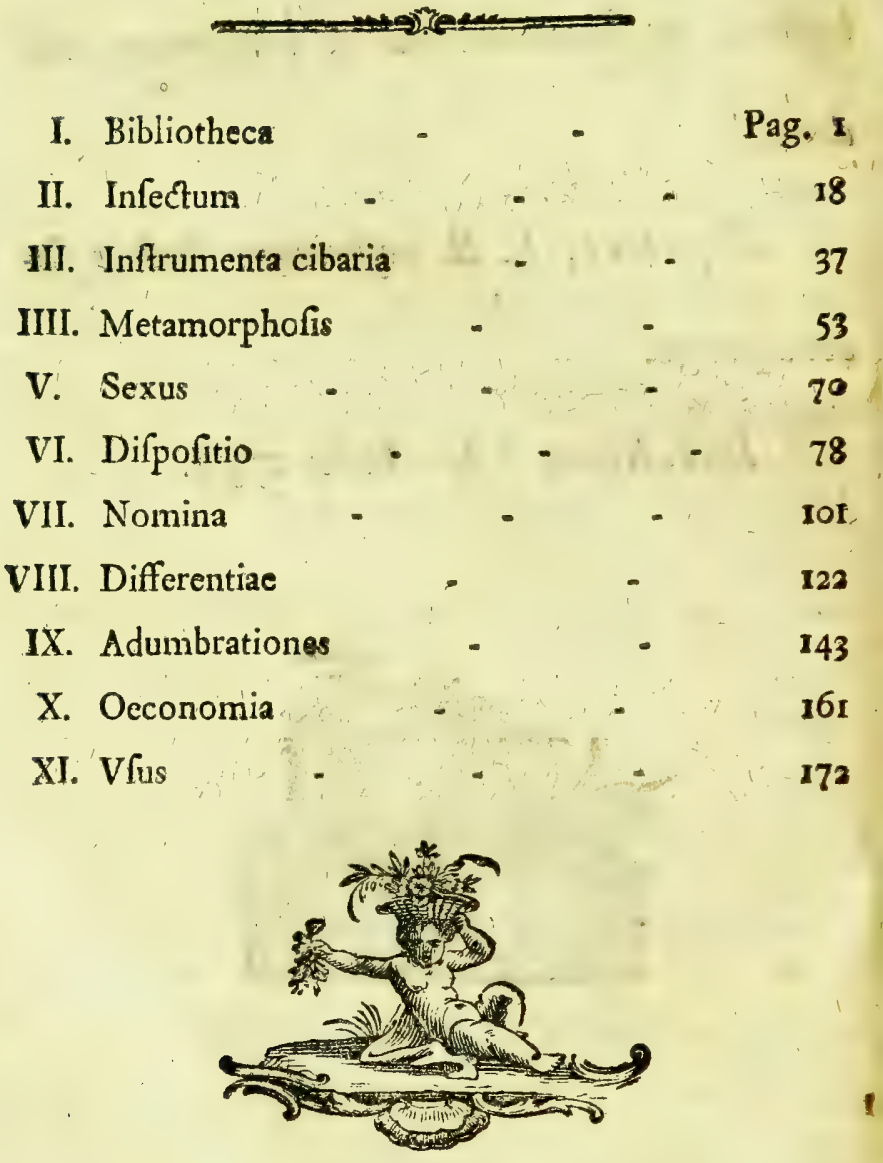

I. BIBLIO- 


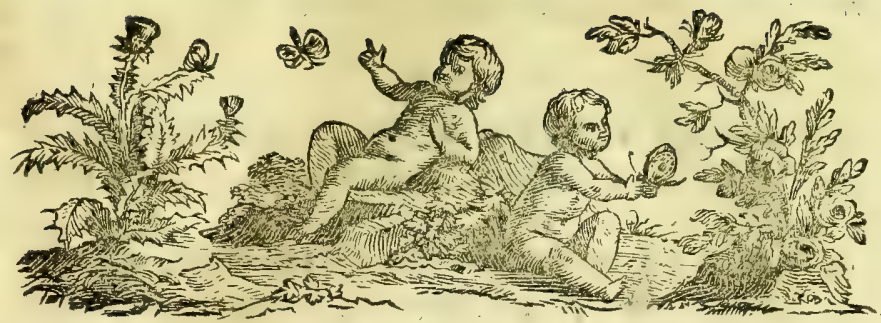

\section{BIBLIOTHECA.}

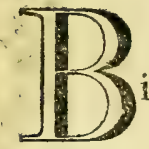

$$
\text { ઈ. } 1 \text {. }
$$

ibliotheca entomologica enumerat libros de Infectis fcriptos.

Bibliotheca Entomologo necefiaria, docet hiftoriam, fata, methodum et defiderata fcientiae.

Bibliotheca tyroni neceflaria, docet, quos auctores ewoluat, qui vtiles, qui fuperflui, quum verbofitas fcientiae calamitas maxima.

\section{§. 2.}

Bibliotheca entomologica vix ante tempora Gefneri afcendit. Antecedentes pauci, obfcuri, vix in confiderationem veniunt.

Entomologia Botanica iunior tam alte afcendere haud valet.

Scripta vetuftinima de infectis obfcura, referta fpeciebus, quae nullo modo extricare valemus absque defcriptionibus et figuris, relinquenda.

Fabr. Entom. 


$$
\text { §. } 3 \text {. }
$$

Entomologi vocantur auctores opere aliquo de infectis clari aut Syftematici, aut Empirici.

Syftematici fcientiae fundamenta ftruunt, inaedificant, Empirici vero obferuationes vagas ad aedificii ornamentum colligunt.

Entomologi primarii fecundum tempus numeramus.

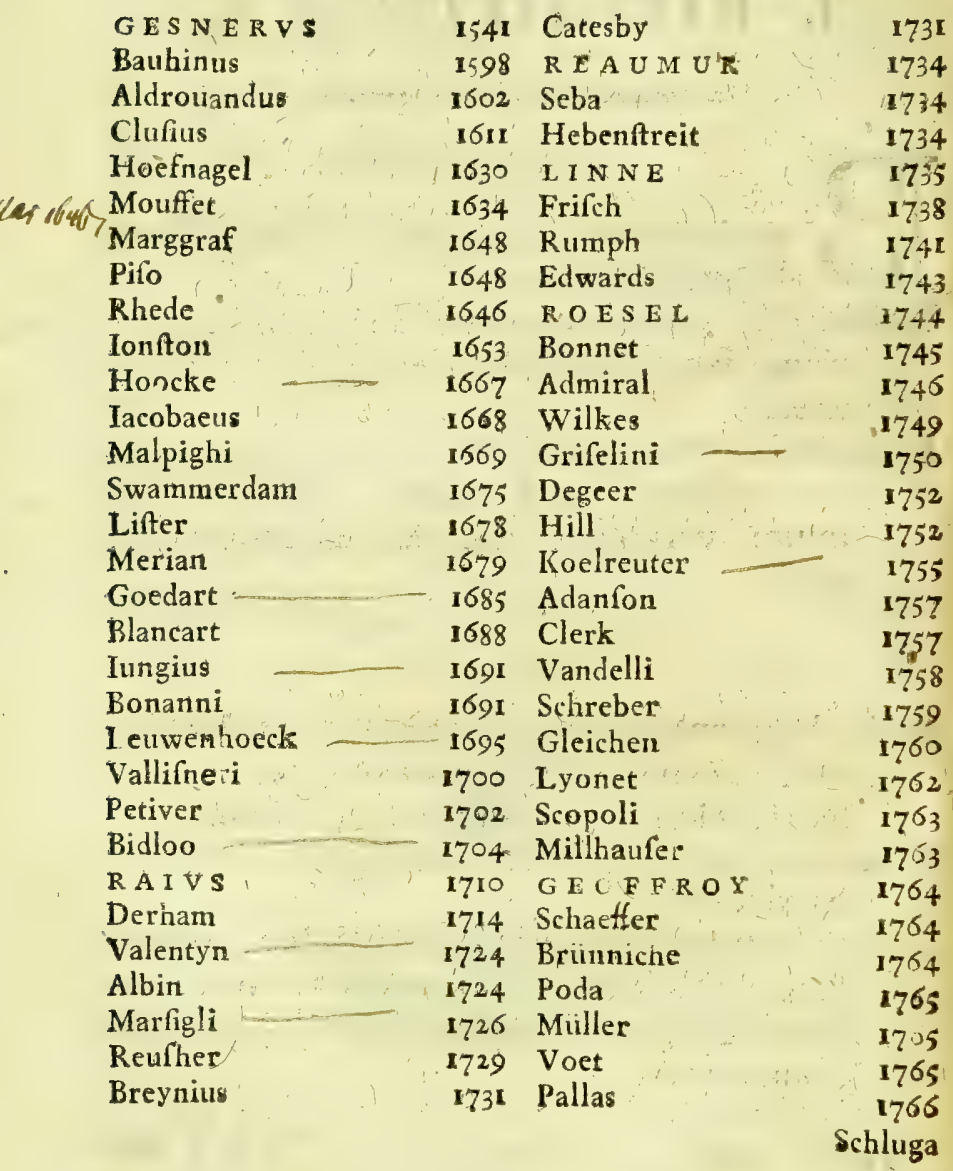


Schluga

Allioni

Drury

Stroem

Sepp.
1767 Cramer

1768 Schieffermüller

1768 Efper

1769 Goeze

$177^{2}$ Fueslin
1775

1776

1777 .

1777

1777

\section{$\$ .4$.}

Syftematici infecta in Claffes, Ordines, Genera, et fpecies difponunt, eoque determinatio. nem et denominationem fpecierum facilitant. Sunt vniuerfales aut particulares.

In fyftemate confiftit fundamentum fcientiae, hoc enim fublato deficit omnis et determinatio et denominatio fpecierum.

Syftemata inuenimus in entomologia varia, at plura adhuc defiderantur.

\section{$\$ .5$.}

Syftematici vniuerfales omnia infecta illis nota in ordinem redegerunt.

Praecipui corum funt:

Iон. Raivs, Anglus, Methodus Infectorum. Londini 1708.8.
- .
Hiftoria Infectorum. Londini
1710. 4. Opus pofthumum.

Claffes a metamorphofi defumfit, Ordines a numero pedum.

I. Ametamorphota.

I. Apoda. Vermes.

a. terreftria,

b. aquatica.

2. Pedata.

a, hexapoda.

$\alpha$. terreftria.

B. aquatica,

b. octopoda.

c. quatuordecimpoda.

d. polypoda, 
a. terreftria,

$\beta$. aquatica.

II: Metamorphota.

1. Laruis et pupis agilibus.

2. Pupa immobili,

a. koleoptera.

b. aneloptera.

$\infty$, alis farinaceis.

$\beta_{*}$ alis membranaceis.

* diptera bipennia.

* tetraptera quadripennia.

III. Metamorphofi fimplici e vermiculo in animalculum volatile, interpofita aliqua quiete.

Martin Listek, Anglus, Syftema Entomologiae in appendice ad Raji Hiftoriam infectorum. Lond. 1710 .

Claffes ab oui figura, Ordines a numero pedum.

I. Ex ouis fphaericis, quae nullam fubeunt metamorphofim.
a. pedibus fenis.
b. pedibus octonis.
c. pedibus plurimis.
d. pedibus nullis. Vermes.

II, E\& ouis longiufculis, quae metamorphofin fubeunt.

a. koleoptera.

b. anelytra.

$\alpha$. penuis quatuor nudis.

$\beta$. pennis quatuor farinaceis.

$\gamma$. pennis duabus.

Carol. Linne, Suecus, Syftema Naturae per tria regna Naturae 1735. fol. 1768. Edit.12. 8.

Claffes $a b$ alis, Ordines a variis partibus defumbit.

I. Coleoptera.

a. antennis clauatis.

b. antennis filiformibus,

c. antennis fetaceis.

II. Hemiptera.

a. roftro inflexo.

b. roftro pectorali. 
III. Lepidoptera.

IV. Neuroptera.

V. Hymenoptera.

VI. Diptera.

VII. Aptera,

a. pedibus fex.

b. pedibus pluribus.

a. capite cum thorace vnito, mamorof/un

$\beta$. capite a thorace diftincto.

Ioh. Avg. Roesell v. Rosenhorf, Germanus, Infektenbeluftigung 1746 .

Syftema in' Prolegomenis propofuit a metamorphofi defumtum.

I. Terreftria.

I. metamorphofin fubeuntia.
a. laruis hexapodis.
b. laruis $10-\mathbf{I} 6$ podis.
c. laruis $18-22$ podis.
d. laruis apodis.

2. absque metamorphofi.
a. pedibus $f \mathrm{e} x$.
b. pedibus octo.
c. pedibus decem.
d. pedibus pluribus.
e. pedibus nullis. Vermes.

-II. Aquatica.

I. metamorphofin fubeuntia.
a. laruis 6 podis.
b. Laruis 16 podis.
c. laruis apodis.

2. absque metamorphofi.
a. pedibus fex.
b. pedibus octo.
c. pedibus decem.
d. pedibus quatuordecim.
e. pedibus nulirs. Vermes.

Geoffroy, Gallus, Hiftoire des Infectes. Paris 1762.4 .

Retinet Claffes Linnaei ab alis defumtas, exceptis hymenopteris, quae cum neuropteris coniunxit. Ordines a numero articulorum tarfi confecit. 
I. Coleoptera.

a. coleopteris integris, duris.

$\alpha$. tarforum articulis quinque.

ß. tarforum articulis quatuor.

$\boldsymbol{\gamma}$. tarforum articulis tribus.

d. tarforum primi et fecundi paris pedum articulis quinque: pedum vero pofteriorum articulis quatuor.

b. colenpteris dimidiatis, duris.

$\alpha$, tarforum articulis quinque.

ß. tarformm articulis quatuor.

$\boldsymbol{\gamma}$. tarforum articulis tribus,

d. tarforum primi et fecundi pedum paris articulis quinque: pedum vero pofticorum articulis quatuor.

c. coleopteris mollibus, membranaceis.

«. tarforum primi et fecundi pedum paris articulis quinque : pofticorum vero pedum quatuor.

B. tarforum articulis duobus.

$\gamma$. tarforum articulis tribus.

d. tarforum articulis quatuor.

II. Hemiptera.

६. tarforum articulis quinque.

III. Lepidoptera.

IV. Tetraptera.

a. tarforum articulis tribus.

b. tarforum articulis quatuor,

V. Diptera,

c. tarforum articulis quinque.

VI. Aptera.

Ego Syftema Entomologiae fecundum numerum, figuram, proportionem et fitum omnium partium oris elaboraui. Flensburgi 1775.

1. Eleuterata. Rimfununtions Kiliae 1777.

a. antennis claua lamellata. Spigmefineng

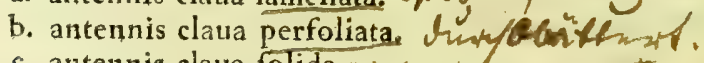

c. antennis claua folida.ymen.

d. antennis moniliformibus,

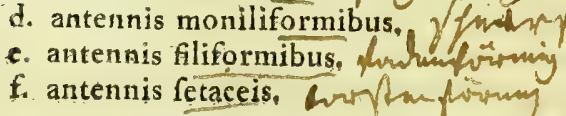
cirritanfinury 
II. Vlonata. Guluchimfors

a. anternis filiformibus.

b. antennis enfiformibus.

c. antennis fetaceis.

III. Syniftata.

a. elinguia.

b. linguaria.

IV. Agonota.

V. Vnogata.

VI. Gloflata. dinfincigens.

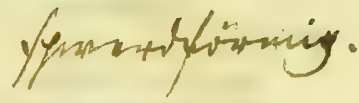

VII. Ryngota.

a. roftro inflexo.

b. roftro arcuato.

c. vagina pectorali.

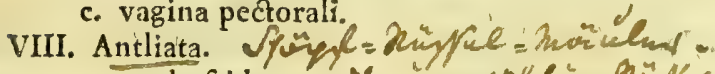

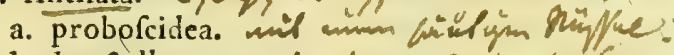

b. hauftells a. unit minman Singy täj/ue.

§. 6.

Syftematici particulares vnius tantum claffis, quin et generis amplioris fyftema compofuere.

Syftemata particularia rite elaborata fyftemati vni-

verfali certitudinem et nitorem praebent.

Pauca iam elaborata inuenimus, alia defiderata

Entomologis oculatis commendo. E. gr.

Ichneumones, Apes, Curculiones, Tineas

aliaque.

Scarabaeorum fiue Eleuteratorum ordines elabo-

rauit Martinvs Lister in appendice ad

RaII hiftoriam infectorum. Lond. 1710.

I. Terreftres. fullitimunt

a. corniculis laminatis.

b. corniculis capiliaceis fue acutis.

$\alpha$. alarum thecis integris.

$\beta$. alarum thecis mutilatis.

c. corniculis promufcide infertis. Gurgulliones Veterum.

«. vnica in medio iunetura.

B. pluribus iuncturis certe ad extrema.

A 4. 
d. os aculeo inftructum culicum more fiue Cimices Veterum.

II. Aquatici.
a. aquae dulcis.
b. aquae marinae.

Rene Antoine Reaumur Gloffata fecundum numerum pedum laruae in ordines redegit.

1. Larua pedibus intermediis 8. omnibus 16 .

2. Larua pedibus intermediis 6 . omnibus 14. fegmentis $4.5 \cdot 6.10 .1 \%$. pedibus deftitutis.

3. Larua pedibus intermediis 6. omnibus 14. fegmentis 4. 5. 9. 10. 1I, pedibus deftitutis.

4. Ląrua pedibus intermediis 6 , omnibus 12. pofticis nullis.

5. Larua pedibus intermediis 4 , omnibus $\mathbf{2}$.

6. Larua pedibus intermedis 2, omnibus 10.

7. Larua pedibus intermediis nullis omnibus 8 .

Schieffermuller eorundem Gloffatorum ordines compofuit partim e laruae partim ex imaginis ftructura.

Verzeichnifs der Schmetterlinge der Wiener Gegend. Wien 1776 .

I. Sphinges.

II. Phalaenae.

a. Bombyces. Syininaf
a. laruis 16 podis.
b, laruis 14 podis.
c. laruis apodis.

ค. Noctuae.
a. laruis 14 podis.
b. laruis 16 podis.
c. laruis I2 podis.

\%. Geometrae.
a. laruis 12 podis.
b. laruis 10 podis.

d. Pyralides,

á longipalpes.

b. breuipalpes.

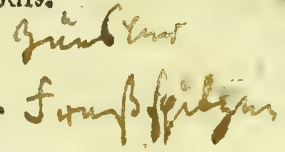




\section{B I B LIOTHECA.}

8. Tortrices.

\section{Plisklisine?}

a. virides.

b. metallicae.

c. flauae.

d. ferrugineae.

e. cincreae.

f. obfcurae.

\%. Tincae.

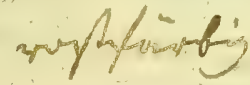

nearcliner
a. bombyciformes.
b. directipalpes.
c. recuruipalpes.
d. impalpes.

ท. Alucitae.

HI. Papiliones.

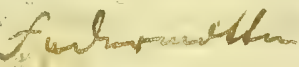

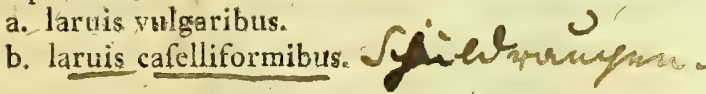

Martinvs Lister Aranearum genus elaborauit

RAI. Hiff:Inf. p. 17 ,

I. Oetonoculi.

a. retiarii.

$\alpha$. in mediis reticulis praedam fpeculantes.

$\beta$. domicilia extra reticula ponentes.

* retibus orbicularibus. minger,

** reticulis conglobatis. Snychlonsecion

*** telis linte oformibus. Cuin minariferfo

$\boldsymbol{\gamma}$. Aranei minus proprie dicti.

* Araneus, qui intra fpeluncam telam conficit, cui foras adnectit reticulam.

** Aranei lintearii parua tela contenti.

b. venatorii.

a. Lupi.

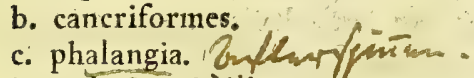

II. Binocuti fue Opiliones.

Carolvs Clerk, Suecus, -idem Aranearum genus diuifit. Aranei Suecici. Holm. I757. 4.

I. Aerei. Eumbfinture -
a. retiarii.

*. verticales retibus orbiculatis.
A 5
ค. irre- 


\section{B. irregulares.}

$\gamma$. textores retiolis denfis.

b. faltatores.

«. Jupi.

乃. phalangia.

$\boldsymbol{y}$. cancriformes.

II. Aquatici.

$$
\text { 6. } \%
$$

Entomologi empirici fpecierum numerum augent et obferuationibus variis faepe vtiliffimis fcientiam ornant. Sunt Defcriptores, Ichniographi, Monographi, Peregrinatores, Fauniftae, Oeconomi, Medici, Anatomici, Phyfiologi, Metamorphofii, Mufeographi, Obferuatores, Micrographi, Theologi, Synonymiftae, Bibliothecarii, Terminologi, Societates.

$$
\text { 6. } 8 .
$$

Defcriptores partes et fpecies infectorum examinant, determinant.

Exoleti. Gefner, Aldrouandus; Mouffet, Lifter, Swamnerdam.

Vfitatiffimi. Linné, Scopoli, Allioni, Forfter, Rajus, Sçhreber, Schulz, Pallas.

$$
\text { 5. } 9 .
$$

Ichniographi figuras infectorum iconibus faepe nitidiflimis exprefferunt.

Icones infectorum pretiofiffimae in nouiffimis temporibus in luxuriam artis multiplicantur. Syftema faepius relinquunt, fpernunt, folis iconibus contenti.

Rudes. Aldrouandus, Ionfton, Mouffet, Blankart, Goedart. 
Pretiofae viuis coloribus fucatae Sepp, Drury, Cramer, Voet, Clerk, Roeffel, Admiral, Albinus, Hill, Schaeffer, Edwards, d'Aubenton, Sulzer.

Nitidae Rumph, Adanfon, Barrelier, Merian.

Malae, fictitiae Louis Renard, Syfteme d'un Medecin Anglois.

\section{§. 10.}

Monographi vnius tantum infecti hiftoriam fpecialifimam tradunt.

Monographiae fpecialiffimae, accuratiffimae certitudinem fcientiae augent.

Selectae funt paucae Linné Phalaena Bombyx,

- Meloe veficatorius.

- Biga infectorum.

Mithaufer Bombyx Milhauferi.

Praecipuae numerantur Breynins Hiftoria Cocci polonici.

Schaeffer Apus pifciformis.

- - Stratiomys Ephippium.

- Mufca Cerambyx.

Barthius Culex.

Degeer Podura, Monoculus.

- Myrmeleon, Thrips.

- Aphis, Ephemera.

\section{II.}

Peregrinatores, amore hiforiae naturalis incitati, diffitas regiones adiere et earum thefauros colligerunt, communicarunt.

Pracftantiflimi funt $\left.\begin{array}{l}\text { Merian } \\ \text { Ralander }\end{array}\right\}$ Surinamenfia,

$\left.\begin{array}{l}\text { Sloane } \\ \text { Browne }\end{array}\right\}$ Iamaicenfia,

Rutuph Amboinenfia.

Adanfon Senegalenfia.

Haffelquijt Aegsptiaca.

Koenig Malabarica.

Rohr Americana.

$\left.\begin{array}{l}\text { Mifo } \\ \text { Pirgraf }\end{array}\right\}$ Brafiliana 
at Ios. Banks, Anglus, et Dan. Sol ander, Suecus, focii indiffolubiles viam ad ditifimam Auftralafiae hiftoriam naturalem aperuere.

$$
\text { §. } 12 .
$$

Fauniftae enumerant infecta certi alicuius loci aut regionis.

Enumeratio fit fyftematica, vt ab omnibus intelligi poffit.

Addantur Locus, Tempus, Metamorphofes,

Defcriptiones fpecierum nunc detectarum, Obferuationes.

Primarii funt Linné Suecica.

Geoffroy Parifina.

Scopoli Carniolica.

Schaeffer Ratisbonenfia.

Miiller Friderichsdalina.

I.ifter Anglica.

\section{13}

Oeconomize vfum aut noxam infectorum in vita communi tradunt.

Linné Noxa Infectorum

- Phalaena Mori

- Hofpita Infector.Flora.

Gleditfch de Locuftis.
'Schirach de Apibus. Reaumur de Tineis. Du Hamel de Tineis. Berniz de Cocco polonico.

$$
\text { 6. } 14 \text {. }
$$

Medici vires infectorum in corpus humanum examinarunt.

Linné Meloe veficatorius.

$W e d e l$ de Cantharidibus.

Eivald de Formicarum vfu medico.

Pre de Millepedis et Formicis.

Roberg de Aftaco fluuiatili,

Sommer de lapidibus Cancrorum. 


\section{15 .}

Anatomici internam infectorum ftructurum obferuarunt.

Blafius Anatomia Animalium.

Lyonet Anatomia Laruae.

Secammerdam Biblia Naturae.

Oligeri Amtomia Gryllotalpae.

Muralto Anatomia Pediculi et Pulicis.

$$
\text { ๑. } 16 .
$$

Phyfiologi actiones naturales infectorum reuelare conati funt.

Leurenhoeck Generationis leges.

Lewis Generatio Infectorum.

Martinet Refpiratio Infectorum.

Rhedi Experimenta circa generationem.

Reyger Generatio Aphidum.

$$
\text { 6. } 17 .
$$

Metamorphofii per triplicem ftatum infecta fecuti funt.

Metamorphofis infectorum triplex ad claffes et genera naturalia viam pandit.

Metamorphofis multorum plane adhuc latet, in primis in Eleuteratorum claffe. Rarius obferuantur, quum fub terra metamorphofin fubeunt.

Roeffel Infektenbeluftigung.

Admiral Obferuationes entomologicae.

Sepp Defcriptiones Infectorum.

Merian Infecta Europaea et Surinamenfia.

Frifch Infecta Berolinenfia.

Wilkes Infecta Berolinenfia. 


$$
\text { ఏ. I8. }
$$

Mufeographi infecta in Mufeo quodam afferuata fiftunt.

Infectum in Mufeo bene obferuatum praeftat omni icone, neceflarium omni Entomologo.

Conferuantur infecta aut ficca acu pertufa in ciftis cera et terebinthino obducendis et vitro claro tegendis.

Nunquam humida ciftis inferenda, ne oleofa euadant. Ad methodum qualemcunque difponenda.

Nomen genericum et fpecificum adfcribenda.

Aliquoties ciftae aere fereno aperiendae, ne mucore tegantur infecta.

Aut humida in vitris fpiritu vini repletis.

Vitra fint omnino hyalina operculo vitreo exacte claufa, ne auolet fpiritus.

Spiritus fit clarus nec rectificatifimus ne partes infectorum rodat.

Nomen genericum et ípecificum vitris adglutinandum, ideoque vnicum infectum in fingulis vitris.

Mufea infectorum in Europa nunc plura. Eminent in primis nobis nota.

Mufeum Reginae Sueciae. Drotningholn.

a Linné Vpfaliae.

Academiae Hafnienfis.

Dr. Schulzii Hamburgi.

Banks Londini.

Britanxicum Londini.

Dr. Hunter Londini.

Tunftall Londini.

Drury Londini.

Lee Hammerfmith.

Teats Londini.

Blackburn Oxonii.

Voet Hagae Comit.

Principis Hagae.

Cramer Amftaelodami.

Geoffroy Parifiis.

Mánduit Parifiis.

Allioni Taurini。 
Mufeum Hernanni Strasburgi.

Fabricii Chilonii.

Mufeographos varios numeramus. Primarii funt:

Linné Mufeum Reginae.

Olearii Mufeum Gottorfianum.

Petinerii Mufeum.

Scbae Thefaurus.

Wormii Mufeutn.

Zannichelli Mufeum.

$$
\text { §. } 19 .
$$

Obferuatores de variis infectorum proprietatibus eorumque neconomia folliciti fuere.

Oeconomia infectorum faepius admiranda magis excoli meretur, quum ad oeconomiam naturae viam pandat. Natura enim nusquam magis, quam in minimis tota eft.

'Linné Miracula infectorum.

- Oratio de memorabilibus in infectis.

- Pandora infectorum.

De la Pluche Spectacle de la Nature,

Senguerdi de Tarantula.

Bonnet de Aphidibus.

Reaumur Memoires.

Degeer Memoires.

Swammerdam de Ephemerae vita.

Roberg de Formicarum natura.

$$
\text { 6. } 20 \text {. }
$$

Micrographi oculo armato infeça minutiffima detegunt, defcribunt.

Microfcopiorum ope in noftris temporibus novum quafi mundum detegimus. Natura enim in minimis vti in maximis infinita.

Praecipui funt $v$. Gleichen varia, Toblon Obferiuationes.

Leuwenhoeck Arcana Naturae. 
Bonanni Obferuationes. Miiller Hiftoria Vermium.

$$
\text { 6. } 21 \text {. }
$$

Theologi aut infecta biblica explicant, aut theologiam naturalem e cognitione infectorum demonftrant.

Bochart Hierozoicon.

Maji Hiftoria animalium facr. fcript.

Scheuchzer Phyfica facra.

Raji fapientia diuina.

Derham Phyfico theologia.

Leffer infecto theologia.

Linné Oeconomia Naturae.

$$
\text { S. } 22 .
$$

Bibliothecarii libros de infectis feriptos vario modo enumerant.

Bibliotheca rite inftructa Entomologo neceffaria inprimis ad fynonymiam rite extricandam.

Bruckmann Bibliotheca animalis.

Le Long Scriptores hiftoriae naturalis Galliae.

Schenchzer Bibliotheca hiftoriae naturalis.

Gronovius Bibliothèca regni animalis.

Munchhanfen Bibliotheca.

$$
\text { S. } 23 .
$$

Synonymiftae diuerfa nomina infectis impofita colligunt:

Synonymia infectorum neceffaria, vt de fingulo infectorum obferuata mox innotefcant.

Synonymia infectorum difficilius eruitur; Veterum defcriptiones, figurae inextricabiles, noftri faeculi vero auctorum nomina et fpecies nirnis multiplicata.

Goeze Collectanea 1777. 


$$
\text { 6. } 24 \text {. }
$$

Terminologi terminos technicos Entomologiae docent, explicant.

Termini technici rite determinati fcientiam facilitant.

Linné Fundamenta Entomologica, Peuceri Appellationes.

$$
\text { \$. } 25 .
$$

Societates ad fcientiarum incrementum inftitutae varia de infectis Actis fuis inferuerunt. Societatum vfus ad conferuandas obferuationes mifcellaneas eximius.

Societas Anglica. .

Germanica Naturac Curioforum. Taurinenfis, :

Bérolinenfis. -

Gallica.

Hafnienfis, -

Vpfalienfis. :

Holmenfis. -

Norwegica.

Lufatica apiaria -

Naturforfcher. - 


\section{I N S E C T V M.}

I

6. I.

Infectorum partes primum a tyrone diftinguendae funt quatuor: Caput, Truncus, Abdomen et Artus.

Omnis infectorun defcriptio recta determinatione partium nititur, itaque haec ante reliqua elaboranda.

$$
\text { ต. }
$$

Caput thoraci affixum, fenfus fere omnes complectens, continet rudimentum cerebri, integumenta et cutem offeam cataphractam confatque ore, oculis, antennis, fronte, gula, ftemmatibus.

Caput plerisque diftinctum, paucis cum thorace coalitum: Aranea, Cancer.

Quibusdam anguftatum antice: Curculio, Panorpa; poftice: Attelabus, Raphidia.

\section{3.}

Os cibum hauriens omnibus commune conftat clypeo, labiis, mandibulis, maxillis, galea, palpis, lingua fpirali, probofcide, rofro, hauftello.

Clypeus, os fuperne tegens.

Labia, os inferne claudentia, ne haufta eruant.

Mandibulae duae, transuerfales, corneae, latera oris fuperne inclidentes.

Maxilláe, itidcm dutae transuerfales faepius membranaceae, latera oris inferne includentes. 
Galea, cylindrica, obtufa, fere veficulofa, maxillarum dorfum tegens.

Palpi duo, quatuor, fex, articulati, fenforii, mobiles. Lingua fpiralis, inter palpos refexos latens, conuoluta. Roftrum, vagina articulata vniualui fetas plerumque tres continens.

Hauftellum, fetis confians vagina aut nulla, aut biualui inarticulata inclufis.

Probofcis, carnofa ftipite cylindrica, recta, capituloque bilabiato, retractili.

\section{\$. 4 .}

Oculi, quibus vident colores, differunt, quoad numerum, fitum, connexionem, compofitionem, figuram.

Numerus bini plerisque.

fex. Aranea.

octo. Aranea.

Situs approxinati. Monoculus.

diftantes. Scarabaeus.

frontales. Phalangium, Aranea.

laterales. Phalaena, Aranea.

Connexio teftae innati. Monoculus.

prominuli. Cicindela, Agrion.

pedunculati. Cancer. Diopfis Linn,

Compofitio fimplices. Scarabaeus, Cancer.

compofiti. Bombyz, Mufca.

Figura fphaerici. Arànea.

oblongi. Buprefis'.

rotundati, Agrion.

\section{\$. 5 .}

Antennae articulatae, mobiles, fenforiae, differunt fecundum numerum, fitum, proportionem, figuram, articulos, apicem, connexionem.

Numerus nullae. Aranea, Trombidinn, Phalangium. duae, plerisquie. quatuor. Onifcus, Pagurus. fex. Aftacus. 
Situs in fronte. Stratiomys. in cantho oculorum. Cimex.' Cicada. fupra oculos. Ricinus. fub oculis. Notonecta.

Proportio corpore breuiores. Scarabaeus. corporis longitudine. Cerambyx, Leptura. corpore longiores. Cerambyx, Locufta. breuifimae. Nepa, Laternaria.

Figura filiformes, vndique eiusdem craffitiei. Elater. clauatae, extrorfum craffiores. Papilio. attenuatae, in medio craffiores. Zygaena. fetaceae, verfus apicem tenuiores. Cerambyx. fubulatae, breues, acutae. Libellula. enfiformes, latae, triangulares. Truxalis. palmatae, in lacinias diuifae. Nepa.

biclauatae, articulo medio et vltimo apice craffioribus, Cimex. irregulares, articulis aliquoticymbiformibus, irregularibus. Cerocoma.

Articuli moniliformes; articulis orbiculatis. Tenebrio, Chryfomela.

cylindricae, articulis cylindricis. Sepidium. ferratae, articulis apice alterius lateris dilatatis. Elater.

pectinatae, articulorum latere interiori ciliato. Bombyx. pilofae, articulis fetis rigidis diftantibus diftinctis. barbatae, articulorum pilis fafciculatis! Phalaena. aculeatae, articulorum aculeis recuruis. Ceramby $x$ datus.

obconicae, articulis bafi anguftioribus. Carabus. fquamatae, articulorum fquamulis quadratis, erectis. Sphinx.

multiarticulatae, articulis plurimis. Aftacus. pauciarticulatae, articulis paucis. Syrphus.

Apex fiffiles, capitulo in lamellas diuifo. Scarabaeus, Melolontha.

perfoliatae, capituli articulis vndique prominulis, diftantibus. Dermeftes, Hydrophilus. folidae, capitulo ouato, integro. Hitter. fecuriformes, articulo compreflo altero lateri dilatato. Syrphus. 
Apex vncinatae, articulo vltimo acuminato, recuruo. Papilio Proteus.

fiffae, articulo vltimo bifido. Cancer.

excauatae, capitulo retufo impreffo. Laternaria. obtufae, articulo vltimo obiufo.

acuminatae, terminantur mucrune. Tabanus.

dentatae, articulo vltimo oblique truncato, dentato. Tabanus.

ariftatae, articulo vltimo feta terminato. Mufca.

Cimex. Syrphus.

plumatae, articulo vltimo feta radiis lateralibus

inftructa terminato. Mufca. Syrphus.

Connexio diftantes, a fe inuicem remotae Nepa.

approximatae. Mufca.

connatae, bafi cohaerentes. Bibio.

pedunculatae. Gammarus.

$$
\text { 6. } 6 .
$$

Frons fuperior capitis pars inter oculos, os et thoracem, et gula inferior inter os et pectus, differunt fubftantia, figura, fuperficie, ftemmatibus.

Subftantia cornea plerisque.

$$
\text { veficularis. Myopa. }
$$

Figura acuminata, terminatur acumine inter antennas. Gryllus.

roftrata, acumine elongato armata. Aftacus.

feutata, tecta thoracis fubftantia cornea explanata." Caffida. Lampyris.

turrita, eleuata, cylindrica, porrecta. Laternaria. Truxalis.

Superficies laeuis, nullis impreffionibus diftineta.

glabra, nulla hirfutie praedita.

punctata, punctis plurimis vagis imprefia.

fulcata, lineis altioribus impreffa,

fcabra, punctis eleuatis adfperfa.

vnicornis, prominentia vnice notabili acuta armata. Scarabaeus.

bicornis. Scarabaeus. Hifpa. Apis.

tuberculata, prominentia parua obtufa inftructa.

Scarabaeus. 
Superficies carinata, linea longitudinali eleuata, acuta. Curculio. canaliculata, linea longitudinali imprefla. Cur. culio. pubefcens, villis paruis tomentofa. Melolontha. pilofa, pilis longioribus rigidioribus inftructa. Phalaena.

hirta, villis denfis longioribus tecta. Apis. Stemmata puncta tria eleuata nitida in vertice frontis. Tettigonia. Sphex.
-

$$
\text { 5.7. }
$$

Truncus inter caput et abdomen conftat thorace, fcutello, pectore, fterno.

Truncus a capite dintinctus plerisque.

cum capite coalitus. Aranea, Phalangium.

$$
\text { 6. } 8 .
$$

Thorax fuperior trunci pars differt quoad figuram, proportionem, fuperficiem, marginem, futuras.

Figura linearis, acqualis vbique latitudinis. Mantis. orbiculatus, cuilis diameter transuerfalis aequalis longitudinali. Silpha. ouatus, cuius diameter transuerfalis breuior lon. gitudinali. Carabus.

ftrumarius, lateribus dilatato inflatis. Gryllus. lunaris, lateribus antice porrectis. Acanthia. retufus, antice finu obturo terminatur.Scarabaeus. acuminatus, terminatur mucrone. Sepidium. lanceolatus, porrectus antice attenuatus, Curcillio anchorago.

transuerfus, cuius diameter transuerfalis fuperat longitudinalem. D tifcus.

planus, cuius difcus cunden cum marginibus fi-

tum tenet.

mucronatus, terminatur finu obtufo cum nucronie. Scarabaeus,

tent is, totum corpus cute calcarea obuoluens. Cancer. 
Proportio abdomine breuior plerisque.

abdominis longitudine. Curculio, Mantis. abdomine longior. Curculio.

Superficiestomentofus," villis vix confpicuis tectus.

pilofus, pilis diftinetis elongatis praeditus.

hifpidus, fetis rigidis fparfis inftructus. Mufca. criftatus, dorfo fafciculis pilorum exafperato.

Bombyx, Noctua.

tuberculatus, prominentiis conuexis, obtufis inaequalis. Scarabaeus, Gryllus.

aculeatus, aculeis rigidis acutis difci fparfis. Cancer. Hifpa.

cornutus, prominentiis longioribus porrectis

Scarabaeus.

glaber, absque omni pubefcentia.

laetis, absque omni inaequalitate.

ineruftatus, tefta calcarea tectus. Aftacus.

ferratus, linea longitudinali eleuata, acu»a, dentata. Gryllus.

carinatus, linea longitudinali eletrata, acuta, laeui. Gryllus.

canaliculatus, linea longitudinali impreffa. Bupreftis.

Atriatus, lineis fuperficialibus longitudinalibus impreffus.

fulcatus, lineis longitudinalibus profundioribus impreflus.

punctatus, punctis paruis excauatis vagis adfperfus.

variolofus, punctis maioribus cicatrifantibus excauatus.

rugofus, lineis transuerfis longitudinalibusque vagis.

plicatus, incifuris profundis transuerfalibus. Aphis.

fcaber, punctis plurimis eleuatis vagis.

Margo marginatus, lateribus prominulis. Silpha, Lampyris.

fpinofus, vtrinque acuimine duro, rigido armatus. Cerambyx.

dentatus, acuminibus breuioribus horizontalibus

fpatio remotis. Prionus.

B 4

Margo 
Margo tentaculatus, tentaculis retractilibus bifidis vtrinque inftructus. Malachius.

callofus, fubftantia a thorace diuerfa vtrinque tectus. Chryfomela collaris.

ciliatus, fetis parallelis longitudinalibus obuallatus.

erofus, finubus maioribus aut minoribus vtrinque excauatus. Cerambyx. Prionus. foliaceus, marginibus valde prominentibus membranaceis. Mantis. deflexus, marginibus declinatis. inermis, marginibus omnino laeuibus.

Suturae quibus reliquis corporis partibus adhaeret, Eleuteratis propriae., capitis anterior. Elytrorum pofterior.

\section{§. 9 .}

Scutellum thoraci poftice adhaerens, inter alas porrectum, differt quoad proportionem, figuram, fuperficiern, apicem.

Infecta aptera, vti et quae elytra connata gerunt, et Gloffata nullo gaudent fcutello.

Cohaeret quidem cum thorace fcutellum, manifefte tamen diftinctum nexu, vfu, figura.

Vfus fcutelli inter volandum alas expandere videtur.

Proportio abdomine breuius, plerisque.

abdominis longitudine. Cimex. Acrydium. abdomine longius. Acrydium. Membracis.

Figura fubrotundum. Scarabaeus.

otratum. Chryfomela.

triangulare. Cetonia.

fornicatum, difco eleuato marginibusque de-

flexis. Acrydium.

quadratum. Ichnuemon. Vefpa.

orbiculatum. Mufca.

fcutatum, totum abdomen tegens. Cimex.

Superficies carinatum, linea longitudinali eleuata. Acrydium. Gryllus. 
Superficies lineatum, ftriis eleuatis longitudinalibus. Crabro fofforia.

fulcatum, linea longitudinali alte impreffa. Sca. rabaeus.

Apex acutum. Cetonia. Membracis.

obtufum. Melolontha. emarginatum. Cimex.

bidentatum. Stratiomys. fexdendatum. Stratiomys. truncatum.

\section{S. 10.}

Pectus inferior feu prona trunci pars thoraci correfpondet.

Pectus iisdem attamen paucioribus differentiis gaudet, quam thorax.

Pectori plerumque pedes quatuor anteriores infectorum hexapodum inferuntur.

$$
\text { 6. II. }
$$

Sternum, linea pectoris longitudinalis, faepe antice pofticeque mucronatum, differt quoad proportionem, apicem.

Sternum fcutello correfpondet non in omnibus exfer. tum.

Proportio abbreuiatum. Hydrophilus. elongatuim. Bupreftis.

Apex integrum. Dytifcus. truncatum. Dytifcus. acuminatum. Hydrophilus.

bifidum. Dytifcus.'

cornutum. Bupreftis.

\section{12.}

Abdomen annulatum fpiraculisque lateralibus pertufum, thoraciaffixum, differt fecundum proportionem, connexionem, figuram, fegmenta, fuperficiem, marginem, anum.

$$
\text { B } 5
$$


Superior abdominis pars dorfum audit, prona vero feu inferior, venter.

Spiracula lateralia ad refpirationem pertufa vtrinque tot, quot fegmenta abdominis.

Proportio breniffimum. Euania.

longifinum. Iulus. Scolopendra.

Comnexio feflile, cuius diameter bafeos certe aequalis fit diametro apicis. Sphex.

petiolatum, cuius diameter bafeos multo minor diametro apicis. Sphex. adnatum, trunci prona parte affixum. Aranea. impofitum, trunci fuperiori parte adhaerens. Euania apperdigafter.

Figura depreffum, cuius diameter transuerfalis fuperat verticalem. Scolopendra.

rotundatum, cuius diameter transuerfalis aequat verticalem. Iulus.

compreffum, cuius diameter transuerfalis cedit verticali. Gryllus. Ichneumon.

lineare, vndique eiusdem craffitiei. Ichneumon. ouatum, cuius diameter transuerfalis minor longitudinali, bafi fegmento circuli circumferipto, apice vero eodem anguftiore. Dytifcus.

orbiculatum, cuins diameter transuerfalis aequat longitudinalem. Aranea.

cylindricum, cuius diameter transuerfalis aequat verticalem, bafi apiceque fegmento circuli aequali circumfripto. Ichneumon.

conicum, cuius diameter transuerfalis aequat verticalem, bafi fegmento circuli circumfcripto, apice vero eodem anguftiore. Apis conica. clauatum, apice incraffatum, rotundatum. Euania, falcatum, petiolatum, compreffrm, incuruum. Ichneumon.

hamofum, apice obtufum, inflexum. Myopa ferruginea.

reconditum, in foffula pectoris latens. Cancer.

Segmenta quatuor. Scarabaeus.

quinque. Dytifcus.

fex. Ichneumon. 
Segmenta plura. Iulus. Scolopendra. nulla fegmenta difincta. Aranea.

Superficies glabrum. Iulus.

tomentofum. Syrphus.

pilofum. Mufca.

fafciculatum. Bupreftis.

canalicutatum. Libellula.

carinatum.' Libellula.

punctatum. Bupreftis.

pellucidum fegmentis corneis transparentibus.

Lampyris. Mufca.

hirtum. Sphinx, Phalaena.

fpinofum. Gryllus.

bicorne, prominentiis duabus cylindricis mollibus. Aphis.

teftatum, cute dura calcarea tectum. Aftacus.

brachiatum, fubtus appendiculis pediformibus inftructum. Aftacus.

Margo integrum. Dermeftes.

ferratum, angulis acutis imbricatis prominens.'

Naucoris.

Jobatum, in partes diftinctas diuifum. Pediculus. plicatum, plicis transuerfalibus profundis diftinctum. Aphis.

foliatum, vtrinque prominens, finuatum. Mantis gongylodes.

haftatum, ventre antice fpina acuta armato. Cimex haemorrhoidalis.

tentaculatum, tentacula ruollia retractília vtrin que exferens. Malachius.

Anus acuminatum. Mordella. Trichius.

fylatum, terminatur prominentia cylindrica. Aphis. Sirex.

aculeatum, aculeo rigido retractili punctorio armatum. Spex. Apis.

dentatum, prominentiis rigidis acutis diftantibus difinctum. Chryfis. Apis.

lamellatum, lamellis duobus aut quatuor com* preflis, approximatis. Libellula. Aefhna. foliaceum, laminis maioribus depreffis fuperne tectum. Aftacus. papillofum,papillis prominulis textoriis. Aranea. 
Anus barbatum, hirfutie longiori circumuallatum. Zygaena. Sefia.

obtufum. Mufca.

\section{13.}

Artus thoraci abdominique adhaerentes funt cau$\mathrm{da}$, aculeus, pedes, alae, halteres, pectines. Vfus artuum ad celeriorem motum et ad defenfionem.

\section{14 .}

Cauda abdomen terminans, eualuis, differt fecundum proportionem, figuram, apicem, fetas. Vfus caudae ad oua ponenda, ad motum dirigendum, vix vnquam ad defenfionem.

Proportio corpore breuior. Forficula. corporis longitudine. Ephemera. corpore longior. Scorpio.

Figura articulata, articulis diftinctis conftans. Scorpio. recurua, verfus apicem fenfim adfcendens. Raphidia. Gryllus. recta, horizontaliter exiens. Gryllus. inflexa, fub abdomine recondita faltatrix. Podura. fetacea, fenfim attenuata. Ephemera. corniculata, fpina cornea, acuta, rigida. Siret. forcipata, vnguibus duobus arcuatis apice conniuentibus. Forficula.

chelata, apice incraffata pollice mobili. Panorpa. dentata. Forficula.

villofa. Lepifma.

Apex abtufą Gryllus.

acuta. Sirex.

vnguiculata, vngue arcuato acuto rigido terminata. Scorpio.

Setae vnifeta. Raphidia. Scorpio. bifeta. Ephemera. Gryllus. trifeta. Ephemera. Lepifrna. penicillata, fetis plurimis inordinatis. Iulus. 


\section{§. I5:}

Aculeus abdomen terminans, biualuis fetam punctoriam rigidam exferens, differt proportione, figura, margine.

Aculeus fyniftatis proprius, diftinguitur a cauda figura, valuulis, vfu.

Vfus ad defenfionem, plerisque ad oua ponenda, inprimis vbi exfertus eft.

Proportio obfoletus. Formica.

abbreuiatus. Ichneumon.

mediocris. Ichneumon.

elongatus. Ichneumon.

Figura fpiralis, fub abdomine conuolutus. Cynips. cylindricus, rotundatus, linearis. Ichneumon, compreffus. Apis. Sphex.

reconditus, intra abdomen retractilis. Apis. Vefpa.

exfertus. Ichneumon.

Margo laeuis nullis, incifuris notatus. Ichneumon. ferratus, incifuris aequalibus imbricatis dentatus. Tenthredo. Apis.

$$
\text { 6. } 16 .
$$

Pedes ad celeriorem motum arctioremque adhaefionem pectori abdominique affixi, conftant femore, tibia, tarfo, differuntque quoad numerum, fitum, vfum.

Marum pedes anteriores faepius ad aretiorem copulam elongati. Cryptocephalus. Cancer.

Numerus quatuor. Papilio.

fex: pleraque.

octo. Aranea.

plures. Onifeus, Iulus, Scolopendra.

Situs pectorales, pectori adhaerentes. abdominales, abdomini inferti. Iulus, Scolopendra.

dorfales, dorfo affixi. Cancer dorfipes. 
VJus curforii, porrecti ambulantes. Cimex. Chryfomela.

greflorii, anticis abbreuiatis absque tarfo. $\mathrm{Pa}$ pilio.

fofforii, tibia breuicomprefla dentata. Truxalis, Scarites, Scarabaeus.

faltatorii, femoribus pofticis incraflatis. Chryfomela. Cicada.

natatorii, pofticis compreffis ciliatis, tarfo mutico

Dytifcus. Notoneeta.

bronchiales, natatorii feffi. Monoculus.

raptorii, femore antico canaliculato, tibiam fal.

catam excipiente. Nepa.

\section{§. 17.}

Femur, fuperior articulus pedem annectens, differt fecundum figuram, marginem, apicem.

Figura angulatum, futuris acutis, prominentibus. Gryllus.

incraffatum, tibia multo latius. Chryfomela.

Curculio.

incuruum, circuli fegmentum defcribens. Mufca diophtalma.

fulcratum, lamina valida, rigida bafeos. Mordella.

canaliculatum, longitudinaliter excauatum. Nepa cinerea.

dilatatum, marginibus porrectis membranaceis. Gryllus.

cornutum. Lamia pedicornis.

Margo dentatum, prominentia vnice vel pluribus diftan.

tibus notatum. Curculio. Verpa. ferratum. Cancer. Gryllus. inerme. Cerambyx.

Apex lobatum, membrana prominente terminatum. Mantis.

fpinofum, fpina acuta, rigida terminatum. Mantis. clauatum, apice craffius. Cimex. inerme, praecedentibus oppofitum. 


\section{§. I8.}

Tibia, fecundus pedisarticulus inter femuret tar. fum, differt quoad figuram, fuperficiem, marginem, apicem.

Figura cylindrica. Gryllus, Chryfomela.

compreffa. Dytifcus. Apis.

triangularis, in medio angulum acutum exferens。

Trox.

fornicata, plana, latere interiore concaua. Tru. xalis.

angulata, angulis acutis prominentibus. Gryllus. falcata, comprefia, arcuata, acuta. Mantis.

pollicata, in medio prominentia aucta inftructa. Nepa.

Superficies pilofa. Phalaena, Sphinx.

nanicata, comprefia pilis denffifimis inordinatis tecta. Apis.

tabernaculata, eleutitionibus variis inordinatis fparfis.

canaliculata. Carabus, Tipula.

glabra.

Margo. dentata. Scarabaeus. Truxalis.

ferrata. Gryllus.

ciliata, pilis approximatis parallelis. Dytifcus.' inermis. Chryfomela.

Apex fpinofa, terminatur mucrone acuto rigido. Carabus.

mutica, praecedenti oppofita. Papilio.

$$
\text { 5. } 19 .
$$

Tarfus, plerumque articulatus pedem terminans, differt quoad articulorum, numerum, figuram, marginem, apicem.

A numero articulorum tarfi ordines infectorum defumfit Geaffroy.

Articuli nullus. Scarabacus.

vnicus, Papilio,

dio. 
Articuli tres.

quatuor. Bupreftis.

quinque. Dytifcus.

fex.

Figura cylindricus. Iulus. Scolopendra.

compreffus. Dytifcus.

fcutatus, articulo medio ad alterum latus dila.

tato, orbiculato. Vefpa cribraria. Dytifcus. fpongiofus, articulis fubtus mollioribus craffioribus. Helops. Chryfomela.

Margo ciliatus. Dytifcus.

fpinofus.

Apex vnguiculatus, mucrone arcuato acuto armatus.

Scarabaeus.

villofus, villis plurimis inordinatis obfitus. Sphinx. Phalaena.

muticus, praecedentibus oppofitus, pedibus natatoriis proprius.

chelatus, articulo vltimo incraffato, fiffo pollice mobili. Cancer. Aftacus.

$$
\text { S. } 20 .
$$

Alae ad celeriorem fugam thoraci affixae funt, aut cruftaceae, vaginantes, Elytra: aut molles, tenues, Alae.

Alas ad claffium determinationem introduxit Linné, cui fucceffores omnes fecuti funt.

$$
\text { \$. } 2 \text { r. }
$$

Elytra, alae binae fuperiores, cruftaceae, abdomen tegentes, differunt quoad proportionem, figuram, fuperficiem, futuras, marginem, apicem.

Elytra quibusdam claffibus propria interdum connata et tunc alae pofticae et fcutellum defunt.

Proportio abbreuiata. Meloe. Leptura.

mediocria. Chryfomela.

clongata. Gryllus. Blatta. 
Figura: linearia, Cicindela.

attenuata, poftice fenfim anguftiora. Leptura,

Necydalis.

plana, vndique eiusdem eleuationis. Blatta.

deflexa, margine interiori altiori. Gryllus.

cruciata, in medio flexa, vt fuperficies interior

appareat. Cimex, Nepa,

gibba, in medio valde eleuata. Chryfomela.

flexilia, preffioni cedunt nec franguntur. Can= tharis, Gryllus.

mollia, preffionis veftigia diu retinentia. Meloe rigida, praecedentibus oppofita. Curculio.

Superficies: tomentofa. Lagria.

pilofa. Melolontha.

fafciculata. Bupreftis.

"quarra laetria, praecedentibus oppofita. Chryfomela. fcabra, punctis eleuatis diftancibus exafperata.

Cerambyx.

tuberculata. Curculio.

verrucofa, punctis maioribus eleuatis cicatrizantibus. Curculio.

fquamata, lamellis erectis breuibus prominulis. Curculio.

punctata. Carabus.

ftriata, lineis longitudinalibus impreffa. Carabus. punctato ftriata, punctis in lineas longitudinales digeftis. Chryfomela.

fulcata, lineis longitudinalibus profuridioribus exarata. Carabus.

porcata, fulcata fulcis punctis oblongis eleuatis adfperfis. Carabus porcatus.

rugofa, lineis variis eleuatis reticulata. Silpha rugofa.

lineata, lineis eleuatis longitudinalibus. Silpha atrata.

crenata, lineis eleuatis longitudinalibus vndulatis. Curculio.

fpinofa, aculeis validis, rigidis, acutis armatà. Curculio, Hifpa.

Lavia Cobsos praecedentibus oppofita.

Sutura: longitudinalis, margo elytrorum conniuentium interior, Dorfalis. 
Sutura: transuerfalis, qua elytra thoraci adhaerent femper binae.

Margó: inarginata. Silpha, Caffida.

ferrata. Bupreftis. dentata. Bupreftis.

finuata, emarginatura notata. Silpha finuata. inermia, praecedentibus oppofita.

Apex: rotundata, fegmento circuli terminata. Gryllus. acuminata, mucrone rigido valido terminata.

Tenebrio.

truncata, poftice obtufa, abfcilfa. Staphylinus. faRigiata, apice emarginata. Leptura, Stenocorius.

mucronata, emarginata cum mucrone in medio emarginaturae. Bupreftis.

\section{22 .}

Alae membranaceae neruofae differunt quoad numerum, proportionem, figuram, fuperficiem, marginem, apicem.

In alis Gloffatorum colorum varietas in fquamis erectis, coloratis.

Numeris: nullae. Cimex, Bombyx, Hippobofa. duae. Coccus, Ephemera.

quatoor. Sphinx, Libeliula.

Proportio: rudimento breui alaruin. Gryllus.

asteriores longiores, Epheméra.

oinnes aequales. Gryllus, Panorpa.

Fivereriores longifimae. Coccinella, Panorpa.

Figura: lineares. Panorpa Coa.

() lanceolatae, vtraque apice attenuatae. Noctua Verbafci, exoleta.

C rotundatae, fere circulum defcribentes. Papilio.

c oblongac. Papilio.

deltoideae, poftice obtufifimae et fere retufae. Pyralis.

laciniatae fiffae, digitatae. Pterophorus. rẹterfae, margine exteriori alae pofticue pro. minente. Bombyx. exfertae, pone ely tra prominentes. Forficula. 
Figura: tectae, fub elytris reconditae. Eleuterata pleraque.

plicatae, lineis longitudinalibus coarctatac. Vefpa.

conuolutae, corpus arcte cingentes. Tinea. rhomboideae, ab angulo poftico ad apicem longiores, quam ad bafin. Papilio. incumbentes, alis fuperioribus inferiores tegentibus. Noctua. patentes, omnibus expanfis. Bombyx, Phalaena. erectae, furfum ad fe inuicem accedentes. $\mathrm{Pa}$ pilio.

deflexae, margine tenuiori atiore, craffiori. Noctua.

falcatae, apice acuminatae, arcuatae. Bombyx Atlas. Phal. falcataria

ftriatae, venis eleuatis diftinctís longitudinalibus exaratae.

reticulatae, venis longitudinalibus transuerfalibusque anoftomofantibus. Heinerobius. clauatae, verfus apicem ineraffatae. Panorpa.

Superficies: fquamatae, lamellis erectis coloratis tectae. Gloflata. pilofae, fetis rigidis diftantibus adfperfae. Muf́ca. Tipula. nudae, praecedentibus oppofitae. feneftratae, fquamatae maculis nudis, pellucidis. Bombyx Atlas. coneolores, vtraque pagina eodem modo coloratae. Papilio.

ocellatae, maculis e variis coloribus annulatis ornatae. Papilio.

pupillatae, ocellatae puncto ocelli medio diftincto. Papilio. coecae, praecedentibus oppofitae.

fafciatae, lineis latioribus transuerfalibus colo. ratis difinctae. Noctua.

ftrigatae, lineis anguftis transuerfalibus coloratis pictae. Phalaena.

Margo: crenatae, incifuris laeuiffipis notatae. Sphinx. Bombyx.

dentatae, incifuris maioribus diftantibus.Sphinz. $\mathrm{C}_{2}$ Margo: 
Margo: caudatae, margine poftico elongato attenuato. Papilio, Truxalis.

emarginatae. Pyralis emargana.

érofae, finubus variis lacerae. Noctua libatrix. ciliatae. Phryganea, Mufca.

angulatae, prominentiis variis horizontalibus diftinctae. Sphinx.

Apex: obtufae.

truncatae. Phryanea.

acutae. Hippobofca.

acuminatae. Bombyx Atlas.

$$
\text { 6. } 23 .
$$

Halteres rudimenta alarum pofticarum fub alis Antliatorum conftant aut capitulo petiolato, aut fquama membranacea fornicata.

Halteres Antliatis folis propria, isque reliqua infecta diptera nunquam gaudent.

Halterum vfus ad aequilibrium melius obferuandum videtur.

Halteres libramenta Schluga audiunt.

$$
\text { 6. } 24 \text {. }
$$

Pectines bini inter abdomen et pectus adhaerentes, altero latere dentati, differunt numero dentium.

Pectines vnico tantum generi Scorpionum proprii.

Numerus dentium maxime differt, quo fpecies Scorpionum facillime diftinguuntur. Vfus pectinum adhuc plane latet. 


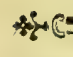

\section{I NS T R V M ENTA CIBARIA.}

Ir

$$
\text { 6. } 1 \text {. }
$$

Inftrumenta cibaria infectorum funt partes oris ad cibum hauriendum dicatae, omnibus communes.

Infecta omnia partibus oris quibusdam gaudent, etiam ea, quae cibo nullo vtuntur, vtBombyx Mori, Ephemera.

Structura inftrumentorum cibariorum maxime fecundum varium infectorum alimentum differt.

Partes oris differentes numeramus inprimis decem.

r. Palpi: articulati, fenforii, mobiles.
a. antici.
b. intermedii.
c. poftici.

2. Clypeus: horizontalis capitis pars cornea porrecta, os fuperne tegens.
a. difcus.
b. limbus.

3. Mandibula transuerfalis a capitis fubftantia cornea propagata.
a. mandibula.
b. dentes.
c. apex.

4. Maxilla transuerfalis, a capitis fubftantia interiori defumta, faepius membranacea.
a. maxilla.
b. dentes.
c. laciniac.

C 3 5. Galea 
5. Galea cylindrica, obtufa, maxillae dorfum tegens.

6. Labium horizontale, capitis pars inferior porrecta os inferne clauden.
a. numerus.
b. laciniae.
c. limbus,
d, difcus.

7. Lingua fpiralis conuoluta, bifida inter palpos ftupo. fos inferta.
a. lacinia fuperior.
b. lacinia inferior,

8. Rofrum inflexum, corneum.

a. vagina articulata fetas continens.

b. fetae,

9. Probofcis membranacea, bilabiata.

a, ftipes cylindricus bafis probofcidis capitulum fuften. tans.

b. capitulum retractile, membranaceum, bilabiatum, 10. Hanftellun porrectum, corneum, inarticulatum.

a. vagina faepius biualuis.

$\alpha$. valuula fuperior.

B. valuula inferior.

b. fetae numero diuerfae.

$$
\text { 6. } 2 .
$$

Structura naturaliffima, quae in plurimis obtinet, manifeitat fe in numero, fitu, proportione et figura omnium partium oris.

Structura omnis eft aut naturaliflima, aut differens, aut fingularis.

Struetura naturalifíma, quae plurimis generibus communis nunquam ad genera diftinguenda inferuire poteft, ideoque a genuino Entomologo haud diffura defcribenda.

Structura differens in omnibus obferuatur generibus, vbi plures characteres ad diftinguen dum genus necefiarii. 
Structura fingularis characterem praebet generis effentialem, quo genus ab omnibus reliquis generibus diftinguitur, $\iota . g r$.

Maxilla cornea multidentata. Melolontha.

Maxilla chelata. Scorpio, Phalangium.

Palpi poftici pilofi. Cicindela.

Palpi poftici longiores fecuriformes. Clerus.

Palpi poftici fafciculis duobus pilorum adhaerentes. Lucanus.

Labium conuolutum maxillas continens. Trombidium.

Palpi linguaeformes. Nomada.

Hauftellum cylindricum bitialue. Hippobofca

Roftrum lamellatum. Pulex.

Roftrum aninulatum. Sigara.

Palpi bafi fetarum exteriorum inferti. Syrphus.

Hauftelli vagina os totum obtegens. Rhingia.

Maxilla tota connata cum labio. Phryganea.

Palpi cheliferí. Scorpio.

Mandibulae nullae. Ephemera.

\section{\$. 3 .}

Numerus eft naturaliffimus, quod quatuor adfint palpi, mañdibulaeduae, maxillae duae, clypeus et labium vnica.

Obtinet naturalifimus hic numerus in primis in Eleuteratis,

Vlonatis et Syniftatis, et in his exceptio rarior.

Palpi fex, mandibulae absque maxillis, clypetis nullus,

Labium-triplex, in Agonatis.

Palpi tantum duo in Vnogatis, in reliquis conteniunt.

Palpi duo, linguaque fpiralis clypeusque absque mandibulis, maxillis, labip in Gloflatis.

Roftrum et Clypeus absque mandibulis, maxillis, palpis et labio in Ryngotis.

Palpi duo, hauftellum faepius probofide receptum, absque mandibulis, maxillis, clypeo et labio in

Antliatis.

Clypeus ideo femper vnicus. Palpi duo, quatuor, fex.

c 4 Mandi- 
Mandibulae femper duae.

Maxillae femper duae.

Labium vnicum, rarifime triplex,

$$
\text { S. } 4 \text {. }
$$

Proportio naturaliflima inuenitur, quod clypeus prominens abfcondat mandibulas tegentes maxillas breuiores, palpis anticis pofticos longitudine fuperantibus, quos iterum labio maiores deprehendimus.

Palpi antici plerumque pofticis longiores, faepe aequales, rariffme breuiores. Clerus.

Clypeus plerumque mandibulis longior, rarius mandibulae prominent. Cicindela,

Mandibulae plerumque maxillis maiores, interdum tamen contrarium obtinet, Apis.

Maxillae palpis anticis faepius breuiores, raro longiores, Apis.

Labium plerumque maxillis et palpis pofticis breuius, rarius maxillis aequale, palpis longius. Apis.

In Gloffatis lingua fpiralis palpis longior; exceptio rariffina, Hepialus,

In Antliatis haufe!lum palpis longius, probofcide breuius, Exceptio rarifima. Tipula,

In Ryngotis roitrum clypeo longius,

$$
\text { \$. } 5 \text {. }
$$

Situm naturalifimum obferuauimus, quod palpi antici maxillae dorfo inhaereant, cui fuperincimbunt, poftici vero labii medium, cuius fuperiorem partem cingunt.

Clypeus femper os fuperne tegit, labium inferne.

Mandibulae immediate clypeo fubiacent et latera oris fuper. ne claudunt.

Maxillae femper fub mandibulis infertae latera oris inferne claudunt.

Palpi antici duo aut quatuor maxillae dorfo adnati. Ex. septio rarifima, Apis, 
Palpi poftici plerumque labii medio laterali, faepe apici, raro parieti interiori inferti, rarillime labio haud adhaerent. Lucanus:"

In Agonatis palpi antici mandibulis, pofticilabio inferti totum os obtegentes.

In Vnogatis palpi duo maxillis adhaerent.

In Glonatis lingua fpiralis femper inter palpos reflexos con. voluta latet.

In Ryngotis vagina fetas continens plerumque capitis apici inferta. Exceptio rarior fub capitis apice Acanthia; pectori Chermes.

In Antliatis probofcis porrecta ftipite craffiori dorfo canaliculato fetas recipit, canalem vero vagina vniualvis claudit. Palpi plerumque ad latera probofcidis inferti.

Vbi probofcis deeft, vagina biualuis fetas continet.

$$
\text { §. } 6 .
$$

Figura eft naturalifima, quod palpi fint filiformes articulis cylindricis aequalibus, clypeus et labium rotundata, integra, mandibulae corneae, arcuatae, maxillae, cylindricae, vnidentatae.

Figura faepius differt et notas genericas plurimas fubminiftrat.

Exempla vid. in Generibus noftris infectorum.

In Gloffatis palpi cylindrici, Atupofi, pilofi, reflexi et lingua cylindrica, conuoluta.

In Ryngotis vagina inflexa, cylindrica, triarticulata, continet fetas fetaceas, acutas, tegiturque clypeo fetaceo.

In Antliatis probofcis ftipite cylindrico capituloque bilabiato includit fetas fetaceas, tegiturque valuula degreffa, acuta.

Vbi probofcis deeft, hauftellum exfertum vagina biualui cylindrica, continet fetas fetaceas.

Hauftellum inflexum. Empis. geniculatum. Myopa.

$$
\text { c } 5 \quad \text { 6. } 7 . \text { Palpi }
$$




\section{7 .}

Palpi differunt quoad a numerum, $\beta$ fitum, $\gamma$ figuram, articulos, apicem, $\delta$ proportionem, aequalitatem.

Numerus: nulli. Notonecta. duo. Aranea, Scolopendra. quatuor. Scarabaeus, Ichneumon. fex. Cicindela, Cancer.

Situs: inferti maxillae dorfo. Scarabaeus. maxillae medio interiori. Apis. inter maxillas. Labii apici. Hifter, Apis. labii medio externo. Ichneurmon. labii medio interno. Cetonia. labii bafi. Nicrophorus, Stenocorus. labii lateribus. Cancers penicillis duobus fub labio abfconditis. Lucanus. mandibulae dorfo. Aftacus. ad latera linguae fpiralis. Gloffata. probofcidi. Mufca. hauftelli vaginae.

= hauftelli fetis, Syrphus.

Figura: fliformes, vndique eirusdem craffitici. Cerocoma.

moniliformes, articulis omnibus globofis. clauti, articulo vltimo craffiori, maiori. Trox.

cylindrici, articulis omnibus cylindricis, aequalibus, Ichneumon.

fecuriformes, articulo vltino ad alterum latus dilatato acuto. Elater, Coccinella. incurui, fupra os incumbentes. Tipula. cheliferi, articulo vltimo bifido, lacinia altera mobili. Scorpio.

bifidi, vsque ad bafin fiff, Cancer. linguaeformes, longiffimi, compreffi, membranacei. Nomada. veficulofi, articulis mollioribus turgidis, Gryl. lus, Atupof, hirfutie molliori tedi. Gloffata. 
Articuli: aequales, articulis omnibus longitudine et $\mathrm{f}$ gura conuenientibus. Donacia.

inaequales, articulis quibusdam maioribus aut craflioribus. Priontus.

rhomboides, plani angulis acutis oblique prominentibus. Crabro.

pilofi, pilis rigidis plurimis adíperfi. Cicindela.

cuneiformes, articulis rotundatis apicem verfus fenfim incraflatis. Carabus.

triangulares, angulis tribus acutis prominentibus. Aftacuś.

Numerus articulorum differt: plerumque palpi $4-5$ articulati, faepe $2-3$, rarifime vero multiarticulata inueniuntur.

Apex: fubulati, articulo vltimo acuminato.

turgidi, articulo vitimo eapitato turgido. Araneae maribus.

truncati, articule, vltimo obtufo abfififo. Prionus.

vnguiculati, articulo vlime corneo, arcuato, acuto. Trombidium.

fiff, articulo vitimo bifido. Alucita,

Proportio : elongati. Scorpio, Ichneumon, abbreuiati. Libellula.

Aequatitas: antici longiores., Seyllarus.

omnes aequalęs. Nicrophorus, intermedii, longiores, Carabusa poftici langiores. Clerus,

\section{8 .}

Linguam fpiralem differentem vidimus quoad a fubftantiam, $\beta$ apicem, $\gamma$ proportionem.

Inter omnia inftrumenta cibaria lingua fpiralis pauciffimas, praebet differentias, ideoque et gloffata diflicilhime determinantur.

Suftantia: cornea, dura, nitida, polita. Sphinx. membranacea, mollis, albida, enuis. Bomby $x_{4}$

Apex: acuta. Zygaena.

obtufa. Sphinx 
Proportio: longifima. Sphinx. abbreuiata. Phalaena. linguae rudimento. Hepialus.

$$
\text { 6. } 9 \text {. }
$$

Mandibula differens eft quoad $\alpha$ numerum, $\beta$ fitum, $\gamma$ figuram, dentes, apicem, $\delta$ proportionem.

Numerus: nulla. Gloffata, Ryngota. duae. Plurima.

Situs: exferta, vltra clypeum prominens. Cicindela. abfcondita, fub clypeo latens. Dermeftes. fepulta, a labiis palpisque omnino tecta. Cancer, Aftacus.

Figura: recta. Crabro, Trombidium. arcuata. Scolopendra. concaua, recta fubtus excauata. Bombyx. fornicata, incurua fubtus excauata. Cancer, Aftacus.

excauata, inanis, vngue perforato. Aranea. articulata. Phalangium.

cylindrica. Scorpio.

forcipata, apicibus fupra incumbentibus. Lucanus, Cicindela.

difformis, breuis, craffa, dentibus inaequalibus inftructa, Iulus.

Dentes: inermis, Chryfomela. vnidentata, multidentata. Cicindela.

Apex: obtufa. Cancer. Iulus. acuminata. Cerocoma. fiffa, apice rima inftructa. Sepidium. bifida, vltra medium fiffa.

bidentata, rima apicis breuiflima laciniis acuminatis. Gyrinus.

bifurcata, rima apicis breuiffima, laciniis obtufis incuruis. Lucanus.

- truncata. Vefpa. denticulata, apice obtufe truncata, vnguiculo auctiffimo dentibusqque armata. Libellula. 
Apex: vnguiculata, vngue arcuato acuto infructa. Aranea.

biunguiculata, vnguibus duobus / praedita. Scorpio.

chelifera, apice incraffata, fiffa: lacinia altera mobili. Phalangium.

Proportio: clypeo breuior, Bruchus.

clypeo longior. Cicindela.

longiflima. Lucanus mas.

$$
\text { S. } 10 .
$$

Maxilla differt quoad a numerum, $\beta$ connexionem, $\gamma$ figuram, confiftentiam, marginem, apicem, lacinias, galeam, $\delta$ proportionem.

Maxilla maxime variat et plerosque praebet generum characteres.

Numerus: nulla. Cancer.

duae. Pleraque.

Connexio: connata, cum labio vltra medium cohaerens. Syniftata.

adnata, tota cum labio cohaerens. Phryganea.

adhaerens, bafi inter fe connatae. Phalangium.

Figura: cylindrica. Aranea. compreffa. Apis.

arcuata. Gyrinus, Carabus, Aefhna. linguaeformis. Apis.

Apex: dilatata, apice compreffa, rotundata. Scaurus.

obtufa. Sepidium.

fiffa. Forficula, Elatta.

fetofa, pilis rigidis obuallata. Cetonia.

acuminata. Carabus.

dentata. Melolontha. Aefhna.

vnguiculata, Aranea, Scorpio.

truncata. Phalangium.

Confiftentia: membranacea. Apis.

cornea. Erotylus.

veficulofa. Blatta. 
Margo: nuda. Aranea.

ciliata, pilis parallelis imbricatis cincta. $\mathrm{Ca}$ rabus.

Laciniae: integra. Zonitis.

vnidentata, ad infertionem palpi dente valido armata. Elater, Scarabaeus.

bifida, vsque ad bafin ffla. Tenebrio.

Obf. Palpi: vbi quatuor maxillae adhaerent, maxilla femper integra.

Galea: maxilla breuior.

- - longior. Blatta.

- - aequalis, Gryllus, Acheta.

trunsata. Blatta.

obsufa. Gryllus.

fornicata. Truxalis.

Proportio: palpis breuior. Pleraque.

- longior.

elongata, in linguae laciniam exteriorem, Apis.

\section{II.}

Clypeum differentem inuenimus quoad a figuguram, fuperficiem, marginem, $\beta$ proportionem.

Figura: rotundatus, Melolontha, Papilio. quadratus. Cetonia, Raphidia. conicus. Bombyx, Notonecta.

fornicatus. Pánorpa,

cylindricus. Phryganea.

fubulatus. Cimex.

inuoluens, porrectus totum os obtegens. Bombyx.

Superficies: annulatus. Cimex.

carinatus, linea media eleuata. Laternaria. canaliculatus, linea media imprefla. Scarabaeus.

cornutus, prominentiis maioribus acutis inftructus. Scarabaeus.

tuberculatus, prominentiis minoribus obtufis armatus, Scarabaeus. 
Superficies: fcaber, punctis preminulis fparfis irroratus. fafciatus, linea transuerfali eleuata notatus. Lucanus.

Margo: integer. Cetonia. incraffatus. Melolontha. ciliatus. Pulex. fifcus. Bombyx. crenatus. Scarabaeus. emarginatus. Scarabaeus. Cercopis. reflexus, margine eleuato reflexo. Melo. lontha.

Proportio: maxilla longior, Byrrhus.

- breuior. Cicindela.

- aequalis. Attelabus. breuifimus. Papilio. longifimus. Cimex.

$$
\text { §. } 12 .
$$

Labium differt quoad $\alpha$ numerum, $\beta$ figuram, marginem, apicem, lacinias, fubftantiam, $\gamma$ proportionem.

Numerus: nullum. Gloffata. Ryngota. vnicum. Eleuterata.

plura., Cancer. Pagurus.

Figura: cylindricum. Scarabaeus, Cetonia. cordatum, apicedilatatum, rotundatum, retufum. Melolontha. Nicrophorus. quadratum. Elophorus. orbiculatum. Opatrum. gibbum, in medio eleuatum. Lagria. obconicum, verfus apicem fenfim dilatatum. Prionus, Mutilla. fornicatum, fubtus concauum. Aefhna. lineare, tenue vndique eiusdem craffitiei.

Chryfis. conuolutum, marginibus fuperne conniuentibus. Trombidium. carinatum, linea intermedia eletrata. Vefpa. linguiforme. Apis.

Margo: integrum. Cryptocephalus. 
Margo: emarginatum. Scarabaeus.

fifum, crena leuiori terminatum. Cetonia, Truxalis.

ciliatum, pilis paralle'is cinctum. Sphaeridium,

crenatum, incifuris rotundatis fuperficialibus. Nicrophorus.

dentatum, prominentiisacutis, validis. Scolopendra.

incraflatem, margine difco craffiori. Gryllus.

Apex: obtufum. Dermeftes, Caffida.

truncatum. Burrhus.

acuminatum, apice mucrone armatum. Bu-

preftis, Bruchus.

haftatum, apice triangulari angulis prominulis. Tentbredo.

rotindatum. Dytifcus.

Laciniae: integrum.

bifidum. Blatta.

trifidum. Forficula.

quadrifidum. Cancer, Pagurus,

quinquefidum. Apis gulofa.

fetarium, feta valida vtrinque armatum.

Vefpa.

Subftantia: corneum. Cicindela.

membranaceum. Cerocoma.

veficulofum. Gryllus, Phalangium.

bafi corneum, apice membranaceum. Apis.

Proportio: palpis pofticis breuius. Ichneumon. Clerus. palpis pofticis aequale. Citonia.

- - - longius, Chryfis.

elongatum, in linguae lacinias interiores. Apis. Nomada.

$$
\text { §. } 13 .
$$

Roftrum differens inuenimus fecundum $\propto$ articulos, fetas, $\beta$ fitum, $\gamma$ figuram, marginem, apicem, proportionem.

Articuli: indifincti. Sigara. duo, Reduuius. 
Articuli: tres. Nepa.

quatuor. Cimex.

quinque. Pulex, Laternaria.

vnica. Pulex.

tres. Laternaria. Cicada.

Situs: in capitis apice. Cicada, Cimex.

fub capitis apice. Acanthia.

vagina pectorali. Chermes.

Figura: canaliculatum, linea longitudinali impreffa,

Laternaria, Petalis.

cylindricum. Cicada.

conicun. Sigara.

fetaceum. Cimex.

rotundatum. Nepa, Naucoris.

lamellatum, lamella vtrinque ad bafin fuffultum. Pulex.

inflexum, fub abdomine inter femora antica

latens. Laternaria.

arcuatum, in circuli fegmentum curuatum.

Nepa, Réduuius.

inuoluens, bafi latiffimum. Sigara.

fulcatum, ftrigis transuerfalibus profundis exaratum. Sigara.

Margo: marginatum, margine prominulo membranaceo.

fpinofum, denticulis acutis, validis armatum. Sigara.

inerme. Aphis.

Apex: obtufum. Cicada. Notonecta. Cimex. acutum. Nepa, Sigara.

fubulatum.' Reduuius.

Proportio: abbreuiatum. Sigara, Notonecta. elongatum. Laternaria. Pulex. obfoletum. Thrips.

$$
\text { 6. } 14 \text {. }
$$

Probofcidem Antliatis folis propriam difierentem vidimus quoad a figuram, ftipitern, capitulum, $\beta$ proportionem.

Probofcis tantum Antliatis propria, nec omnia illa ea gaudent. 
Figura: inflexa, porrecta fub pectore latens. Enpis. cylindrica. Mufca. canaliculata. Tabanus. hautelliformis. Empis, Conops.

Stipes: cornea. Empis. membranacea. Rhingia, Tabanus. fracta. Mufca. geniculata. Conops.

Capitulum: labiis integris. Bibio.

- ciliatis. Rhagio, Empis.

- acutis. Syrphus.

- acuminatis.

- rotundatis. Bibio.

- - onatis. Mufca.

Proportio: abbreuiata. Tipula. elongata. Empis. retracta, intra labia tumida poro pertufa ab. fcondita. Oeftrus. nulla. Bombylius.

\section{†. 15 .}

Hauftellum differt fecundum $\alpha$ fetas, $\beta$ figuram, vaginam, $\gamma$ proportionem.

Hauftello Antliatis folis proprio omnia gaudent.

Probofcis fi adeft hauftellum aut absque vagina aut vagina vniualui plerumque inuenitur, quum fetae intra probofcidis canalem dorfalem latent.

Setat: vnica. Tipula, Stratiomys, Conops. duae. Stomoxys.

tres. Bibio, Rhagio, Bombylius. quatuor. Syrphus. quinque. Tabanus, Culex. fetaceae. Tipula. acuta. Rhagio. cylindrica. Stratiomys. aequales. Tabanus. inaequales. Syrphus, Culex,

Figura: forricatum, Rhîngia. cultratum. Rhingia. 
Figura: canaliculatum. Bibio.

inflexum. Empis.

geniculatum. Conops.

gibbum. Afilus.

rectum. Afilus.

fetaceum. Bombylius.

cylindricum. Hippobofca, Rhagio.

flexile, Culex.

Vagina: nulla. Tipula.

vniualuis: Ribio.

biualuis. Myopa.

valuulis aequalibus. Hippobofca.

valuulis inaequalibus. Myopa, Afilus.

canaliculata.

acuminata, Tabanus.

abbreuiata.

fiffa, Afilus.

Proportio: breuiffimum. Tipula.

longiffimum. Bombylius.

$$
\text { ๒. } 16 .
$$

Palpi antici differunt a lacinia maxillae bifidae, quod palpi femper articulati, mobiles, fenforii, lacinia maxillae nunquam.

Palpos facillime pro lacinia maxillae aflumi e Chryfomelis aliisque apparet.

$$
\text { ๑. } 17 \text {. }
$$

Galea a maxilla bifida differt, quod galea femper cylindrice, veficulofe, maxillae fuper incumbat, cum e contrario lacinia maxillae exterior cornea, introrfum plana, maxillae partem conftituat.

Galea a maxilla omnino diftincta differt figura, fubftantia, cohaefione. 


\section{18 .}

Maxillae labiumque elongata, membranacea, inter mandibulas inflexa, linguam conftituunt. Lingua Syniftatis quibusdam Apibus, Nomadis, aliisque propria, folummodo e maxillis labioque elongatis compofita, ideoque haud partem oris propriam conftituit.

Vfus praecipuus linguae ad hauriendum nectar florum videtur.

\section{19.}

Probofcis differt ab hauftello, quod probofcis femper bilabiata, hauftellum vero nunquam.

Empis, Conops aliaque genera manifefte horum monftrant affinitatem.

Hauftellum, claffis continens characterem, femper in Antliatis adeft, probofcis faepe omnino deeft. 


\title{
IIII. METAMORPHOSIS.
}

M

\author{
§. I.
}

etamorphofis dicitur mutatio fructurae infectorum quadruplex, ab ouo ad imaginem, et comprehendit Ouum, Laruam, Pupam et Imaginem.

Metamorphofis quadruplex omnibus quidem communis, fecundum gradus tamen differt, quum alia totam mutent ftructuram, alia vero detractis tantum tunicis in imaginem tranfeant.

Cognitio ideo eiusdem infecti quadruplex.

$$
\text { 6. } 2 .
$$

Metamorphofis infectorum ad ordines naturales viam pandit, ideoque femper obferuanda et diftincte tradenda.

Idem eft infectum aetate tantum et forma mutatum. Differens vero iuuentus et differentem fenectutem indicare videtur.

Infecta ideo metamorphofi a fe inuicem differentia nunquam idem genus et vix eandem claffem intrabunt.

\section{\$.3.}

Ouum tunicatum fub minima mole continens rudimentum animalculi futuri eiusque nutrimentum, differt fecundum figuram, fitum, veftitum, colorem. 
Iñfecta omnia, quantum nouimus, ouipara, exceptis folis Aphidibus, tefte Reaumurio, vere ouiparis et autumno viuiparis.

Locus ouorum differt fecundum alimentum exclufae laruae, quin ipfâ animalium corpora illis expofita.

Cura matris pro ouorum conferuatione fumma, fingularis, admiranda.

Figura: globofa. Aranea.

hemifphaerica. Cancer.

oblonga.

conica. Truxalis.

cylindrica.

petiolata, filo elongato infident. Hemero. bius.

, coronata, pilis quibusdam rigidis apice ar. mata. Nepa.

Situs:- folitaria, fparfa a fe inuicem feparata deponuntur. Ichneumon.

aggregata, plura in eodem loco depofita.

Truxalis, Gryllotalpa.

annulata, aliis corporibus annulatim adhae.

rentia. Bombyx neuftria.

adhaerentia, fub matris abdomine circum.

feruntur branchiis adhaerentia. Aftacus. innata, fub valuulis abdominis aperiendis latentia. Onifcus.

faccata, in facculo filis contexto? pedibus ' pofticis impofita. Aranea.

abdominalia, intra matris abdomen exclufa. Coccus.

Veftitus : gummofa, materia quadam tenaciadglutinata. Oeftrus.

, pilofa, pilis puluerulentis abdominis obducta. Bombyx difpar.

fauora, in fallis vario modo conftructis abfcondita. Vefpa, Ápis.

, faccata, filis tenuitfimis, creberrimis circumdata. Aranea. 
Veftitus: foliata, intra folium contolutum vtraque extremitate claufum conferuata. Attelabus. gallata, intra gallam a matris punctura excrefcéntem latentia. Cynips.

impofita, intra reliquorum animalium corpora latentia. Oefirus, Sphex.

glebata, intra terrae glebain depofitú. Scarabaeus.

cufodita, intra aceruum e foliis quisquiliisque acumulaturn afferuata. Formica.

nuda, omni veftitu prbata. Pulex, Mufea.

Color: ouorum varius. Pleraque tamen funt alba, grifea, viridia aut brunnea. Colores mixti raro inueniuntur. -

\section{§. 4.}

Larua ruptis oui tunicis prodiens infantiam infecti continet omnino fterilem.

Larua mollis, fucculenta, fterilis, vorax, alimento proprio nutrit imaginem latentem in adultiorem aetatem.

Larua crefcens quater plerumque exuuias deponit, quae corporis molem haud amplius continere valent.

Laruae fynonyma nunc obfoleta funt: Eruca, Vermis.

\section{\$. 5 .}

Rupta vltimo laruae tunica Pupa prodit. Continet infecti adolefcentiam in vegetam aetatem.

Pupa durior haud amplius crefcens, fterilis, faepius quiefcens roborat imaginem latentem vsque ad maturitatem.

Synonyma Pupae funt Chryfalis, Nympha, Aurelia.
D 4
๒. 6. Me- 


\section{§. 6.}

Metamorphofis fecundum variam laruae et pupae ftructuram varia.

I. completa, larua et pupa currentibus, agilibus, omnibus partibus imagini fimillimis. Semper tamen voraces, crefcentes, fteriles, exutias deponentes. Aranea, Cancer, Aftacus.

2. femicompleta, larua hexapoda agili, absque alis; pupa agili alarum rudimentis. Cimex, Libellula.

3. incompleta, larua hexapoda vel polypoda fucculenta, tarda; pupa pedata, quiefcens. Scarabaeus, Apis, Formica.

4. obtecta, larua polypoda, agilis, fucculenta; pupa apoda, quiefcens, corticata, thorace abdomineque diftinctis. Gloffata.

5. coarctata, larua apoda, annulata, mobilis; pupa apoda, immobilis. Coarctata intra globum parte nulla diftinctum. Oeftrus, Mufca.

$$
\text { 6. } 7 \text {. }
$$

Larua pupaque metamorphofeos completae partibus differentiisque omnino parentum gaudent.

Larua pupaque metamorphofeos completae parentibus fimillimae, difficillime diftinguuntur. Difficiliorem reddunt fpecierum determinationem et fpecies multiplicant. Araneae e. gr. plures fpecies forfitan laruae aut pur pae reliquarum.

$$
\text { 6. } 8 .
$$

Larua metamorphofeos femicompletae conftat capite, thorace, abdomine, pedibus, cauda. Caput uiffert quoad os; antennas, forcipes et oculos. 
Os: roftratum. Cimex, Nepa.

galeatum. Gryllus, Locufta.

palpigerum. Libellula.

Antennae: fetaceae. Locufta, Blatta.

filiformes. Gryllus.

fubulatae. Libellula.

longiffimae. Locufta.

breuifimae. Nepa.

enfatae. Truxalis.

palmatae. Nepa.

triarticulatae. Nepa.

Forceps: laruis pupisque huius metamorphofeos pro* pria, articulata, vnguiculata fub capite inferta.

biunguiculata, vnguibus duøbus arcuatis armata. Libellula.

octounguiculata, vtrinque quatuor vnguibus inftructa. Agrion.

clauata, extrorfum incraffata. Libellula. bifida, vltra medium in duas lacinias aequales diuifa. Agrion.

pollicata, dente porrecto cylindrico mutico in medio inftructa. Agrion.

Oculi: femper duo, vtrinque capiti inferti, differunt inprimis figura.

oblongi. Truxalis. fphaerici. Libellula. prominuli. Agrion.

Thorax inter caput et abdomen differt figura, margine, fuperficie, proportione.

Figura: linearis. Mantis.

planus. Libellula, Agrion.

ftrumarius. Mantis.

rotundatus. Gryllus.

transuerfus. Nepa.

marginatus. Aefhna.

criftatus. Cimex.

Proportio: abbreuiatus. Pleraque.

mediocris. Mantis.

elongatus. Mantis gongylodes.

Superficies: pilofus. Libellula. 
Superficies: laeuis. Gryllus. carinatus. Gryllis. cultratus. Gryllus. ferratus. Cimex. nodofus. Gryllus. variolofus. Locufta.

Margo: dentatus. Gryllus. inermis. Nepa. deflexus. Locufta. fpinofus. Cimex.

Scutellum: laruis omnino deeft.

Abdomen annulatum, fpiraculisque pertufum, differt figura, fuperficie, margine, ano.

Figura: depreffum. Libellula, Nepa. rotundatum. Agrion. compreffum. Gryllus. otatum. Nepa.

Superficies: glabrum. Nepa, Notonecta. pilofum. Libellula. fpinofum. Gryllus. inerme. Locufta.

Margo: ferratum. Naucoris. foliatum. Mantis gongylodes. ciliatum. Notonecta. fafciculatum. Ephemera.

Anus: acuminatus. fyylatus. Acheta campeftris. dentatus. Libellula. obtufus.

Cauda abdomen terminans.

bifeta. Gryllus, Nepa.

trifeta. Ephemera. trifoliata, lamellis ouatis latioribus. Agrion. recta. Gryllus. recurua: Gryllus. articulata. Blatta. forcipata. Forficula. 
Pedes omnibus fex thoraci affixi conftant femore, tibia, tarfo et funt.

curforii. Cimex.

faltatorii. Gryllus, Cicada.

natatorii.. Nepa, Notonecta.

Femur: fuperior pedis articulus.

angulatum. Gryllus.

lobatum. Mantis gongylodes.

fpinofum, Mantis.

muticum. Locufta.

ferratum. Gryllus.

dilatatum. Gryllus.

Tibia: fecundus pedis articulus.

cylindrica. Gryllus.

compreffa. Notonecta.

fornicata. Truxalis.

angulata. Gryllus.

dentata. Truxalis.

ferrata. Locufta.

ciliata. Nepa.

inermis. Libellula.

canaliculata. Nepa.

pollicata. Nepa.

Tarfus: articulatus, pedem terminans.

biarticulatus, Nepa.

quadriarticulatus.

quinquearticulatus. Gryllus.

compreffus. Notonecta.

cylindricus. Gryllus.

ciliatus. Notonecta.

muticus. Notonecta.

vnguiculatus. Gryllus.

Pupa huius metamorphofeos agilis, currens ftatura et partibus laruae, tantummodo rudimenta alarum acquirit corpori breuiora, thoraci affixa.

\section{9 :}

Larua metamorphofeos. incompletae conftat capite, corpore, pedibus, cauda.

Thorax 
Thorax in omnibus huius metamorphofeos lartis haud diftinctus.

Laruae apodae huius metamorphofeos vix diftin-

ctam diuifionem conftituere valent, quum Siricis larua hexapoda fit.

\section{\$. 10.}

Caput differens inuenimus fecundum os, antennas, frontem, oculos.

Os: inftructum mandibulis, maxillis, palpis, clypeo, labioque cum ore parentis plerumque conuenit. Exceptio rarior. Pulex, os maxillofum.

Myrmeleon, mandibulis elongatis forcipatis.

Antennae: filiformes. Melolontha. fubulatae. Scarabaeus. fetaceae. Dytifcus. nullae, Tenthredo.

Frons: glabra. Melolontha. rotundata. Melolontha, Lueanus. fcabra. Scarabaeus naficornis. depreffa. Dytifcus. nitida. Curculio.

Oculi: orbiculati. Apis. ouati. Scarabaeus.

$$
\text { f. } \mathrm{Ir} \text {. }
$$

Corpus annulatum, fpiraculis pertufum differt quoad figuram, fuperficiem, marginem, anum.

Spiracula vtrinque nouem ad latera corporis difincta, plerumque colorata.

Figura: rotundatum; fupra cleuatum, fubtus planum. Scarabaeus, Melolontha. attenuatum. Cerambyx. depreffum. Carabus, Caffida. cylindricum. Tenthredo. 


\section{METAMORPHOSIS.}

Figura: conicum. Yefpa.

oviatum. Myrmeleon.

filiforme. Gyrinus.

collare, verfus caput angufatum. Dytifcus fulcatus,

Margo: obtufum. Lucanus, Cerambyx. fpinoftum. Coccinella, Caffida. fafciculatum. Hydrophilus, Myrmeleon. ferratum. Carabus.

Superficies: glabrum. Scarabaeus.

plicatum, Scarabaeus, Sirex.

pilofum. Pulex.

papillofum, tuberculis eleuatis mollibus tectum. Coccinella.

aculeatum, prominentiis ereckis rigidis armatum. Coccinella.

radiatum, articulis poftice fpinis acutis baf con'natis diftinctis. , Nicrophorus.

mamillatum, verruca cylindrica eleuata dorfali inftructum. Phryganea.

Anus: veficulofum, fubftantia tumida, molli fubtus tectum. Scarabaeus, Lucanus.

obtufum. Scarabaeus, Melolontha.

acutum. Cerambyx.

ftylatum. Sirex.

dentatum. Carabus.

afcendens. Coccinella,

\section{§. 12.}

Pedes ad celeriorem motum corpori fubtus affixi differunt numero, fitu, articulis, apice.

Vbi plures quam fex pedes adfunt, anteriores fiue pectorales tantum veri pedes, reliqui omnes fpurii et mutici.

Diuifio pedum in femur, tibiam, tarfum hic applicari haud poteft, quum plurimi, vtin pri. mis omnes fpurii, vnico tantum conftant articulo. 
Numerus: nulli. Pulex, Vefpa.

fex. Eleuterata, Sirex.

octodecim. Tenthredo.

viginti duo. Tenthredo, Curculio. Raj. Inf, 3. tab. 66 .

Situs: pectorales, fex pedes veri, vnguiculati, anteriori corporis parti inferti.

abdominales, obtufi, mutici medio corporis adhaerentes, numero indeterminato. caudales, duo obtufi mutici fub ano collacati.

Articuli: vniarticulati, fpurii omnes. quadriarticulati. Dytifcus, fexarticulati. Lucanus. pilofi. Melolontha, fpinofi. Myrmeleon.

Proportio: abbreuiati. Sirex, Cerambyx. elongati. Dytifcus,

Apex: obtufi, fpurii omnes. mutici, fpurii omnes. vnguiculati. Citonia, Lucanus. biunguiculati. Dytifcus.

\section{13.}

Cauda abdomen terminans ad motum accelerandum, dirigendum, differt figura, fetis, margine.

Figura: reflexa. Caffida.

fubulata. Caffida.

inflexa, fetis arcuatis, deflexis. Hydro. philus.

filiformis. Pulex.

Setae: bifeta. Caffida, Dytifcus. trifeta.

quadrifeta. Gyrinus.

bifida. Phryganea.

Margo: natatoria, pilis breuiffimis ciliata, Dytifcus.

nuda. Caffida, Pulex. 


\section{S. 14 .}

Pupa metamorphofeos/completae quiefcens in incunabulo proprio continet animalculum perfectum, omnibus partibus completum, excepta cauda imagini fimillimum.

Partes huius pupae cum partibus imaginis conuenientes vid. fupra.

Alae complicatae, fub abdomine inflexae, cum antennis pedibusque tenui membrana inclufae latent.

Cauda ad motum abdominis differt quoad figuram, fetas.

Figura: annulata, articulis diftinetis at immobilibus. Lucanus.

lunata, duabus lamellis arcuatis acutis, $\mathrm{Hy}$. drophilus.

filiformis. Dytifcus.

reflexa. Caffida.

fetacea. Caffida.

Setae: bifeta. Lucanus mas.

quadrifeta. Lucanus femina,

Incunabulum pupae fecundum variam eius confiftentiam differt.

pillularia; intra terrae glebam intus politam latens. Scarabaeus.

alligata, filis quibusdam circa corpus adhaerens. Chryfomela, Tenthredo.

cuftodita, intra cellulas aut aceruos vario modo conftructos afferuata. Apis, Verpa, Formica, Termes.

\section{S. 15.}

Larua metamorphofeos obtectae fucculenta, mollis, polypoda, conftat capite, corpore, pedibus, cauda. 
Metamorphofis haec laruaeque hae Gloffatis folis propriae.

$$
\text { ๑. } 16 .
$$

Caput os, oculos frontemque continens absque antennis, differt quoad figuram, fuperficiem. Figura: orbiculatum. Papilio Machaon. ouatum. Sphinx. cordatum. Papilio c. album, Antiopa. acuminatum, fupra corpus angulo acuto prominens. Sphinx Tiliae, Populi. abfconditum, fub corporis primo, articulo latens. Papilio Betulae.

Superficies: aculeatum, fpinis compofitis armatum. $\mathrm{Pa}$ pilio Cardui , Proráa.

fpinofum, Spinis erectis diftinctis praeditum. Papilio Maluae.

tentaculatum, tentaculis duobus mollibus retractilibus inftructum. Papilio Machaon, Apollo.

puftulofum, tuberculis eleuatis pilis longioribus tectis obfitum. Bombyx potatoria. pilofum, pilis rigidis longioribus tectum. Bombyx Caja.

$$
\text { 5. } 17 \text {. }
$$

Corpus fucculentum, annulatum, fpiraculisque pertufum differt figura, fuperficie.

Figura: cylindricum. Papilio Antiopa. incraffatum. Papilio Podalirius, Machaon. attenuatum, verfus caput fenfim anguftatum.

Papilio Podalirius. ouatum. Papilio Betulae. pyramidatum, vltimo articulo tuberculo elevato angulato. Bombyx oculea, pyramidea.

gibbofum, gibberibus eleuatis angulatum. Bombyx Ziczae, triplafia. 
Figura: hamofum, cornubus eleuatis mollibus arcuatis diftinctum. Phalaena fyringaria. inaequale, gibberibus et eleuationibns variis praeditum. Bombyx Fagi.

cornutum, poftice prominentia fubulata molli inftrućtum. Sphinx.

Superficies: aculeatum, fpinis compofitis armatum. Papilio Antiopa, polychloros.

canaliculatum, dorfi medio impreffo. Papilio Betulae.

fcabrum, punctis prominulis afperun. Sphinx ocellata.

hirtum, pilis denfiffimis elongatis vndique tectum. Bombyx Caja.

fafciculatum, pilis approximatis elongatis hinc inde adf́perfum. Bombyx potatoria, fafcelina.

ftellatum, tuberculis eleuatis, pilis erectis rigidis elongatis obfitis. Bombyx pauonia. pilofum, pilis rigidis diftantibus elongatis Noctua quadra.

fpinofum, fpinis fimplicibus armatum. Bom2 byx camelina.

- nudum, omni pubefcentia orbatum. Bombyx Mori.

? glabrum. Phalaena.

coriaceum, cute duriore tectum. Papilio

Betulae.

$$
\text { 6. } 18 .
$$

Pedes femper plures quam fex, differunt numero, fitu, figura, apice.

Pedum numero diuifiones plurimae laruarum. Pedes anteriores femper fex, reliqui omnes fpurit numero differunt.

Numerus: decem. Phalaena. duodecim. Noctua gamma, quatuordecim. Tinea. redecim. Bombyy. 
Situs: pectorales, qui anteriori corporis parti ad. haerent femper vnguiculati. abdominales, corporis medio adhaerentes fpurii. caudales, pofteriori corporis parti inferti.

Figura: cylindrici, abdominales caudalesque. incurui, pectorales omnes: articulati. Bombyx Fagi.

Apex: obtufi, abdomináles caudalésque. acuti, pectorales. mutici, abdominales. vnguiculati, pectorales.

$$
\text { S. } 19 \text {. }
$$

Cauda abdomen terminans bifeta pauciffimis do. nata et his pedes caudales omnino nulli.

filiformis. Bombyx Fagi. fetacea. Bombyx vinula.

$$
\text { \$. } 20 .
$$

Pupa metamorphofeos obtectae coarctata, incruftata, quiefcens, thorace abdomineque diftinctis, differt quoad incunabulum et cohaefionem.

Incunabulam: nuda, absque vllo integumento. Papilio Antiopá.

folliculata integumento e filis folis contexto." Bombyx Mori.

inuolucrata, integumento eltfilis aliisque variis rebus, pilis, corporis quisquiliis elaborato. Bombyx Caja.

fubterratica, fub terra metamorphofin fubiens. Sphinx.

Cohlaefio: pupis nudis tahtum proprium, quum reliquae omnes libeřae intra incunabulumi quiefcant. adhaerens, poftice filis aliquot adnectitur, vt thorax terram fpectet. Papilio. 
Cohaefio: alligata, circa collum filis aliquot transuerfis adhaerens, horizontaliter quiefcens. Papilio Machaon, Podalirius.

$$
\text { \$. 21. }
$$

Thorax, pupae pars anterior corticata absque annulis et absque fpiraculis, differt fecundum figuram, fuperficiem, marginem.

Figura: cornutus, antice mucronibus duobus porrectis, rigidis, acutis armatus. Papilio Antiopa, polychloros.

ouatus. Papilio Atalanta.

acuminatus. Papilio Machaon.

caudatus, antice muerone porrecto rigido in-

Atructus. Sphinx Conuoluuli.

oblongus. Phalaena.

afcendens, apice fenfim eleuato. Papilio

Cardamines.

marginatus, marginibus - attenuatis acutis.

Bombyx Milhauferi.

mucronatus, late emarginatus cum mucrone

in medio emarginaturae. Bombyx Milhauferi.

Superficies: carinatus, linea media eleuata. Papilio. canaliculatus, linea media impreffa. Papilio. dentatus, dentículis eleuatis adfperfus. Papilio Paphia. inaequalis, eleuationibus variis praeditus. Papilip. pilofus. Bombyx. laeuis. Phalaena. glaber. Phalaena.

$$
\text { §. } 22 .
$$

Abdomen corticatum, annulatum fpiraculisque pertufum, differt figura, fuperficie, apice.

Figura: ouatum. attenuatum. Papilio Machaon. incraffatum. Papilio Betulae. 
Superficies: dentatum. Papilio Antiopa, polychloros, Io. carinatum. Papilio. Roef. Inf. x. tab. 7. pilofum. Bombyx antiqua. tomentofum. Noctua.

laeue. Pyralis. glabrum. Phalaena.

Apex: obtufum.

ftylatum. Sphinx ocellata. acuminatum. Sphinx ftellatarum.

$$
\text { \$. } 23 .
$$

Larua metamorphofeos coarctatae apoda, annulata mouens annulis expandendis conftat $\mathrm{Ca}$ pite abdomineque, et differt quoad figuram, fuperficiem, apicem.

Pleraeque huius metamorphofeos laruae lente feftinant, victitant Aphidibus, cadaueribusque animalium.

Exuuias haud exuunt, nequidem metamorphofin fubeuntes.

Laruae hae pleraeque molles, albidae.

Figura: cylindrica. Tipula.

attenuata. Mufea, Stratiomys.

clatuata, poftice, fentim incraffata. Mufea carnaria.

Superficies: glabra. Muf́a. pilofa. Tipula. rugofa. Stratiomys.

Apex: truncata, fegmento vltimo plano. Mufca carnaria.

radiata, vltimo fegmento fpinis mollibus circumpofito. Syrphus.

barbata, fafciculo pilorum terminata. Stratiomys.

coronata, tuberculis mollibus eleuatis cir* cumdata. Mufca carnaria.

dentata, prominentiis variis eleuatis terminata. Mufca carnaria. obtufa. Mufca mellina. acuta. Múfoa. 


\section{24 .}

Pupa huius metamorphofeos coarctata, corticata, immobilis, nullis partibus diftincta differt figura, fuperficie, apice.

Pupa haec plane immobilis, cortice duriori tecta, absque omni parte imaginis latentis.

Figura: cylindrica. 'Tipula. attenuata. Stratiomys. ouata. Mufca carnaria.

i Superficies: dentata, prominentiis eleuatis acutis praedita. Tipula. glabra. Mufca. rugofa. Stratiomy.

Apex: cornuta, apice anteriori prominentiis aliquot praedita. Tipula.

caudata, apice poftice prominente. Tipula, Syrphus.

barbata, fafciculo pilorum terminata. Stratiomys. obtufa. Mufca carnaria.

$$
\text { 6. } 25 .
$$

Imago perfecta, generans, pariens, agilis plerumque alata virilem infectorum aetatem continet et vltimo detractis omnibus tunicis prouenit.

Robur pupa quiefcente acquirit latens imago et detracta pupae tunica, omnibus partibus completa exit.

Imago haud amplius crefcit, quin plures inuenimus fpecies, quae ne alimentum quidem hauriunt, fola generatione intentae.

Generatione peracta breui tempore iterum pereunt et in cibum in primis auium abeunt.

Synonymon imaginis eft infectum perfectum.

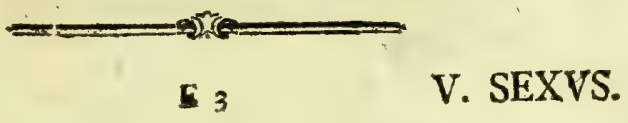




\section{V. $\quad \mathrm{S} \quad \mathrm{E} \quad \mathrm{X} \quad \mathrm{V} \quad \mathrm{S}$.}

Sol.

Sexus infectorum ad multiplicationem indiuiduorum comprehendit marem, faeminam et neutra, femper in diftinctis indiuiduis.

Genitalia plurimorum infectorum in abdominis apice fita, vbi pro excrementis et genitura communis exieus.

Aranea mas in palpis, femina fub abdominis bafin.

Cancer mas et femina fub abdominis bafin.

Libelluka mas in pectore, femina in apice abdominis ges nitalia gerunt.

Androgyna et hermaphrodita in Entomologia omnino nulla.

\section{§. 2.}

Infectis variis ad facilitandum coitum inftrumenta varia dedit natura et quidem mari et feminae.

Libellula, maribus cauda appendiculata, qua feminas|arripiunt.

Dytifcus, maribus fcuta tarfis'ad arctiorem copulam adhaerentia, feminis vero multis dorfum fulcatum aut feo miftriatum.

Vefpa clypeata et cribraria, maribus tibias clypeatas conceffit

$$
\text { S. } 3 \text {. }
$$

Mas generans, viuificans plerumque venere vaga prurit; polyandria rarior; monogamia, 


$$
\text { V. } S \text { E } X \vee \text { S. }
$$

Venere vaga pruriunt Eleuterata, Glofata, Antliata, quorum etiam mares nullum ouorum et pofteritatis curam gerunt.

Polyandriae naturalis exemplum luculentifimum et forfan vnicurn in apum fingulari republica.

Monogamae forfan funt Formicae et Termes mutuo auxilio coniunctae, at certo haud conftat.

\section{\$. 4 .}

Femina concipiens, pariens fola pofteritatis curam gerit.

Femina mari plerumque maior, craffior. Exceptio rarifima vti in Scarabaeis.

In' polyandria principatum tenet, a fpadonibus nutritur, exit raro fatellitibus femper ftipata, maribus ignauis circumdata.

Inftrumenta feminis ad oua ponenda conceffa funt aculeus, cauda.

Cura feminae in ouis ponendis fingularis, admiranda. Polt depofitionem vero ea omnino plerumque relinquit.

\section{§. 5 :}

Neutra absque genitalibus fterilia, quibusdam focietate ad commodiorem vitam et pofteritatis conferuationem iuncta.

Neutra in fingulari Apum et Formicarum republica inuenimus.

Inferuiunt inprimis ad conftruendos et implendos fauos, ad defendendos maritos, ad alendas laruas et ad cultodiendas pupas.

Vita eorum in oeconomia naturae pretio proprio nullo munita, ideoque periculo vitae negotia peragunt et emortuis maritis a nego- tiis defiftunt, quum omnem pofteritatis fpem amiferint.

$$
\mathrm{I}_{4} \text { \$. } 6 . \mathrm{Lar}-
$$


§. 6.

Larua pupaque absque genitalibus femper fteriles nutriunt, cuftodiunt imaginem latentem in vegetiorem aetatem.

Larua proprio cibo vorax nutrit imaginem inclufam vsque ad adolefcentiam.

Pupa faepius quiefcens, corticata roborat imaginem vsque ad virilitatem.

Sexus imaginis in larua et pupa latentis quodam. modo ab oculo confueto magnitudine et craffitie partium diftinguitur, quum femi nae plerumque maiores, craffiores.

\section{'. 7 .}

Mas et femina fobolem propagant fimul, nec ab ouo folo nec a genitura fola oritur proles. Confirmant hoc analogia, experientia, anatomia.

Analogia. Animalia perfectiora, vitia hacreditaria, Experientia. Apes, Bombyces.

Anatomia. Confideratio diligentiar ouarii vel vaforum fpermaticorum.

Ergo generatio aequiuoca, ergo hermaphrodita et androgyna in Entomologia nulla.

\section{Q.8.}

Corpus infectorum duplici conftat ftamine, interiori medullari et exteriori corticali.

Omnia animalium corpora duplici hoc principio diftincto componuntur.

Principium medullare comprehendit cerebri rudimentum eiusque prolongationes, nervos.

Princi- 
Princípium vero corticale continetmufculos, cutem reliquasque corporis externas partes.

\section{9.}

Omnis generatio confiftit in combinatione principii medullaris cum corticali.

Ambo principia per fe inertia, coniuncta veró multiplicabilia in infinitum.

Suadent hoc ratio, analogia cum vegetabilibus, obferuata.

Ratio, principiorum diuerfitas, corporis incrernentum.

Obferuata, principiorum inertia, extenfio.

Vegetabilia, gemmae, furculi, prolepfis.

Ergo noua creatio omnino nulla, fed omnis generatio continuata multiplicatio principii medullaris et corticalis in initio creati.

\section{\$. 10.}

Principium medullare a matre, corticale a patre. Confirmant hoc obferuata, hybrida, anatomia, vegetabilia.

Obferuata. Vitia haereditaria a patre, a matre, fimilitudo cum parentibus in exteriori figura, in internis affectibus.

Hybrida animalia, vegetabiliaque patri habitu exteriori fimillima.

Anatomia. Nerui terminantur nudi in ouario. Semen e contrario paternum e fanguine praeparatur. Nerui tantum ad erectionem inferuiunt.

Vegetabilia. Stamina e ligno, piftllum e medulla, comparatio foecundationis cum gemmis.

Ergo rudimentum animalis noui non in ouo materno folo, fed continet ouum tantum rudimentum medullare. 
Ergo rudimentum animalis noui haud in femine paterno folo, fed continet femen tantum rudimentum principii corticalis et coniunctione amborum omnis generatio.

\section{II.}

Ad vnamquamque ideo infectorum fpeciem ne. ceflario requiruntur mas et femina; neutra autem accidentalia tantum.

Absque mare et femina generatio et propagatio fpeciei omnino nulla.

Neutra ad fpeciei propagationem necefiaria haud effe, probat eorum defectus in plurimis fpeciebus.

\section{12.}

Infecta quotquot nouimus ouipara. Probat hoc metamorphofis, experientia, anatomia.

Aphides vere viuiparos autumno ouiparos obferuauit Reaumur.

Scorpiones viuiparos affeuerat Rhedi: an recte?

Coccorum matres grauidae affigunt fe ramo immobiles nec oula ponunt, aftamen viuipara dici haud poffunt; quum femper oua intra corpus exclufa matrem intus deurant, vsque dum proueniant. Mater ideo quafi integurmentum ouorum.

Onifi fub abdomen gerunt oua intra falliculum valuulis aperiendum, vsque dum excluduntur, attamen viuipari haud dicendi, quum oua iam antea pofita.

Aphides $\mathrm{ab}$ vnico coitu per quatuor vel quinque generatio. nes grauidas obferuauit Reaumur. Exemplum in tota natura vnicum, inauditum, incredibile. Analogia, ftructura partium, generationis leges
contradicere videntur. 


\section{\$. 13.}

Femina foecundata fumma cura deponit oua, ne laedantur, in loco apto, vt larua exclufa nutrimento, quiete et fecuritate omni gaudeat.

Oeftrus per totum diem fupra pecorum dorfum fufpenfa haeret, vt outm in ea deponat.

Aranea faccum filis ccntextum, ouis repletum continuo circumfert.

Sphex fummo labore laruam arripit, enecat et ouo impraegnatam fepelit.

Attenta huius indagatio viam ad naturae oecononiam pandit, quae f́cientiae noftrae vltimus finjs.

Oua Mufcarum, Culicum et Pulicum detexit Roefell oculartiffinus.

\section{14.}

Oui foecundati effentia confiftit in puncto falienti; reliquae vero partes omnes ad nutrimentum, ad integumentum aut ad exclufionem tantum inferuiunt. "

Punctum faliens oui rudimentum nou: animalculi continet et fenfim fe nutrimento e vitello albumineque oui haufto expandit.

Monftrat primo cor micans cerebrique rudimentum, quae ambo pari paffu obambulant; vsque dum ruptis oui integumentis animalculum prouenit paruum quidem, attamen omnibus partibus completum.

Oui integumenta funt membranae duae tenues, interiores, et exterior cruftacea; ad exclufionem vero inferuit bulla aerea in omni ouo foecundato inter membranas interiores. haerens. 


$$
\text { 6. } 15 \text {. }
$$

Oua fimulac depofuit femina raro eorum confervationis viteriorem curam gerit.

Infecta, vti omnia animalia fanguine frigido gaudentia, nunquam ouis incubant.

Femina curam fummam in depofitione ouorum adhibet, fimulac vero ea pofuit, plerumque eajomnino relinquit. Exceptio rarior.

Aftaci fub abdomine oua gerunt.

Aranea faccum ouis repletum circumfert.

Apes et Formicae ouorum et conferuationem neutris commendant.

Onifets oua in loculamento quadritualui fub pectore gerit.

Coccus immobilis oua intra abdomen excludit, quae exclufa fibi exitum paraut.

$$
\text { 6. } 16 .
$$

Fertilitas infectorum ftupenda, vt numero negotiis fufficiant, quum magnitudine minus valerent.

Parua infectorum moles fertilitate immenfa numeroque infinito compenfatur.

Elephas vix quotannis vnicum parit pullum.

Canis octo:

Gallina viginti.

Bombyx $3-400$.

Apis 4000 oula quotannis ponit.

Aphides, Acari, Pediculi innumera prole faepius infeftant vix coërcendi.

Tempus grauiditatis ideo etiam infeetis multo brevius.

Intra aliquot horas concipere ouaque ponere faepias valent. Ephemera, Mufca carnaria. 


$$
\begin{gathered}
\text { S. } 17 . \\
\text { J }
\end{gathered}
$$

Infecta venere exhaufta breui tempore pereunt. Mares mox poft copulam, feminae vero poft ouorum depofitionem.

Infecta pleraque annua vix per hyemem viuunt, exceptis folis aquaticis quibusdam, vti Cancer, Aftacus, Monoculus, quae quotannis cum crufta laboriofe fenectutem exuunt. An forte laruae et pupae? An imagines etiam perfiftentes?

Propagatio fpeciei vltimus creationis finis, ideoque et infecta, quae nuptias nondum celebrarunt, perfiftunt, hybernant et fequenti vere iterum proueniunt. 


\section{D I S P O S I T I O.}

$\mathrm{F}$ 6. $x$

undamentum entomologiae duplex eft, Difpofitio et Denominatio.

Difpofitio infectorum fecundum vera fcientiae principia fundamentum praebet denominationis. Furdamentum hoc fi vacillat totum tandem ruit aedificium.

Cardine hoc duplici tota nititur fcientia entomologica; qui ergo hos rite perfpexerit, verus eft Entomologus, alius non.

\section{Q. 2.}

Difpofitio infectorum fiftit diuifiones fiue coniunctiones eorum, et eft artificialis, quae claffes et ordines, vel naturalis, quae genera, fpecies et varietates docet.

Scientia entomologica in incunabulis adhuc tenera iacet, quum difpofitio artificialis nondum rite elaborata fit.

Duo tantum habemus entomologiae fyftemata; quae fundamento quodam quamuis vacillanti inaedificata funt, nempe Linnaei et Geoffroyei, quorum alter nimis naturam fequens faepius amifit fyltema, alter vero fyftemati nimis deditus naturae vim intulit, genera multiplicauit et characteribus dubiis diftinxit. 


\section{3 .}

Syftema examinat infecta per Claffes, Ordines, Genera, Species et Varietates.

Numerus fpecierum in entomologia fere infinitus et nifi in ordinem redigantur, chaos femper erit entomologia.

Syftemate veris principiis inaedificato adiuuante breui tempore infecta determinare, nominare addifcimus, absque vero hoc nulla vnquam certitudo fperanda.

$$
\text { §. } 4 \text {. }
$$

Species tot numeramus, quot diuerfae formae conftantes exiftunt hodie.

Species propagantur ouis matrum, quae rumpuntur, excrefcunt metamorphofi triplici in imaginem matri fimillimam.

Species haud intereunt, quibusdam annis quidem in minori copia inueniuntur, attamen nunquam omnino exitirpantur.

Species nouas prouenire in infectis e mifcela varia exiftentium, fuadere videntur naturae leges, copia et affinitas fpecierum.

Natura non facit faltus, fed a minimis incipit et a primordio minimo fumma abundantia.

Scarabaeus vacca, nuchicornis, ouatus.

Coccinellae plurimae.

Papilio Brafficae, Rapae, Napi, Sinapis, Monufte. Ichneumones plurimi.

Tenthredines variae.

Mufca carnaria, laruarum, radicum, domettica, Mufca vomitoria, cadauerina, Caefar.

Ergo copula differentium haud femper eandem fpeciem certe demonftrat. 
Coccinella bipunctata et quadripuftulata.

Chryfornela Alni et Betulae.

\section{\$. 5 .}

Varietates tot dicimus, quot differentia ex eiusdem fpeciei ouis producuntur infecta.

Differentia fexus maris, feminae et neutri vnica eft naturalis et conftans varietas.

Reliquae omnes oriuntur a cauffa accidentali, quae fi mutatur, reducitur varietas iterum ad fpeciem.

Varietates leuiflimas vix curat Entomologus, nifi fint fexus, quae femper annotari merentur. Varietates flagellum funt fcientiae, difficillime enim determinatur, quid fit fpecies, quid varietas, quum cultura infectorum rarior.

$$
\text { \$. } 5 .
$$

Genera tot funt, quot fimiliter conftructa inftrumenta cibaria proferunt diuerfae fpecies naturales.

In conftruendis generibus habitus et metamorphofis occulte confulenda, ne diftinguenda combinentur, combinanda diftingauntur.

Genera naturalia abunde demonftrant Curculiones, Scarabaei, Papiliones, Sphinges, Bombyces et alia fere innumera.

Cauendum tamen, ne nimis imitando naturam fyftematis amittamus filum ariadneum.

$$
\text { 6. } 7 \text {. }
$$

Claffis eft generum plurium conuenientia fecundum leges artis et fyftematis. 
Naturales exiftere infectorum claffes vix dubitandum. Suadent ratio, detecta, obferuata. At nondum tempus eft eas elaborare, quum tyrones adhuc fcientiae fimus.

Artificiales ideo fubftituendi funt, vsque dum plurimis laboribus plurimisque inuentis gra $=$ datim ad naturales accedamus,

\section{§. 8.}

Ordo eft claffium fubdiuifio, ne plura genera diftinguenda fimul et femel euadant, quam animus facile affequatur.

Ordo tantummodo ad facilitandum fyftema, ideo que etiam magis arbitrarius.

Quo magis naturalis, eo etiam praeftantior, tan= tummodo fit facilis et diftinctus.

\section{9 .}

Habitus eft conformitas quaedam infectorum affinium et congenerum in metamorphofi, alatione, pedatione, caudatione, pubefcentia, tentaculatione, lucidatione, excretione.

Habitus infectorum in conficiendis generibus occulte confulendus, ne genera naturalia frangantur; nimis vero habitui adhaerere eft ftultitiam loco fapientiae inuenire.

Habitus faepius genus indicat, at nunquiam de monftrat, quim habitus determinari aut defcribi haut poffit.

i. Metamorpho/is eft mittatio formae et ftrieturae eiusdein infect. vid. fupta.

Metamorphofis maxime ad ordines et generd inaturalia viam monftrat, quum nunqquatn infecta diuerfae tnetamorphofeos idem genus naturale et vix eutidem ordinem naturalem intrent.

Fabr. Entoms 
Larua et pupa teneram aetatem infecti continent et differens iutentus et diferentem fenectutem indicare videtur.

Metamorphofi completa. Cancer, Pagurus, Scyllarus, Aftacus, Gammarus.

Aranea, Trombidium, Phalan. gium.

Scorpio, Iulus, Scolopendra. femicompleta. Forficula, Gryllus, Mantis, Blatta, Truxalis, Acrydium, Acheta, Loeufta.

Ryngota, Pulice excepto.

Libelitula, Aefhna, Agrion, Ephemera.

incompleta. Eleuterata. Syniftata. , Pulex. obtecta. Gloffata. coaretata. Antliata.

2. Alatio dicitur ftructura et fitus alarum in thorace.

Ex alatione fyftema entomologiae confecere anteceflores omnes, Gum conftantiorem crediderint. Habitum faepius optime indicat, at ad clafium characteres conficiendos vix valet.

Alae nullae. Aranea, Trombidium, Phalangium.

Cancer, Pagurus, Scyllarus, Aftacus, Gan॰ marus.

Lepifmá, Podtura, Monoculus, Onifcus, Henorobius.

Iulus, Scolopendra, Scorpio.

Mutilla, Formica, Termes.

Acanthia, Aphis, Coccus, Chermes, Pulex.

Acarus, Hippobofca, Pediculus.

duae. Antliata, exceptis Acaro, Hippobofca, Pe. diculo.

Ephemera.

Chermes.

Eleuterata elytris coinatis. 
Alae quatuor fuperioribus

cruftaceis. Eleuterata.
omnibus mem-
branaceis de-
flexis. Vlonata.

Cicada, Laternaria, Membracis, Tettigonia, Cercopis.

cruciatiss. Nepa, Notonecta, Cimex, fquamatis. Glollàta. nudis. Syniftata.

fuperioribus Leptura, Staphylinus, Forfiabbreuiatis. cula.

filis.

Pterophorus.

plicatis.

Vefpa, Tenthredo, Sphex, Apis, Formica.

3. Pedatio ftructura dicitur, numerus et fitús pedum.

hexapoda. Pleraque.

octopoda. Aranca, Trombidium, Scorpio, Phalangium.

Cancer, Pagurus, Scyllarus, Aftacus, Gammarus.

polypoda. Monoculus, Onifcus.

Iulus, Scolopendra.

natatorii. Hydrophilus, Dytifcus, Gyrinus.

Notonecta, Nepa, Sigara, Naucoris.

bronchiales, Monoculus.

faltatorii. Chryfomela, Curcilio, Attelabus.

Gryllus, Locufta.

Cicada, Cercopis, Chermes, Pulex.

chelati. Cancer, Pagurus, Scyllarus, Aftacus, Gammarus.

Acartus.

fulcrati. Dytif́cus, Mordella, Tenebrio.

ambulatorii. Scarabaeus, Dermeftes, Chryfomela, Clerus.

Cimex, Nepa.

Vefpa, Sphex, Ichneumon, Formica, Mu* tilla.

Mufea, - Tabanus, Empiš

Iulus, Scolopendra. 
ambulatorii. Mantis, Acrydium, Acheta. adhaerentes vingue diplici. Hippobofa, Pediculus.

4. Caudatio eft fitus et figura caudae abdomen terminantis.

Cauda nulla, Scarabaeus, Dermeftes, Chryfomela, Curculio.

Laternaria, Cimex, Cicada.

Mufca, Syrphus, Tabanus.

Phryganea, Hemorobius.

vnifeta. Raphidia.

Scorpio.

bifeta. Locufta.

Ephemera, Phryganea, Podura, Mo noculus.

trifeta. Ephemera, Lepifina.

aculeata. Syniftata.

forficata. Forficula, Panorpa.

5. Pubefcentia eft armatura infectorum, qua ab externis iniuris defenduntur.

lanata. Bombylius, Melolontha。

tomentofa, Syrphus.

fafciculata. Bupreftis, Cetonia.

pilofa. Mufca, Afilus.

vernicofa. Curculio, Gryllus.

fpinofa, Curculio, Cerambyx.

aculeata. Hifpa, Curculio, Lamia

6. Tentaculationem nominamus fitum et figuram partiun retractilium, fenfum continentium.

Tentacula frontis。

ad os.

Apes fpeculatores. Linn.

thoracis.

vtrinque ad late.

ra.

Tabanus roftratus. Linis,

ád bafin primi et

fecundi fegmeh-

ti abdominis. Malachius.

Malachius. 
7. Lucidatio eft fitus partium lucsm praebentium ad coitum facilitandum.
fub abdomine.
frontis roftrati,
Lampyris,
punctorum thoracis. Elater.
fegmentorum abdo.
minalium,
Mufca, Syrphus.

8. Excretio eft copia liquoris infecto capto effluente,

$\begin{array}{ll}\begin{array}{l}\text { vomitus. } \\ \text { crepitus ventris, } \\ \text { oleum limpidum e carabus crepitans, } \\ \text { geniculiş. }\end{array} & \text { Meloẹ. }\end{array}$

§. 10.

Difpofitionem infectorum artificialem a folis inftrumentis cibariis defumfimus.

Anteceffores omnes mox ab hac, mox ab altera infectorum parte charaeteres claffium et generum defumfere. Quale quaefo fyftema plantarum, fi mox a radice, mox a caule aut a foliis, mox a floribus characteres defumerentur?

Linneus ideo ingenio fyftematico fummo natus, infurficientes, vacillantes videns characteres, rariffime noua genera introduxit, ne characteribus hifce accumulatis maior oriatur confufio.

Mihi vero inftrumenta cibaria fola characteres praebent fufficientes, conftantes.

Inftrumenta vero cibaria funt:
Palpi. Linn.
Clypeus. Fab.
Labium, Fab,
Roftrum, Linn,
Labium, Linn.
Seta. Linn.
Vagina. Linn,
Lingua fpiralis, Linn.
Probofcis. Scop.

Antennulae, Raj. Schluga. 
Mandibula. Fab.

Maxilla, Fab.

Galea. Fab.

Probofcis. Linn.

Stipes. Fab.

Capitulum. Fab.

Hautellum. 'Fab.

Valuula. Fab.

(Seta-Litn.)
Maxilla. Linn.

Roftrum. Scop.

Roftrum. Linn.

Vagina. Linn.

Inftrumenta haec cibaria ad diftinguenda genera infectorum iam c'etecta et adhuc detegenda abunde fufficiunt.

\section{C. iI.}

Claffium characteres firmi fint, diftincti et nullo modo vacillantes, iisdemque femper ex partibus defumti.

Claffes fi vacillant, totum tandem ruit fyftema.

Quo naturalior claffis, eo cacteris paribus praeftantior fyftema : attamen cauendum, ne fequendo naturam fyftema amittamus, quum non claffes naturales fed artificiales elaboramus.

Diuifio Linnaei claffium, cui omnes noftri Entomologi tam arcte adhaerent, fundamento quodam inaedificata $a b$ alis folis characteres defumens. Male ideo Scopoli quorundam characteres mutauit et retinuit reliquos.

Coleoptera.

Lepidoptera.

Aculeata.

Pedeftria,
Probofcidea.

Neuroptera.

Halterata,

Veterum diuifio infectorum in terreftria et aquatica iam diu explofa eft. 


\section{ร. 12.}

Claffis, quo amplior eo etiam difficilior euadit, quum plura genera fimul et femel fint diftinguenda.

Eleuterata in primis claffem conftituunt difficiliorem, quum plura contineat genera.

Vlonata vero e contrario claffern faciliorem fiftunt, quum pauciffima adfint genera.

$$
\text { ๑. 13. }
$$

Ordinum characteres magis arbitrarii, quum folummodo ad facilitandum fyftema inferviant.

Ordinum character fi vacillat, minus nocet, nam fyltematis partem effentialem haud continet.

Sit tantum breuis, diftinctus et facilis.

\section{§. 14 .}

Ordo genera inter fe magis affinia proxime collocabit, ve facilius diftinguantur.

Collocentur propius affinia, vt differentia eorum magis eluceat.

Exempli loco fint Gloffatá.

\begin{tabular}{l|l} 
Papilio. & male igitur $\begin{array}{c}\text { Pupilio. } \\
\text { Tinea. } \\
\text { Sphinx. } \\
\text { Sefia. }\end{array}$ Bombyx. \\
Zygaena. & Pyralis. \\
Bombyx. & Sphinx. \\
Noctua. & Alucita. \\
Phalaena. & Zygaena. \\
Pyralis. & Noctua. \\
Hepialus. & Pterophorus. \\
Pterophorus. & Sefia. \\
Alucita. & Hepialus. \\
Tinea. & Phalaena.
\end{tabular}




\section{15.}

Generum characteribus fixis tota nititur fcientia entomologica. Sint itaque conftantes, fint folido inaedificati fundamento.

Genera fi rite determinata, firmo ftatfcientia talo, falís vero generibus omnia confundi neceffe eft.

Generum progreffus hic fuit.

Veteres genera condiderunt vaga, indeterminata absque nomine et absque charactere; vit Rajus aliique.

Linnaeus primus fcientiam in formam fyftematis redegit, genera condidit, characteres nominaque eorum dedit.

Geoffroyeus genera haud pauca addidit, characteribus magis deditus.

Scopoli genera inprimis Antliatorum variis nouis auxit.

Brynniche pauca addidit.

Ego omnia haec genera fecundum leges naturae et artis examinaui, characteres ab inftrumentis cibariis defumfi et omnia tanquam noua condidi.

Genera Linneana,

Scarabaeus,

Lucanus.

Dermeftes,

Hifter.

Pauffus.

Byrrhus,

Gyrinus

Silpha.

Cafiida.

Ptinus.

Cocçinella. Chryfomela.
Hirpa,

Bruchus.

Curculio.

Attelabus.

Cerambyx.

Leptura.

Necydalis.

Lampyris.

Cantharis,

Elater.

Cicindela, Bupreftis. 
Dytif́cus.

Carabus.

Tenebrio.

Meloe.

Mordella.

Staphylinus,

Forficula,

Blatta.

Gryllus.

Laternaria,

Cicada.

Notonecta,

Nepa.

Cimex,

Aphis.

Coccus.

Chermes.

Thrips.

Papilio,

Sphinx.

Phalaena.

Libellula.

Ephemera,

Phryganea.

Hemerobius,

Myrmeleon,

Panorpa,

Raphidia.

Cynips.

Tenthredo,

Sirex.

Ichneumor.

Scopoli.

Gibbium,

Lethrus,

Afcia.

Graphium.

Battus.

Pterourus,

Argus.

Argyreus.
Sphex.

Chryfis,

Vefpa.

Apis.

Formica.

Mutilla.

Oeltrus.

Tipula.

Mufca,

Diopfis.

Tabanus,

Culex.

Empis.

Conops.

Afilus.

Bombylius.

Hippobofea,

Lepifina.

Podura.

Termes.

Pediculus.

Pulex.

Acarus,

Phalangium,

Aranea.

Scorpio,

Cancer.

Monocultus.

Scolopendra,

Onifcus.

Iulus.

Tortrix.

Geometra.

Anthrocera.

Trochylium.

Macrogloffum,

Spectrum.

Eucera.

Hirtea. 
Styrex.

Sicus.

Anthrax.

Brynniche.

Bugo.

Geoffroy.

Ptilinus.

Copris.

Byrrhus.

Anthrenus.

Ciffela.

Peltis.

Bruchus.

Lampytis.

Omalyfus.

Hydrophilus.

Gyrinus.

Melolontha.

Prionus.

Stenocorus.

Luperus.

Cryptocephalus.

Crioceris.

Altica.

Galeruca.

Mylabris.

Rhinomacer.

Boftrichus.

Clerus.

Anthribus.

Scolytus.

Anafpis.

Tritoma.

\section{Noltra.}

Trox.

Melolontha.

Trichius.

Cetonia.

Apate.
Erax.

Rhingia.

Apos.

Xiphifura.

Diaperis:

Pyrochroa.

Pterophorus.

Tinea.

Formicaleo.

Vrocerus.

Eulophus.

Stomoxys.

Voluccella.

Bibio

Notoxus.

Cerocoma.

Acrydium.

Locufta.

Mantis.

Naucoris.

Corixa.

Pfylla.

Perla.

Crabro.

Diplolepis.

Strationys.

Nemotelus.

Scatopfe.

Chelifer.

Binoculus.
Melyris.

Ips.

Sphaeridium.

Tritoma.

Nicrophorus.

Elophorus, 
Elophorus.

Nitidula.

Erodilis.

Cucujus.

Spondylis.

Scaurtis.

Zygia.

Mylabris.

Lymexylon.

Blaps.

Helops.

Paederus.

Opatrum.

Oxyporus.

Scarites.

Apalus.

Pimelia.

Malachius.

Sepidium.

Anobium.

Calopus.

Lytta.

Lagria.

Erotylus.

Alurnus.

Donacia.

Saperda.

Lamia.

Zonitis.

Callidium.

Rhagium.

Elaphrus.

Truxalis.

Acheta.
Semblis。

Tiphia.

Termes.

Scolia.

Thÿnnus.

Bembex.

Scyllarus.

Aftacus.

Gammarus.

Sefia.

Zygaena.

Rombyx.

Noctua.

Hepialus.

Pyralis.

Alucita.

Euania.

Leucofpis

Afcalaphus.

Andrena.

Nomada.

Pagurus.

Aefhna.

Agrion.

Trombidium.

Membracis.

Tettigonia.

Cercopis.

Acanthia.

Reduuitus.

Rhagio.

Syrphus.

Stomoxys.

Myopa.

\section{16.}

Characteres generum omnium $a b$ iisdem femper partibus defumendi.

Vix infectum inuenimus, quod non aliqua parte corporis a reliquis congeneribus recedat, 
ideo tot genera, quod fere funt fpecies. Inde tot orta funt genera vaga, indeterminata, vt praeftantillimus fyftematicus ipfe Linnaeus vix aufus fit noua condere ge.. nera.

Nos inftrumenta cibaria hunc in finem introduximus, affumfimus et ea conftantiffima obferuauimus.

Gentera ficta ideo affirmamus omnia, quae in partibus iis= dem et fimilibus fundamentum haud agnofcunt.

Copris Geoff. thorace cornuto non effet Scarabaeus antennis lamellatis.

Laria Scop. femoribus non fulcratis non effet Silpha thorace marginato.

Necydalis, elytris dimidiatis. Leptura thorace rotundato, Leptura Linn. elytris attenuatis. Ceramby $\mathrm{x}$ thorace fpis nofo.

Cerambyx Scop. thorace attritu ftridente. Leptura.

Mordella Scop. femoribus fulcratis. Bupreftis.

Carabus Scop. femoribus fulcratis. Tenebrio; et fic in reliquis fere omnibus.

\section{1 \%.}

Character generis omnibus fpeciebus fub eodem genere militantibus conueniat.

Canon hic fi laeditur, omnis profternitur fyfte. matis et generum certitudo, hac vero de. trufa femper vacillabit feientia.

Scarabacus antennis filiformibus. Linn.

Dermeftes antennis filiformibus. Linn.

Leptura elytris linearibus. Linn.

Papilio antennis filiformibus. Linn.

Cerambyx thorace ratundato. Linn,

Elater thorace edentulo. Scop.

$$
\text { ๑. } 18 \text {. }
$$

Plurima genera notam aliquam fingularem in inftrumentis cibariis gerunt, 
Notae hae fi conftantes' omnibusque fpeciebus conueniunt characteres praebent optimos.

Fafciculi fetaruin fub mandibulis. Lucanus.

Os protractum in roftrum. Curculio, Attelabus, $\mathrm{Pa}-$ norpa.

Palpi cheliformes. Scorpio.

Mandibula chelifera. Phalangium.

Palpi inter maxillas connati. Scolopendra.

Roftrum lamellatum. Pulex.

Hautellum cylindricum biualue. Hippobofca。

Palpi incurui vinguiculati. Trombidium.

Palpi linguaeformes. Nomada.

$$
\text { ๑. Ig. }
$$

In multis generibus aliqua pars oris a congeneribus aberrat.

Clypeum diuerfum inuenimus in Melolontha, Scarabaeo. "Mandibulam. Lucanus.

Labium. Scarabaeus, Cetonia, Apis.

Palpos. Scarabaeus, Aranea.

Maxillam confantiffimam inuenimus, vix in congener bus variat.

\section{§. 20.}

Numerum nunquam, figuram interdum, fitum raro, proportionem rariflime in congeneribus diuerfa inuenimus:

Numerus partium omnium in eodem genere fem. per idem, conftantifimus.

Figura interdum variat, vti Clypeus Melolonthae,

Labium Scarabaei, Apis.

Situs partium vix aberrat, nifi fint palpi poftici. Scarabaéus.

Proportionem me in congeneribus variantem vidiffe vix memini.

6. 2I. In- 


\section{§. 2I.}

Inftrumenta cibaria fecundum varium fexum eiusdem fpeciei rariflime differentia inue. niuntur.

Plerumque omnia eiusdem fpeciei infecta partibus exacte fimilibus gaudent. Exceptio rariflima.

Mandibulae differentes Lucanus Ceruus, Curculio difpar. Palpi Aranea.

Maxillae et labium tunc conftantiflima femper fimillima.

$$
\text { 6. } 22 .
$$

Antennae ad generum charąteres minus valent, quam plurimi eftimant.

Antennis ad genera diftinguenda nimis adhaeferunt anteceffores omnes.

Saepius tamen differunt antennae infectorum fub codem ge. nere militantium. Curculio, Melolontha, Onifcus, Tabanus, Tenthredo.

Saepius differunt fecundum fexum eiusdem fpeciei. Cero* coma, Phalaena, Elater.

Saepius etiam omnino defunt. Aranea, Trombidium, Scorpio.

Antennarum characteres tamen femper generibus appofui, quum fyftema facilitent.

$$
\text { 6. } 23 .
$$

Inftrumenta cibaria fi conueniunt, antennae autem differunt, ceteris paribus coniungenda funt genera.

Inftrumenta cibaria characteres veros effentiales generum praebent, antennae vero tantum fuccedaneos, ideoque rariflime adhibendae. 
In Gloffatis antennas ad genera diftinguenda coacti arhibuimus, quum genera naturalis huius claflis difficillime determinentur, attamen determinatio horum generum nondum fatisfecit:

Ad ordinum characteres conficiendos potius inferuiunt.

$$
\text { ๑. } 24 \text {. }
$$

Metamorphofis quidem nunquam generis characterem conltituit, ad finem characterum tamen femper adduxi, quum viam ad ordines et genera naturalia breuiflimam monfiret.

Metamorphofis nullo modo characterem generis praebere valet, quum characteres ab infecti perfecti partibus, non vero a mutatione varia ftructurae defumi debeant.

Metamorphofis tamen probe obferuanda, quum viam rectam ad naturam ducat. Nota enim metamorphofi omnium, vix dubium de ordine naturali foret.

Metamorphofin ińprimis loco characterum introduxere Swammerdam Lifter, Roefiel, Reaumur, Deger.

$$
\text { ઈ. } 25 \text {. }
$$

Character eft definitio generis, isque triplex datur, factitius, effentialis et naturalis.

Charactere generico diftinguitur. genus a reliquis omnibus, cum definitione ideo conuenit.

Character habitualis ab habitu externo, quem affumfere Raius alique veteres in determinatione generum per fe exoleuit; rite enim determinari aut defcribi haud poteft.

๑. 26. Cha- 


\section{26 .}

Character effentialis notam generi foli, cui applicatur propriam et fingularem adminiftrat, vt genus mox ab omnibus reliquis eiusdem ordinis naturalis diftinguatur.

Character effentialis optimus, facillimus, at vix vbique poffibilis.

Character hic quo breuior, quo diftinctior, eo ceteris paribus etiam praeftantior.

Exempla plura huius characteris fubminiftrat Syftema Entomologiae. Flensb. 1776.

Lucanus, Clerus, Melolontha, Cicindela, Acrydium, Locufta.

Laternaria, Sigara, Pulex.

Phryganea, Vefpa, Apis, Nomada.

Tipula, Bibio, Syrphus, Mufca, Tabanis, Empis, Hip. pobofca.

Scorpio, Phalangium, Aranea, Trombidium, Scolo. pendra,

\section{\$. 27.}

Character factitius genus ab aliis generibus eius* dem tantum ordinis artificialis diftinguit.

Ad genera extra ordinem naturalem diftinguenda affumit notas aut pauciores aut plures, quum contra effentialis character nota vnica genera $a b$ omnibus reliquis fub eodem ordine naturali militantibus diftinguit.

Effentiali ideo longe poft ponendus nec vnquam affumendus, vbi effentialis adduci poteft:

Character factitius effentiali magis generalis omni generi applicabilis, effentialis vero in mul tis generibus adhuc deficit, e. gr. in Glofiatis vix eruendus. 
6. 28.

Character naturalis notas omnes genericas poffibiles allegat, ideoque effentialem et factitium includit.

Ego primus in Entomologia characteres naturales compofui, introduxi, quibus omne fyftema niti debet.

Omnes adducit notas excepta tamen ftructura naturaliffima, quae omnibus conuenit.

Generum eft infallibilis cuftos, femper immutabilis permanebit plurimis etiam nouis generibus detectis, tantum excludantur notae fuperfluae, finouae fpecies a congeneribus in vna alteraue parte diuerfae recipiantur.

Character effentialis nouis detectis generibus faepius fallax euadit, naturalis nunquam; ideoque et character naturalis isque folus fundamentum generum in Entomologia firmum continet.

Op!s fane eft infiniti laboris characteres dare generum naturales, vt omnes generum fpecies comprehendant. Inftrumenta omnia cibaria examinanda, etiam quae in infectis paruis vifum eludunt.

Examinaui, defcripfi, determinaui fere omnia mihi nota adhibito tantum microfcopio parvo, fimplici. In animalculis absque microfcopio vix vifibilibus notas microfcopio quaerere neceffe erit.

Genera mea Infectorum, Kiliae $1777 .{ }^{2}$ characterum naturalium exempla abunde praebent.

$$
\text { f. } 29 \text {. }
$$

Character naturalis in omnibus licet diuerfiffimis fyftematibus immutabilis feruari debet. Fabr. Entom. 
Quamdiu fyftematici quotidie nouos generum characteres nouosque conceptus introducunt, tamdiu nunquam genera ftabiliuntur, nulla fcientiae erit certitudo et breui tempore ad priftinam barbariem redibit Entomologia:

\section{30.}

Characteres, qui vifu haud obtinentur, nullo modo adhibendi.

Mitto hic veterum characteres, qui faepe habita-

tionem, alimentum aliaque loco characteris affumebant.

Oculus praebet fenfum conftantiffimum, reliqui faepe variant nec rite determinari valent.

Characteres ideo omnes a fono Entomologo vero omnino indigni.

Cicada Scop. Gens ftridula, terreftris.

Leptura Scop. Thorax fubrotundus atterens absque fono. Cerambyx Scop. Thorax attritu ftridens.

Characteres ab odore defumti itidem omnino reiiciendi.

Cimex Scop. Gens curforia plerumque foetens.

$$
\text { 6. } 3 \text { I. }
$$

Characteres generici a loco defumti omnino ex Entomologia exftirpandi.

Locus infectorum femper fubintelligitur, accidentalis tamen femper eft. Laruae faepius aquaticae, quarum imagines terreftres.

Dytifcus Scop. Gens aquatica, fegnis.

Notonecta Scop; Gens aquatiea, nataris in dorfo。 Cimex Scop. Gens terreftris, curforia. Pediculus Scop. Habitatio in animalibus. 


\section{S. 32.}

Characteres generici a colore mutuati nullo modo valent.

Color infectorum eft maxime accidentalis, faepius varians vix ad fpecierum differentias, nunquam vero ad generum characteres ad= hibendus.

Chryfis Linn. Corpus auratum.

Chryfis Brynn. Corpus auratum.

\section{$\$ \cdot 33$.}

Characteres generici a comparatione cum alio infectorum genere defumti nullo modo tolerandi.

Omne fimile claudicat et tertium comparationis haud femper eruitur.

Tyronibus inferuire ftudernus, qui genera vix vlla nouerint, et illis comparatio femper obfcura.

Necydalis Scop. Antennae cerambycinae:

Termes Scop. Facies Pediculi.

Pediculo cognatus et fimiliss. Raj:

\section{\$. 34 .}

Characteres generici omnes, qui non a numero, figura, fitu et proportione partium infecto: rum defumuntur, omnino excludendi.

Varii varias infectorum proprietates loco characeris affumferunt at perperam, nunquam alios characteres, quam e partibus ipfis de= fumtos admittimus.

Carabus Scop: Corpus agile.

Dytifcus Scop. Corpuis fegne:

Ephemera: Volatus grauis, vita breuis:

$$
6 \hat{z} \quad 35 \mathrm{Ge}=
$$




\section{§. 35.}

Genus vnica fpecie conftare poteft, licet plurimis faepius componitur.

Vnicam fpeciem continent.

$$
\begin{aligned}
& \text { Calopus. } \\
& \text { 3.-Melyais. } \\
& \text { Alurnus. } \\
& \begin{array}{l}
\text { Setrrtas } 3 \\
\text {-Eerocoma. ú } \\
\text { Lentofpis. } 4 .
\end{array}
\end{aligned}
$$

Plurimis fpeciebus conftant alia genera, quae Entomologis in primis commendo.

Curculio.

Phalaena.

Ichneumon.

Mufca.

Acarus.
Papilio.

Tinea.

Apis.

Tipula.

Pediculus.
Sphinx.

Cimex.

Syrphis.

Aranea.

Phryganea.

$$
\text { §. } 36 \text {. }
$$

Termini artis in characteribus genericis puri eligendi, obfcuri, erronei et dubii omnino relegandi.

Termini artis vfum praebent eximium in compendiofe loquendo. Sint folummodo adaequatis definitionibus rite determinati, conftantes et rite adhibiti.

Roftrum Cimicis, Curculionis, Bombylii, Mufcae, multum a fe inuicem differunt.

Hauftellum. Roftrum. Linn. Probofcis. Scop.

Auxi Entomologiam plurimis inprimis inftrumentorum cibariorum, vti Clypeus, Labium, Mandibula, Maxilla, Galea, Hauftellum. 


\section{N O M I N A.}

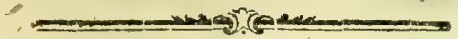

$$
\text { §. I. }
$$

Denominatio alterum Entomologiae fundamentum de nominibus difponit eaque determinat, auget.

Nomina fi pereunt, perit et cognitio rerum.

Demtis nominibus rite determinatis aliis ideas

noftras nullo modo communicare valemus.

Veterum nomina plerumque praeltantiffima, ideoque et omnia nomina Linnaeana in veterum eruditione trita, retinui, quamuis eorum fontes fáepius ignoramus.

$$
\text { †. } 2 .
$$

Nomina vera infectis imponere Entomologis gem nuinis tartum in poteftate eft.

Denominatio infectorum facillima quidem videtur, at difficillima tamen eft, quum cognitionem generum omnium ante conditorum eorumque nominum fupponat.

Nomina abfurda infectis plurimis ab idiotis impofita funt e. gr.

Molitor. Scarabaetus.

Cerutus volans, Lucantis.

Gallina Mariae. Coccinella.

Aedilis. Cerambyx.

Vrfus. Bombyx.

Libatrix. Bombyx.

Leopardus. Sphinx.

Meticulofa. Noetwa. 
Admirabilis. Bombyx.

Terribilis. Bombyx.

Somnolentus. Bombyx. Audax, intrepidus. Hemerobius. Abyflus Satanae. Monoculus.

\section{\$. 3 .}

Nomina infectorum omnia funt vel claflis et or dinis, vel generis et fpeciei; illa femper in enunciatione infecti funt muta, haec vero, fonora.

Infectum nomine generico et fpecifico inftructum, perfecte nominatum eft.

Nomen claffis et ordinis nunquam nomen infecti intrabunt, quamuis fubintelligantur.

$$
\text { §. } 4 .
$$

Nomina claffium continebunt characterem effentialem fuae claffis.

Nomina funt onera artis ineuitabilia, ideoque quantum fieri potent facilitanda.

Nomina claffum Linneana abs alis claffes defumens optima, nec mala Schlugiana latina.

Linnaeana.

Coleoptera.

Hemiptera.

Lepidoptera.

Neuroptera.

Hymenoptera.

Diptera.

Aptera.
Schlugiana.

Vaginantia.

Semivaginantia.

Farinacea, I

Venofa.

Bialata.

Nuda.

\section{\$. 5.}

Nomina ełaffium omnia eadem lingua proponenda funt. 
Nomina latina aut graeca bona funt, at eadem per omnes claffes retineri debent.

Male ideo Scopoli mutauit Linnaei Aptera in Pedeftria, $\mathrm{Hy}$ menoptera in Aculeata, et reliquit reliqua Graeca.

\section{§. 6.}

Nomina claffium iisdem femper partibus defumenda funt.

Characteres claffium ab iisdem femper partibus defumendi; nomina vero exprimant characterem. Ergo et nomina abiisdem femper partibus fint petenda.

Mutatit et Scopoli quarundan claflium nomina defumens Linnaei, Hemiptera in Probofcidea, Hymenoptera in Aculeata, Diptera in Halterata et Aptera in Pedeftria, quo ipfo et determinatio et denominatio magis lubricae.

\section{7 .}

Claffium nomina vnico tantum conftabunt vocabulo nec nimis compofito.

Nimis compofita mihì dicuntur verba, quae plura quam duo vocabula continent.

Characterem loco nominis affumere inconfultum, quum nimis longus difficillime memoria retineatur.

Ex ouis fphaericis exclufa, atque vltima et integra forma etfi hon magnitudine nata. Lifter.

Ex ouis longiufculis vermiculi nati, e quibus adultis Chryfalides fiunt, aut quae nuda et in nympha effe dicuntur, quae omnia non aliud funt quam ftatus quidam feu conditiones adoleferidi a victus ratione. Lifter.

$$
\text { G } 4 \text { S. } 8 \text {. No- }
$$




\section{8 .}

Nominum ordinum cum nominibus claffium par eft ratio, attamen magis libera funt.

Contineant characterem effentialem fui ordinis.

Antennis filiformibus.

Antennis fetaceis.

Sint omnia in eadem lingua propofita.

Omnia eiusdem claffis iisdem partibus petenda. Vnico aut duobus conftent tantum vocabulis.

$$
\text { 6. } 9 .
$$

Quaecunque infecta genere conueniunt eodem nomine generico defignanda funt.

Afellus Raj. Pulex marinus Raj. Onifcus.

Libelia Raj. Mufca rarilima in Italia capta Raj. Libellula.

Cimex Raj. Mufca cimiciformis Raj. Cimex.

Character genericus idem et idem nomen fupponit, quum character definitionem et generis et nominis contineat.

$$
\text { 5. } 10 .
$$

Quaecunque e contrario infecta genere differunt, diuerfo nomine generico diftinguenda funt.

Scarabaeus maximus. Melolontha.

Scarabaeus magnus. Scarabaeus.

Scarabaeus maiufculus. Nicrophorus.

Scarabaeus viridis. Chryfomela,

Scarabaeus alter. Coccinella.

Scarabaeus olens. Cerambyx.

Scarabaeus niger. Spondylis.

Scarabaeus viridis. Cicindela.

Scarabaeus caftaneus. Elater.

Scarabaeus niger. Tenebrio.

Scarabaeus niger. Carabus. 
Scarabaeus cauda furcata. Forficula.

Scarabaeus maiufculus. Staphylinus.

Scarabaeus mollis. Meloe.

Scarabaeus maiufculus. Curculio. I

$$
\text { 6. II. }
$$

Nomen genericum in eodem genere vnicum tantum erit.

Vnicum genus, vnicum nomen, ne oriatur confufio.

Cantharis feu Scarabaeus.

Smaragdulus fite Viridulus Merr.

$$
\text { §. } 12 .
$$

Nomen genericum in eodem genere femper idem erit.

Character generis femper idem, ergo et nomen.

Silpha Linn.

Bupreftis Linn.

Empis Linn.

Afilus Linn.

Conops Linn.

Lucanus (Scop)ainn. Platycerus Geoff.

Lepifma Linn.

Carabus Linn.
Peltis Geoff.

Cucuius Geoff.

Afilus Scop.

Erax Scop.

Empis Scop. :

Forficina Geoff.

Bupreftis Geoff.

Nominum genericorum enim mutatio femper anfam confufionis praebet.

\section{\$. 13.}

Nomen genericum vnum idemque ad diuerfa defignanda genera affumtum altero loco excludendum erit.

Attelabus Linn. Attelabus.

- - Geoff. Hiffer. 


$\begin{array}{cl}\text { Cantharis Linn. Cantharis. } \\ \text { Bupreftis Linn. } \\ \text { Afilus Linn. Geoff. } & \text { Carabus. } \\ - \text { - Scop. } & \text { Emplus. }\end{array}$

$$
\text { 6. } 14 .
$$

Qui nouum genus conftituit, eidem nomen etiam imponere tenetur.

Nomen eit fonus generis, ideoque absque nomine genus indicari non potelt, et absque nomine cognitio generis perit.

Perlarum forte fpecies. Aldr.

Pediculo cognatus et fimilis. Raj.

Ad Scolopendram accedens. Raj.

Mufca rariffima in Italia capta. Raj.

$$
\text { 6. } 15 .
$$

Nomina generica e duobus nominibus integris ac diftinctis facta e republica entomologica plane releganda funt.

Len Aphidis Reaum. Scorpio Mufca Frifch. Mufca Scorpiura Merr. Vefpa Ichneumon Raj. Scorpio Araneus Frifh. Locufta Pulex Swamm. Mufça Cerambyx Schaeff.
Hemorobius,

Panorpa.

Panorpa.

Ichneumon,

Scorpio.

Ciçada.

Leptura,

$$
\text { 5. } 16 .
$$

Nomina generica ex duobus vocabulis diftinetis et integris compofita tolerari non debent.

Ceruus volans Imp. Lucanus.

Taurus volans. Lucanus,

Mufca tripilis, Ichneumon. 


\section{Mufca apiformis Pet. Bombylius. \\ Mufca cimiciformis Raj. Cimez.}

$$
\text { 6. } 17 .
$$

Nomina generica e duobus vocabulis latinis integris et compofitis reiicienda funt.

Ruricolus.

Formicaleo Geoff,

Gryllotalpa Raj.

Ligniperda Pall.

Binoculus Geoff.
Carabus. Myrmeleon. Acrydium. Apate. Monoculus.

Graeca talia optima at latinae linguae omnino contraria funt.

Formicaleo Geoff, Myrmeleon.

Ligniperda Pall. Lymexylon.

$$
\text { ๑. } 18 .
$$

Nomina generica hybrida e vocabulo graeco et latino compofita haud agnofcenda funt.

Monoculus Linn.

$$
\text { \$. } 19 .
$$

Nomina generica cui fyllaba vna vel altera praeponitur aut in fine additur, vt aliud plane genus quam antea fignificet, Entomologis indigna funt.

Syllaba pracpofita.

Hydrocantharis. Raj. Donacia.

Binoculus. Geoff. Monoculus.

Syllaba in fine addita.

Afellus. Raj.

Cancellus. Raj.

Libelloides. Schaeff.

Coccinella.
Onifcus.

Cancer.

Afcalaphus.

Coccus. 


\section{\$. 20.}

Nomina generica fimili fono exeuntia anfam praebent confufionis.

Fornicaleo. Raj.

Chamaeleo. Goed.

Leo Aphidis. Reaum.

Rediculus. Raj.

Pediculus marinus. Raj.

Pediculo cognatus. Raj.

Mufca forpiura. Merr,

Mufca tripilis. Mouff.

Murca apiformis. Pet.

Mufca cimiciformis. Raj. Cimex.
Myrmeleon.

Stratiomys.

Hemerobius.

Pediculus.

Onifcus.

Termes.

Panorpa.

Ichneumion.

Boinbylius.

\section{\$. 21.}

Nomina generica infectorum cum Botanicorum, Zoologorum, Lithologorum aut Medicorum nomenclaturis communia, fi ab Ento. mologis poftea affumta, ad ipfos remittenda.

\section{Quadrupedia.}

Ceruus volans

Taurus volans\}

Leo Aphidis. Hemerobius.

Botanica.

Squilla Klein, Gammarus, Ephemera.

Coris. Acanthia.

Staphylinus,

Serratula Schulz. Helops.

\section{Lapides.}

Smaragdulus vel viridulus Merret. Citonia. Perla Petiv, Hemerobius.

\section{Coeleftio.}

Capricornus Degeer. ramby $x$.

Mathematica.

Geometra Scop. Phalaena.

Tortix Scop. Pyralis.
Ampribia.

Teftudo Blank. Cáffida,
Anthrax Scop.

\section{Medica.}




\section{§. 22.}

Nomina generica contraria fpeciei alicui fui generis mala funt, vix toleranda.

Boftrichus glaber.

Curculio nobilis.

Scarabaeus arboreus.

$$
\text { 6. } 23 .
$$

Nomina generica diminutiua e lingua latina contorta toleranda, quamuis praeftantiflima haud funt.

Forficula

Nitidula

Mordella

Coccinella
Fanceps.

Nitidus.

Mordes.

Coccus.

\section{24 .}

Nomina generica obfcura graeca et latina, quorum fontes quidem ignoramus, tamen retinenda funt; barbara vero omnino excludenda.

Etymologia nominum inprimis latinorum dificillime eruitur et eruta faepius tamen dubia perfiftit.

Nomina barbara, quae quidam in Entomologia in nouiffimis temporibus introduxerunt, omnino reiicienda, quum nullo modo intelligantur et difficile pronuncientur.

Objcura latina.

Tenebrio, Tenebrae.

Lucanus Plinii.

Cicada.

Cimex. Mordella. Mordeo.

Chermes.

Obfcura Graeca.

Silpha

Attelaburs

Cantharis

Carabus

Necydalis

Staphylinus $\sigma \cdot \lambda \varphi n$

$e \tau \tau \tau \dot{\pi} \lambda \alpha \beta$ as

noviagus

$x \propto \rho \propto \alpha \beta O s$

sercodadis

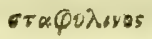


Nitidula Cicer.

Paederus.

Opatrum.

Truxalis, Plinil.

Crabro, Plinii.

Hifter.

Forficula. Forfex.

Locufta Plinii. d

Formica.

- Vefua.

Termes。

Apis.

Cancer.

Pagurus.

Scyllarus.

Aftacus.

Gammiarus.

Aranea.

Phalangium.

Papilio.

Phalaena.

Noctua. Nox.

Tinea.

Fulgora. Fulgeo.

Pulex.

Nepa.

Reduuius.

Tipula.

Bibio.

Mufca.

Tabanus.

Oeftrus.

Culex.

Afilus.

Pediculus.

Acarus.

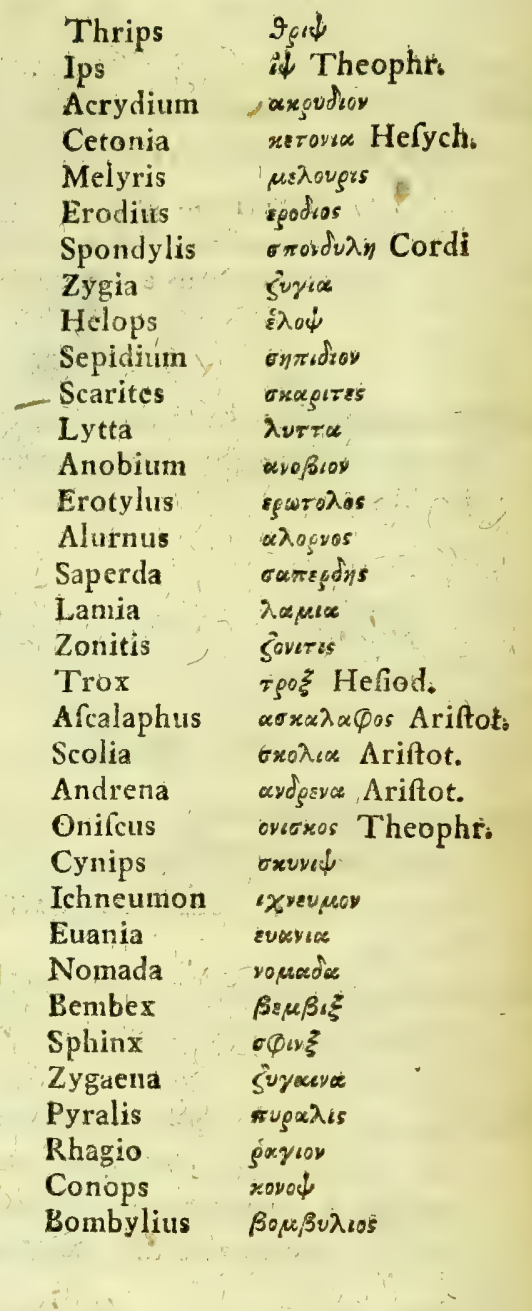

Nomina generica, quae characterem effentialem; habitum aut proprietatem fingularem infectorum fub genere militantium exprimunt, femper optima funt 
VII. $N$ O $M \quad I \quad N \quad A$.

\begin{tabular}{|c|c|c|}
\hline Scarabaeus & fodio & $\sigma \times \alpha \pi \tau \omega$ \\
\hline Dermeftes & pellis & $\delta \leqslant \rho \mu \alpha$ \\
\hline Trichius & capillae & Tosxes \\
\hline Apate & impoftura & $\alpha \pi \alpha \tau \eta$ \\
\hline Nicrophorus & vefpillo & yirgọogos \\
\hline Sphaeridium & rotunditas & opargar \\
\hline Elophrus & palus & $\varepsilon \lambda_{O S}$ \\
\hline Coccinella & granum & roxkos \\
\hline Curculio f.Gurgul. & toruus & 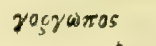 \\
\hline Chryfomela. & poma aurea & 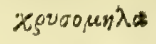 \\
\hline Scaurus & pedibus inflexis & oxavgos \\
\hline Lampyris & Fax & $\lambda \propto \mu \pi \approx s$ \\
\hline Leptura & attenuo & $\lambda_{\varepsilon \pi \pi \text { row }}$ \\
\hline Bupreftis & $\begin{array}{l}\text { bos }(\beta \times 5) \text { inflam- } \\
\text { mans }\end{array}$ & $\pi_{\rho}$ grins \\
\hline Dytifcus & vrinator & Jutทs \\
\hline Cryptoce & $\begin{array}{l}\text { abfiondo } \\
\text { caput }\end{array}$ & $\begin{array}{l}x_{g} v \pi \tau u \\
\pi \varepsilon \varphi \alpha \lambda \eta\end{array}$ \\
\hline Melolontha & pomarium & $\mu \eta \lambda\rangle, 0 \nu$ \\
\hline Mylabris & molitrix & 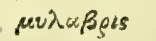 \\
\hline Lymexylon & $\begin{array}{l}\text { perdo } \\
\text { lignum }\end{array}$ & 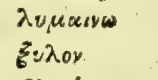 \\
\hline Blaps & inutilis & $\beta \lambda \propto \alpha$ \\
\hline Pimelia & obefus & $\pi t \mu \varepsilon \lambda \xi \xi$ \\
\hline Oxyporus & celeripes & 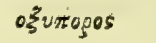 \\
\hline Apalus & mollis & $\alpha \pi \alpha \lambda o s$ \\
\hline Lagria & lanugo & $\lambda \alpha \chi^{y \eta}$ \\
\hline Malachius & malachites & $\mu x \lambda \propto \chi \chi<\tau \% s$ \\
\hline Calopus & pulcr.pedes habeas & $x \approx \lambda 0 \pi \& s$ \\
\hline Donacia & arundo & Sovorz \\
\hline Hydrophilus & aqua' & idwo \\
\hline Rhagium & fpina & $\rho^{\alpha x} x<s$ \\
\hline Elaphrus & agilis & $<\lambda \mu \varphi_{\rho} \circ s$ \\
\hline Blatta & noceo & $\beta \lambda \alpha \pi \tau \omega$ \\
\hline Gryllus & grunnio & $\gamma \rho v \lambda \lambda_{1} \zeta \omega$ \\
\hline Byrrhus & pellis & Bugous \\
\hline Bruchus & ftrideo & Bouxw \\
\hline Anthrenus & flos & $\alpha y 905$ \\
\hline Boftrichus & cincinnus & Boorguxos \\
\hline Chryfis & aurea & xguris \\
\hline Myrmelion & formisa & 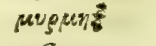 \\
\hline Tiphia & palus & thos \\
\hline
\end{tabular}

Raphidia 
Raphidia

Thynnus

Ephemera

Lepifina

Hemerobius

Mutilla

Agrion

Trombidium

Scolopendra

Scorpio

Selia

Hepialus

Pterophorus

Notonecta

Aphis

Tettigonia

Coccus

Acanthia

Natucoris

Syrphus

Empis

Stomoxys

Hippobofea

Mantis acicula cum impetu fero vnius diei

fquama

dies

mutilus

ferus

grumulus

aflulae corporis

exacerbo

tinea

febris lenta

ala

humeo

dirimo

ftrideo

granum

ruina

nauticus

vulgatus

imbibo

os facio

equus

vates

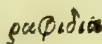

grva

Q Q n uepos

$\lambda \varepsilon \pi \sigma \tau \mu \alpha$

घं $u s \rho \alpha$

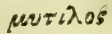

aygios

Ifoufardioy

$\sigma \times 0 \lambda \circ \psi$

$\sigma \times 0 \rho \pi t 0 \omega$

$\sigma \eta \sigma$

घं $\pi$ เ人ग.os

$\pi \tau \varepsilon \rho \theta y$

vоrsw

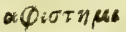

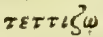

roxxos

$\alpha x \alpha v 9 \alpha$

varx入mpos

बथ पैos

c $\mu \pi$ ivat

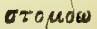

intos

Mxyzis

\section{26 .}

Nomen genericum antiquum antiquo genericonvenit.

Nomina veterum difficillime eruuntur et eruta dubia tamen femper perfiftunt, quum figurae et defcriptiones vix vllae.

Antiqua ideo nomina, quum indeterminata, fuperflua fint optime infectis iam diu notis imponuntur.

Scarabaei genus antea fub fe comprehendebat Cetoniam, Melolontham, Lucanum, Trichium, at detectis characteribus nouis effentialibus notifima illa in. fecta noua nomina aftumere nequeunt, hinc an. tiquiffima illa recepta fuere. Trichius vero vix veteribus notus noum nomen affumfit. 


\section{\$. 27.}

Nomen genericum dignum, alio licet aptiore permutare non licet.

Nomina in veterum eruditione trita pleraque optima haud mutanda, quamuis interdum eorum deriuationem ignoremus.

Melolontha maxilla dentata aptius Gnathodonthus effen* tiali nomine vocari poffet.

Carabus reliquis infectis maxime praedatur ideoque illi „nomen Leiftus conueniret.

Abftineamus vero a tali mutatione in infinitum, quae tantummodo confufionem et tandem ruinam fcientiae parit.

$$
\text { \$. } 28 .
$$

Nomina generica noua haud fingenda, quamdiu fynonyma digna in promtu funt.

Antiquum fi difiungitur genus, noua nomina effingenda non funt, quamdiu antiqua adfunt, nam antiquo generi antiquum conuenit nomen. \$. 26.

Nouum genus detectum melius nouo nomine nominatur, quamuis antiqua nomina haud deeffent.

$$
\text { 6. } 29 .
$$

Nomen genericum vnius generis, nifi fuperuacaneum, in aliud transferri haud debet.

Omnes nominum mutationes anfam praebent confufionis. Maneant ideo omnia, nifi fint noxia aut abfurda, de quibus iam dictum.

e. $\mathrm{gr}$. 
Scopoli mutauit Linnaei Afilus in Erax, Empis in Afilus et Conops in Empis: inde neceffario oritur confufio, quum iam idean aliorum infectorum cum his 110 . minibus combinare foleamus.

\section{\$. 30.}

Si genus receptum fecundum leges naturae et artis in plura dirimatur, tum nomen antea commune vulgatiffimo infecto manebit.

Scarabaei genus quum dirimerem in Scarabaeum, Melo. lontham, Cetoniam, Trichium et Lucanum, neceffario Scarabaeus hoc nomen commune antea omnibus concedere debui, quum infecta generis frequentiffima notiflima fint.

\section{3I.}

Nomina Entomologiae generica omnia latinis litteris pingenda.

Sonus nominum, quantum fieri poteft, facilitandus, ideoque nec graeca, nec barbara admittimus; et terminationem graecam in latinam mutamus.

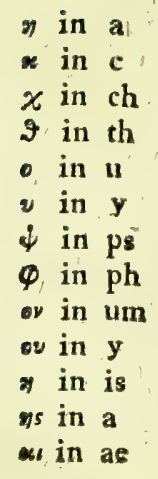

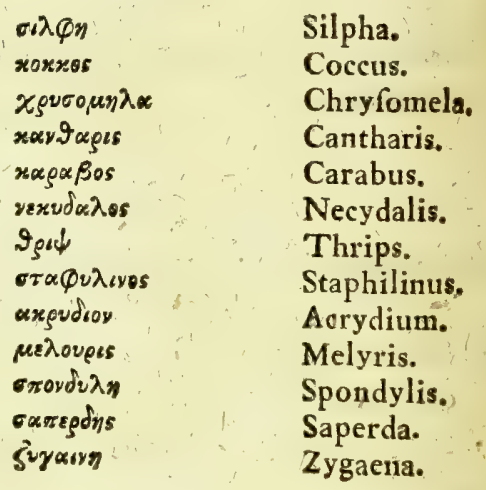




\section{32.}

Nomina generica fesquipedalia, enunciatu difficilia et naufeofa femper fugienda.

Sesquipedalia dicimus verba, quae plures quam duodecim litteras continent.

Cryptocephalus. Geoff.

Naufeofa, quae nefcio quid infueti produnt.

$\begin{array}{ll}\text { Anthrax. } & \text { Scop. } \\ \text { Erax. } & \text { Scop. } \\ \text { Bugo. } & \text { Brynn. }\end{array}$

Q. 33.

Terminis artis loco nominum genericorum abuti inconfultum femper erit.

Hexapus Raj.

Millepes Matth. Onifcus:

$$
\text { 6. } 34 \text {. }
$$

Nomina triuialia a Linnaeo primo introducta vocamus nomina fpecierum propria.

Linnaeus his Zoologiam, Botanicam et Mineralogiam locupletauit.

Vfus nominum triuialium eximius in breuitate et conftantia. Differentiae enim fpecificae faepius nimis longae euadunt et nouis detectis fpeciebus mutari debent. Nomina vero triuialia femper permaneant.

Nomina triuialia fere innumera nominibus clafficis et genericis magis libera funt, attamen quibusdam regulis limitata.

\section{35 .}

Nomina triuialia vnico tantum conftabunt vocabulo, nec nimis compofito aut fesquipedali. 
Commendant fe nomina triuialia in primis breuitate, ideoque nomen fit vnicum.

Soarabaeus flos Chalci ftriatus. Voet.

- orphanus maculofus. Voet.

-. - fcarabaeoides crifpans.

Vocabula fesquipedalia femper fugienda, quum difficilius memoria retineantur.

Mufca coeruleophtalmica. Scop.

Chryfomela Friderichsdalenfis. Müller.

$$
\text { 6. } 36 \text {. }
$$

Nomina triuialia in oides definentia ad fimilitudinem quandam cum alio genere exprimendam minus placent.

Nomina generica in oides Botanicorum omnino reiecta in Triuialibus infectorum nune iterum introducta.

Notitiam reliquorum generum praefupponit talis comparatio; at imprimis tyrones docereftudemus.

Nofcitur infectum ex nomine, et nomen ex infecto, ambo vero ex proprio charactere; comparatio igitur nunquam admittenda.

Habitus praeterea faepius fallit et in eodem genere interdum infecta, quae habitu differunt, quo ipfo comparatio fallax euadit.

Erax conopfoides. Scop.

Erax tenthredoides. Scop.

Tipula hemerobioides, Scop。

Tipula phalaenoides. Linn.

Múfa conopfoides. Linn.

Lucanus caraboides. Linn.

Afilus crabroniformis. Linn。

Erax crabroniformis. Scop。

Apis vefpiformis. Scop.

Sphex vefpoides. Scop. 


\section{S. 37.}

Nomina triuialia nunquam gradum comparatiuum aut fuperlatiuum admittunt.

Comparatiuus et fuperlatiuus femper comparationem cum reliquis fpeciebus eiusdem generis indicant, quae nullo modo admittenda.

Necydalis maior.

- - minor.

- - ninima.

Deteratur Species Necydalis adhuc minor, tune Necydalis antea minima vocata maior euadit.

\section{38.}

Nomina triuialia in eadem fpecie multiplicata femper confufionem praebent, ideoque omnî modo euitanda.

Nullum ideo nomen triuiale proponendum absque iufta differentia; vt mox innotefcat fpecies.

Nomina triuialia antecefforum inprimis Linnaei fancte feruaui.

Scarabaeus longipes Scop.

- - - illyricus Scop.

Papilio Dryas Scop.

- - Fagi Scop.

- - Achine Scop.

- - Polymeda Scop.

- riuularis Scop.

- Amyntas Scop.

- - Menalcas Scop.
Schaefferi, Linn. Taurus Linn.

Phaedra Linn.

Hermione Linn.

Dejanira Linn.

Hiperanthus Lint.

Prorfa Linn.

Arcana Linn.

Pamphilus.

\section{\$. 39.}

Nomina triuialia a loco aut ab anni temporibus defumta toleranda, quanuis haud optima. 
Locus et tempus infecti funt maxime accidentalia, quamuis absque loco aut tempore cogitari haud poffit. Infecta plerumque plurimis regionibus, plurimisque anni temporibus communia.

Toleranda tamen funt, quamuis haud imitanda, quum aliquam infecti ideam quamuis accidentalem communicent.

Cicindela germanica.

- - - maura.

Chryfomela americana. Scorpio europaeus.

- - americanus.

- - afer.

- - auftralafiae.

- - maurus.
Searabaeus vernalis.

Melolontha folftitialis.

Dermeftes vernalis Myll.

\section{§. 40.}

Nomina triuialia a magnitudine defumta haud optima, ideoque non imitanda.

Magnitudo a loco, a climate, ab alimento nimis

variat, ideoque fpecies haud diftinguit nec nomen intrare debeat.

Maiores et minores fpecies deteguntur ideoque fpecies, quae olim giganteae aut pygmeae erant, intermediae euadunt, quum magnitad femper relatiua.

Bupreftis gigantea.

- - minuta.
Chryfomela gigantea. - - minuta.

\section{S. 4L.}

Nomina triuialia ad clariffimorum virorum memoriam conferuandam introducta fancte fervanda. 
Hoc vnicum et fummum laboris praemium cafte difpenfandum ad imitamentum et ornamentum Entomologiae.

Botanici nomina generica hunc in finem introduxerunt, at in Entomologia genera pauciora raroque noua deteguntur.

Nomina triuialia ideo primus introduxit Linné, quum conlftantia fint. Idemque femper erit. Ambo conferuant nomen, ambo indicant virum de fcientia bene meritum.

Nomina trinialia Papilionum fplendidorum patronorum fautorumque memoriae, Pyralidum vero amatorum, Tinearum denique fcriptorum dicauit a Linné, quem et nos fecuti fumus.

Scopoli hic nomina triuialia Aranearum recepit, at minus placent. Aranearum fpecies luridae, ingratae nee adhuc rite determinatae. Varietates, metamorphofeos et fexus plures adhuc reducendae, at nomen viri de feientia bene meriti in Entomologia deleretur.

Nomina claffium et ordinum in eundem finem nuperrime affumfit idem Scopoli, at nomina haec inconftantia femper vacillant. Nouus fyftematicus nouos claffes et noua nomina affumit. Nomina generica et triuialia rite determinata eaque fola permanebunt.

\section{S. 42 .}

Nomina triuialia infectorum, quorum laruae plantis victitant, optime e plantis, quibus victitant laruae, defumuntur.

Dant talia nomina pulchritudinem et nitorem fcientiae, vt mox conftet, in quibus plantis quaerenda, quomodo educanda fit larva; quibus plantis noceat et hoc e folo nomine. 
Quamdiu ideo alimentum laruae ignoramus, im. ponatur nomen vagum vndiquaque libere defumtum, quum fuccedaneum tantum fit.

Chryfomela Vitellinae.

Curculio Palmarum.

- Populi.

- . Graminis.

- - Salicis.

- - Populi.

- - Betulae.

\section{43.}

Nomina triuialia infectorum, quorum laruae plantis haud victitant, habitum aut differentiam fpecificam exprimere deberent.

Difficile et interdum impoffibile erit vnico vocabulo characterem fpeciei exprimere, vbi vero nomen tale inuenitur, praeftantiffimum femper erit.

Sphex cribraria.

- clypeata.

Scarabaeus naficornis.

- - nuchicornis.
Ptinus flabellicornis. Scarabaeus mobilicornis. Mufca pellucida.

\section{§. 44 .}

Nomina triuialia a coloribus defumta nullo modo - excludere valemus.

Colores difficillime quidem rite verbis exprimun-

tur, in eadem fpecie nimis ludunt, quo ipfo nomina a coloribus defumta lubrica et incerta euadunt.

Chryfomela 10 punctata faepe punctis tantum fex aut octo vidimus.

Attamen quum differentias fpecificas a coloribus coacti defumimus, et nomina triuialia differentias exprimentia isdem coloribus defumere neceffe erit. 


$$
\text { 6. } 45 \text {. }
$$

Nomina triuialia nunquam absque fumma vrgen-

te neceffitate mutanda funt.

Omnis mutatio nominum anfam confufionis praebet, funt ideo omni modo conferuanda.

Nomen vagum pro nomine vago, vti pleraque funt, fubftituere fuperuacaneum foret. $\mathrm{Mu}$ tentur ideo nunquam, nifi cibus aut habitus aut character effentialis exprimi poffint.

$$
\text { 5. } 46 \text {. }
$$

Nomina triuialia propria aut fubftantiua litteris maioribus initialibus, adiectiua vero minoribus pingere foleo.

Affumamus modum aliquem ad aequalitatem nominum obtinendam.

Scarabacus Hercules. Scarabaeus ftercorarius,

... Nicanor. - _ . vernalis, 


\title{
VIII. D I F F E R E N T I A E.
}

\author{
6. $\mathrm{r}$.
}

ifferentia fpecifica legitima diftinguit infectum $a b$ omnibus congeneribus.

Differentiae ideo omnes, quae infectum a congeneribus haud diftinguunt, falfae funt.

Searabaeus totus niger, capite inermi Geoff.

Differentiae itidem, quae infectum ab aliis quam congeneribus diftingunnt, falfae funt, quum fuperflua contineant.

Quo plures Entomologus nouerit infectorum fpecies, eo ceteris paribus etiam praeftantior erit, quum omnis vera cognitio humana cognitione fpecierum nitatur.

$$
\text { 6. } 2 \text {. }
$$

Differentia continet characterem fpeciei effentialem, Defcriptio vero naturalem.

Differentia ideo defcriptione vndique breuior, quum defcriptio differentiam femper contineat.

Tota fpeciei cognitio nititur differentia, ideoque in hac condenda fumma adhibenda diligentia, ne varietates in fpecierum numerum introducamus, aut fpecies varietatum loco affumamus. 
б. 3 .

Differentiá omnis a partibus infectorum haud ludentibus defumenda.

Varietates diftinctas effe fpecies, nemo fanus facile dixerit.

Apum femina, mares, neutra.

Formicae alatae, apterae.

Lucanus Ceruus mas, fermina et fic in innumeris.

Erroneae ideo omnes funt differentiae fpecificae, quae varietates loco fpeciei tradunt.

$$
\text { 5. } 4 .
$$

Differentiae a magnitudine defumtae nullo modo tolerandae.

Magnitudo mutatur in animalibus vti in plantis loco, climate, alimento, ideoque fpecies nunquam rite determinat.

Nicrophorus vulgaris in America boreali noftro triplo maior.

Apis femina et mares neutris maiores.

Menfuratio ideo infectorum accuratiffima in noviffimis temporibus introducta minus placet, quum femper incerta fpeciem nunquam diftinguat. Proportio partium inter fe conftantior maiorem praeberet vtilitatem.

In differentia ideo nunquam affumenda eft magnitudo, quum notam conftituat ludicram, faepius variantem.

Lucanus fufcus maximus, Drury.

Coccinella Popüli noftratum gigas. Scop.

Scarabaeus magnus.

- - - maximus.

- - - maiufcultis.

- . - exiguus. 
Scarabaeus paruus.

- - minimus. Lifter.

\section{$\$ .5$.}

Notae collatitiae cum aliis fpeciebus diuerfi generis in differentia euitandae.

Differentia infectum tantum a congeneribus diftinguit, character vero ab infectis reliquorum generum.

Tyronibusinferuire ftudemus, ideoque nullam in: fectorum notitiam praefupponere valemus.

Differentiae ideo omnes malae, quae notitiam aliorum infectorum fupponunt.

Carabus metallicus thorace lateribus conniuentibus vti in Scarabaeis. Scop.

Tenebrio molitor Carabi minoris ftatura et habitu. Scop.

Dytifeus minimus ftatura Chryfomelae nemorum. Scop. Conops calcitrans Mufcae domefticae fimilis vt ouum ouo. Scop.

\section{§. 6.}

Notae collatitiae cum aliis fpeciebus eiusdem generis mala funt.

Nofcatur infectum e differentia et differentia ex infecto, vtrumque vero ex propriis notis in illa fcriptis, in hoc delineatis. Tertium nullo modo admittendum.

Magiftri eft condere differentiam, tyronis ex ea nofcere infectum.

Reliquąe fpecies eiusdem generis non femper adfunt, vt comparentur.

Erroneae ideo omnes funt differentiae notas collatitias continentes. 
Dermeftes murinus, fatura prioris. Scopoli.

Carabus junceus, ftatura vulgaris at thorax pone anguftatus eodem modo conftructus, vt in granulato. Scop.

Bupreftis picta, guttatae fubaequalis fed latior. Pall.

Scarabaeus cyathiger, elytra paullo faturatiora, quam in folftitiali. Scop.

$$
\text { 6. } 7 .
$$

Inuentoris aut alius cuiuscunque nomen in differentia nunquam adhibeatur.

Nomen inuentoris haud ad notas fed ad hiftoriam infecti pertinet, differentiam ideo haud intrabit, at ad finem defcriptionis aut fynonymorum collocabitur, ne hiftoria deficiat. Difierentias ideo omnes erroneas ftatuimus, quac nomen aut inuentoris aut defcriptoris continent.

Afellus aquaticus Gefneri. Raj. Pulex marinus Bellonii, Mouffeti et Gefneri. Raj.

Pediculus marinus Bellonii et Gefneri. Raj.

Blatta prima feu mollis Mouffeti. Raj.

Locufta Pulex Swammerdamii. Raj.

Mufca cimiciformis Dom. Willugbeji., Raj.

\section{8.}

Locus natalis fpecies nunquam diftinguit.

Locus quidem infecto proximus, attamen varians,

quum a loco in locum moueatur.

Infecta etiam in mufaeis nofcere iuuat.

Variae regiones faepe eadem alunt infecta, vti America et Europa feptentrionalis.

Addatur vero locus, fi conftat, in fine fynonymorum, vt innotefcat, vnde defumendum fit infectum. 
Falfae ergo omnes funt differentiae a regione, ab alimento, a folo, aut a frequentia defumtae.

\section{a folo.}

Araneus in ericetis feu rupibus degens. Raj.

Gryllus Gryllotal pa cuniculos fub terra culta fodit, globo-

fum nodum ibi ftruit. Scop. Mufca ambulat fuper aquas

ftagnantes. Scop.

\section{ab alimento.}

Scarabacus in ftercore boui- Mufca rariffima in Italia cano degens. Raj.

Dermeftes habitatio in Cada-

veribus. Scop.

Dermeftes gregarius in fun. Scarabaeus vulgaris maior. gis habitans. Scop.

Scarabaeus alter arboreus. Papilio vrticaria vulgatiffima. Lif. a regione.

Crabroni congener in Italia capta. Raj.

Papilio alis ampliffimis maior virginiana. Raj.

Papilio fulphureus Iamaicenfis. Raj. pta. Raj.
Locufta Anglica vulgatiflima. Raj. Raj.

Raj.

\section{\$. 9 .}

Differentiae a larua et pupa defumtae in Entomologia reiiciendae.

Differentias reales faepe adminiftrat larua, at raro infectorum metamorphofin rite cognofcimus. Laruae praeterea raro aut nunquam in mufaeis occurrunt, ideoque in differentia omittendae.

In defcriptione vero defcriptio laruae et pupae optime additur, vt infectum in omni metamorphofeos ftatu cognofcatur.

Falfas ideo omnes vocamus differentias a larua aut pupa defumtas.

Mufca Fungorum, larua in Agaricis et Boletis habitans. Scop. 
Mufca putris, larua faltatrix in cafeo butyraceo molli of humidiori degens. Scop.

Mufca Braficariae Erucae. Raj.

$$
\text { 6. } 10 .
$$

Tempus infectorum differentias praebet femper erroneas.

Tempus eft infecti accidentale. Exiftit tempus haud in infecto, fed infectum in tempore.

Variat tempus fecundum maiorem aut minorem caloris gradum in diuerfis regionibus et diverfis annis diuerfum.

Scarabaeus folftitialis, natiuitas aeftiua circa dies caniculares. Scop.

\section{ઈ. II.}

Color in eadem fpecie mire ludit, hinc in differentia, nifi omnes aliae notae defunt, affumendus non erit.

Color leuiffimas praebet differentias, vifum oblectat at infinite ludit.

Variat color in eodem indiuiduo aetate.

Color ruber in nuper natis pallidus.

- - obfcurus fenfim faturatior fiue niger euadit.

Variat color in eadem fpecie fexu aut cafu.

Stenocorus meridianus, femina nigricans, mas teftaceus. Nicrophorus et vulgaris et germanicus innumeras coloris varietates praebent, nullo modo diftinguendas.

Accedit, quod nunquam colores adaequate determinare aut verbis exprimere valeamus. Nimia eorum eft varietas et mifcela.

Colorum 
Colorum fyftema quidem elaborarunt viri meritiffimi Scopoli et Poda, at vacillans femper erit, quum eorum colores aeque ludentes ac ipforum infectorum.

Sit e. gr. Color viridis compofitus ex coeruleo et flauo; at differens mifcela differentium colorum componendorum differentem dabit colorem viridem; nam et praeftantia ingredientium et minima variatio in compofitione infignem praebet differentiam.

Colores vero a colore rerum vfitatiffimarum defumtis adhuc magis fallaces funt.

e. gr. Color carneus: cutis iunior fani hominis;

- grifeus; capilli cani, qui infinite ludunt.

Colores ideo e differentia, quantum licet, expellere confultum duco, $v t$ tandem fcientia firmo ftet talo.

Demtis vero coloribus nondum infecta diftinguere valemus. Seri forte nepotes effentiales fpecierum differentias detegent, et tunc colores omnino excludendi.

\section{12.}

Odorem nunquam differentiam diftinctam tradere contendimus.

Olfactus maxime obfcurus inter omnes noftros fenfus, examinat tenuiffima corporum effluvia, quae nunquam rite determinare vale- mus, quum limites haud admittant.

Erroneae ideo funt omnes differentiae, quae ab odore defumuntur.

Dermeftes Vefpillo olet ve Mofchus, Acaris infeftatur. Scop.

Cerambyx mofchatus: Elytra viridia, odor Mofchi. Scop. 
Scarabaeus Capricornus dictus maior, viridis, odoratus. Raj.

Scarabaeus magnus fuaweolens. Lift.

Odor infectorum praeterea faepe tantum temporarius.

\section{§. 13.}

Differentiae, quae vnicum tantum fexum comprehendunt, femper malae.

Sexus alter nunquam fpeciem confituit, ideoque proponat etiam differentia notas omni fexui communes, quum e differentia haud fexum fed fpeciem cognofcere debeamus.

Falfas ideo effe omnes Scarabaeorum differentias a cornubus defumtas, Ichneumonum ab aculeo contendimus.

Tipula Idrienfis, antennae maris pectinatae. Scop. Afilus pennipes, pedes poftici longi : alteri fexui pennati. Scop.

Chryfomela Friderichsdalenfis, elytris fanguineis immaculatis. Müll.

\section{§. 14.}

Differentiae infectorum omnes, quae a proprietatibus defumuntur, ludicrae.

Infecta absque accidentalibus per fe diftinguere laboramus, ideoque omnes notas, quae haud a corpore ipfo defumuntur, plane reiiciendas effe credimus, quum nunquam characterem infecti effentialem contineant.

Cimex lectularius, rufus, compreflus, domefticus, homini moleftus.

Tipula phalaenoides, alis deflexis fuper folia affiduo curfitans.

Fabr. Entom. 
Mufca proftrata, domefticae fimillima, celerrime auolans renolansque in eundem locum, pectori et abdomini infidet pedibus expanfis. Scop.

Empis calcitrans, Mufcae domefticae fimilis, vt ouun ouo, ingruente pluuia tibias noftras valde pungens. Scop.

\section{15.}

Pubefcentia differentias haud fpeinendas interdum offert.

Pubefcentia comprehendit fpinas et hirfutiem, quarum priores pofteriori conftantiores funt.

Spinas reales praebere differentias e Curculionibus, Hifpis, Lamiis aliisque patet, quae omnes fpinis optime dignofcuntur.

Hirfuties interdum differentias exhibet haudludicras, vti conftat e Buprefti fafciculari ethirfuto et aliis haud paucis.

Ad hirfutiem tamen haud confugiendum, nifi omnes aliae viae praeclufae fint. Abraditur enim facillime et infecta hirfuta aetate faepius glabra euadunt.

$$
\text { ઈ. } 16 .
$$

Antennarum notae differentias faepe optimas fuppeditant.

Antennae ad characteres generum vix vfurpandae, differentias fpecificas faepe optimas offerunt.

Antennarum proportio Cerambyces diftinguit.

Antennarum lamellis feptenis. Męlolontha Fullo.

Antennis fubtus actileatis. Lamia Rubus.

Antennis hirtis. Cerambyx hifpidus.

Antennarum quatuor anterioribus articulis eleuatis. Ce. rambyx Cerdo. 
Antennarum articulis quatuor primis barbatis. Ceram. byx barbicornis.

Antennarum fafciculo flabellicorni. Elater flabellicornis. Antennis vncinatis, Papilio Proteus.

$$
\text { 6. } 17 \text {. }
$$

Caput differentias interdum naturalifimas fubminiftrat.

Curculionum fpecies demto roftro difficillime diftinguun* tur.

Capite fub maxillis fpinofo, fabro Cerambyx fpinibarbis.

Capite bicorni. Hifpa bicornis.

- - - Sphinx cornuta.

- . Apis bicornis.

Situs oculorum in Araneis diuerfus fpecies optime diftinguit.

$$
\text { 6. } 18 \text {. }
$$

Thorax differentias naturaliffimas, optimas exhibet.

Thorax in multis infectis magnus, fpeciofus differentias praebet diuerfiffimas, facillimas. Thoracis differentias fupra dedimus.

Thorace in cornu fupra caput protenfo. Notoxus thonon ceros.

Thorace fpinofo. Hifpa aculeata.

$$
\text { 5. Ig. }
$$

Abdomen et Anus haud raro praefertim in anelytris differentias edunt optimas.

Abdominis notae in Eleuteratis vix adhibendae, quum ab elytris tectae vix oculis pateant. 
Reliquorum vero claffium genera vix ac ne vix quidem demtis abdominis notis diftinguuntur.

Euania appendigafter; abdomine thoraci impofito.

Leucofpis dorfigera, abdomine canaliculato aculeum recipiente.

Anus rariores praebet notas at faepe conftantes. Chryfis fpecies dentium numero in ano differunt. A pis quadridentata ano quadridentato.

Mordella aculeata ano aculeato.

\section{\$. 20 .}

Sternum exfertum et Pectines, quibusdam tantum generibus proprii, differentias optimas relinquunt.

Scarabaeus Chryfis, fterno porrecto.

Bupreftis fternicornis, fterno cornuto.

Pectines foli Scorpionum generi proprii numero radiorum fpecies diftinguunt.

$$
\text { \$. 21. }
$$

Scutellum in differentia vndique magni faciendum.

Scutellum multas praebet differentias diftinctas et faciles.

Scarabaeorum diuifio in fcutellatos et exfcutellatos optima. Cimices feutello longitudine corporis.

Stratiomys fpecies fcutelli dentibus diftinguuntur.

$$
\text { \$. } 22 .
$$

Alae elegantifimas, naturaliffimas differentias exhibent.

Natura in nulla parte magis fuit polymorpha, quam et in figura et in colore alarum. 
Commendant fe alae ad differentias, quod fpeciofiffimae fint, quod fpecies facie diuerfiffimas efficiant, quod facillimas differentias fubminiftrent.

Elytra eleuteratorum.

Alae glofaţorum,

Alae antliatorum.

Characteres alarum in praecedentibus dedimus.

$$
2 \quad \text { S. } 23 .
$$

Differentiae a cauda petitae faepius naturales, $a b$ aculeo vero defumtae nullo modo valent.

Caudam faepius vtroque fexui communem inuenimus et notas praebet diftinctas, faciles.

Forficulae fpecies.

Ephemera cauda bifeta, trifeta, mutica.

Gryllorum vero feminae folae caudatae.

Aculeus vero in differentia haud adhibendus, quum mares plerumque nullum gerant.

Apis femina et neutra aculeata.

- - mares inermes.

\section{24 .}

Pedibus fpecies haud paucae facile et rite determinantur.

Curculionum amplum genus fecundum pedes diuiditur.

Chryfomelae faltatoriae.

Attelabus Betulae, pedibus faltatoriis.

Scarabaeus Schaefferi, pedibus elongatis.

Iulus et Scolopendra numero pedum.

Obferuandum tamen femper erit, pedes anteriores faepius fexu differre, pofteriores vix vnquam. 
Marum pedes antici elongati.

Cryptocephalus longimanus.

Marum pedes antici clypeati.

Dytifcus, Vefpa cribraria, clypeata.

$$
\text { §. } 25 \text {. }
$$

Inftumenta cibaria faepius differentias bonas, conftantes fubminiftrant.

Plurimae funt partes oris, et interdum differentias praeberent optimas, attamen ad eas haud confugiendum, nifi omnes aliae viae praeclufae fint.

Sunt enim partes oris plerumque minutiffimae et faepius haud nifi deftructo infecto exfumi poffunt. Facilitandae vero, quantum licer, funt differentiae fpecificae.

Lucanus mandibulis diftinguitur.

Prionus Luzonum mandibulis porrectis bifidis. Apis linguaria lingua feptemfida.

\section{26.}

Notae genericae in differentia fpecifica vfurpatae abfurdae funt.

Notae genericae in omnibus fpeciebus confentiunt, ideoque nullo modo diftinguunt.

Erroneas ideo effe omnes differentias ftatuimus, quae notas fpecificas a generibus defumunt. Silpha pedicularia thorace marginato. Linn.

$$
\text { 6. } 27 .
$$

Differentiae charąteri generico contrariae genus haud rite determinatum demonftrant.

Character genericus fit fingulis fpeciebus fub eodem genere militantibus applicabilis: vide fupra. 
In genere ideo rite determinato character genericus et differentia fpecifica nunquam contraria effe poffunt.

Elater degener thorace edentulo. Scop。

Papilio antennis filiformibus.

$$
\text { ๑. } 28 \text {. }
$$

Differentia fpecifica omnis e numero, figura, fitu et proportione variarum infecti partium neceffario defumatur.

Notae omnes, quae in infecti partibus fundamentum haud agnofcunt, femper fallaces funt.

Color. S. II.

Magnitudo. \$. 4.

Collatio. $\int \cdot 5.6$.

Auctoritas. 6.7.

Locus. 5.8 .

Alimentum. 6.8 .
Frequentia. \$. 8.

Metamorpholis. 9.9.

Tempus. I. 10.

Sexus. $\mathbb{1}$ I2.

Proprietates, \$. 13.

Fidas vero notas a folis infecti partibus defumendas contendimus.

Pubeficentia. 0.15.

Caput. 6.17.

Abdomen. 6.19.

Scutellum. 6.2I,

Cauda. 6. 23 .

Inftrumenta cibaria. $\oint .25$.
Antennae, $\oint, 16$. Thorax. \$. 18.

Sternuin. \$. 20 ,

Alae. $\$ .22$.

Pedes. §. 24.

Modi, quibus differentia harum partium defumitur, iidem quatuor funt, quum in genere Numerus, Figura, Situs et Proportio vbique conftantes in Infecto, in Mufaeo, in Icone.

$$
\text { ๑. } 29 .
$$

Differentia fpecifica genuina eft vel fynoptica, vel effentialis. 
Inueftigandae funt omnes fpeciei notae pollibiles et ex his optimae eligendae, vt tandem fpecies rite determinetur.

Differentia effentialis fynopticae femper antepoponenda, et vbi illa inuenta haec omnino deferenda erit.

Silpha finuata elytris lineis tribus eleuatis, fpatio interiecto punctato, thorace fcabro. Geoff. Synoptice.

Silpha finuata elytris apice finuatis. Effent.

$$
\text { 6. } 30 .
$$

Differentia fpecifica fynoptica infectis congeneribus notas femi dichotomas imponit.

Differentiae effentiales vbi defunt, ad fynopfin confugiendum, ideoque fynopfis eft fuccedanea differentiae effentialis.

In vaftiflimis generibus faepius fynopfin coacti affumimus.

Curculio longiroftris, femoribus quatuor anterioribus dentatis, elytris polline flauefcentibus fupra apicem gibbofis.

\section{3r.}

Differentia effentialis notam differentiae fingularem fuaeue fpeciei tantummodo propriam exhibet.

Differentia effentialis vnica abfoluitur idea vnicoque vocabulo.

Commendat fe breuitate, facilitate, certitudine. Derecta differentia effentiali primo fpecies rite diftinguitur et tunc tandem metam propofitam affequamur.

Naucoris abdomine ferrato.

Nepa corpore lineari. 
Hippobofca alis fubulatis.

Hippobofca alis nullis.

Acanthia alis nullis.

Attelabus pedibus faltatoriis.

Stratiomys fcutello fexdentato.

Hifpa capite bicorni.

Notoxus thorace in cornu protenfo.

Scolopendra pedibus duodecim.

\section{§. 32.}

Differentia fpecifica quo breuior, eo etiam ceteris paribus praeftantior.

Breuitas differentiae ad pulchritudinem, certitudinem et facilitatem omnino neceffaria. $\mathrm{Na}$ tura ipfa vbique compendiofiflima et naturam fequi vndique iuuabit.

Differentiam nunquam plura quam duodecim vocabula admittere ftatuit Linné in re herbaria. Sufficiant etiam in Entomologia, quin raro duodecim opus habeamus.

Stupendae itaque funt differentiae illae fesquipedaless, quae defcriptiones differentiarum loco fiftunt.

Phalaena libatrix. Scop.

Alae anticae ceruinae; bafi maculis quatuor ochraceis: media longa prifmatica, fafciis binis linearibus pallidioribus: poftica duplici, punctis duobus albis, margine externo denticulata ita, vt diftantia apicis ad primum dentem eadem fit, quae ab eodem dente ad angulum pofticum.

Phalaena Coffus.' Scop.

Thorax antice linea transuerfa atra, poftice maculis binis lateralibus nigris. Alae pofticae murinae, bafi albidae, obfcurioribus anaftomofantibus lineis reticulatae, anticae bafi et medio murinae, alibi albae, vtrinque lituris ftrigisque transuerfis nigris lineolisque murinis ramofisque variegatae. 
Cancer Mantis. Scop.

Thorax oblongo cordatus, laeuis: lineis eminentibus quin fue. Manus adactylae, falcatae, compreflae, dentibus fex longis vnilateralibus. Abdomen futuris, decem: anticis minoribus, omnibus fex lineis eleuatis longitudinaliter an. gulatis.

\section{§. 33.}

Differentia nulla admittit vocabula, nifi quibus a congeneribus neceffario diftinguitur infectum.

Differentia quo breuior, eo etiam ceteris paribus praeftantior $\S .32$.

Exulent ideo tautologia et flofculi oratorii.

Scarabaeus viridis nitens thorace infra aequali non prominente. Geoff. Tautologia.

Sphex fegmentis fuluo colore tinctis, pro fuluis. Scop.

$$
\text { §. } 34 \text {. }
$$

Differentia nulla fpeciei in fuo genere folitariae imponi poteft.

Differentia diftinguit fpecies a congeneribus, vbi

ideo congeneres defúnt, differentia fuperflua, quum nil demonftret.

Superuacaneae ideo funt differentiae infectis in fuo genere folitariis impofitae.

Rhingia roftrata, Antennae, roftrum, fcutellum, abdomen ferruginea. Thorax cinerafcens lineis nigris longitudinalibus, Scop.

Pulex irritans, Antennae articulis quatuor, oculì nigri pupilla alba. Scop.

\section{\$. 35 .}

Differentia non erit tropis rhetoricis figurata, multo minus erronea, fed fideliter, quae natura dictitat, exponat.

Tropi 
Tropi femper obfcuri, quo vero diftinctior differentia eo etiam melior.

Synecdoche totius pro parte frequentiffima in

Entomologia, vbi de toto praedicatur, quod tantum de parte valet.

Araneus rufus criftatus. Raj. pro mandibulis criftatis.

$$
\text { \$. } 36 .
$$

Differentia terminis pofitiuis vtatur, nunquam vero negantibus.

Negatiua re vera nihil dicunt, quum nunquam notam infecti pofitiuam praebeant.

Negatiua tantum vocabulorum augent numerum fine neceffitate et absque vtilitate, quum femper vocabula habeamus pofitiua, quae ideas oppofitas exprimunt.

Scarabaeus quarto paullo maior, elytris flauo f́paticeis fine maculis Raj. immaculatis fule vnicoloribus.

Scarabaeus viridis nitens, thorace infra aequali non prominente. Geoff.

\subsection{7.}

Similitudo omnis in differentia vfurpata notiffima fit, licet et haec Entomologo minus digna.

Omnis fimilitudo claudicat, nunquam certas, firmas ideas communicat, ideoque prorfus potius erit excludenda.

Malae inprimis funt omnes fimilitudines de rebus, quae variant, nec omnibus notis defumtae.

Papilio Pruni. Scop.

Supra ad angulum ani maculae colore Gummi Ceraforum. Phalaena chlorofata. Scop.

Albida feu colore eodem fere vt vultus in Cachexia vir: ginea. 
Scarabaeus cyathiger. Scop.

Elytra margine nigra, fi vnita fuerint, maculam communem gerunt cyatho fimilem atram.

Phalaena inflammata. Scop.

Alae anticae hepaticae.

Aranea nigricans clunibus ad fimilitudinem querni folii pictis. Raj.

\section{38 .}

Omne adiectiuum in differentia fequi debet fubftantiuum fuum.

Ordo idearum naturaliffimus eft, quod primo partem, de qua loquitur, nominemus, et tunc quod de hac parte dicitur.

Scarabaeus maior, corpore longo angufto niger; curn tribus in vtrauis ala lineis transuerfis lutefentibus. Raj.

Rectius Scarabacus maior niger, ala vtraque lineis tribus transuerfis lutefcentibus, corpore longo angufto.

\section{\$. 39.}

Adiectiua in differentia vfurpata e terminis artis felectis, fi modo fufficiant, petenda funt.

Terminis artis conftantibus rite determinatis facillima euadit fcientia.

Synonyma terminorum excludenda et vnicus optimus retinendus.

Silpha atrata elytris punctatis. Linn. 3 puncta- elytris rugulofis. Scop. ta. Silpha fabulofa thorace emarginato. Linn. \{ emargiLinea transuerfalis lata dicitur - $\quad$ Fafcia. Linea transuerfalis angufta - - Striga. Linea longituditialis a bafi ad apicem - Stria. Linea longitudinalis abbreuiata - Lineola.

Promifeue 
Promifcue antea Entomologi adhibuerunt terminos hos quatuor.

Periphrafin ideo nunquam admittat Entomologus, quamdiu termini rite determinati in promtu funt.

Sphex fegmentis fuluo colore tinctis. Scop. pro fuluis.

$$
\text { S. } 40 \text {. }
$$

Particulas adiectiua et fubftantiua coniungentes differentia omnino excludit.

Cafu ablatiuo absque vlla praepofitione notae omnes in differentia proponuntur, ne vocabulorum numerus absque neceffitate augeatur.

Vbi vero duo dicierfa in eodem infecto indicanda funt, notam que vel $v z$ in fine fequentis vocabuli adhibere folemus.

Leptura melanura nigra elytris rubefcentibus liuidisue, futura apiceque nigris.

Hifter apterus.' Scop.

Fuluus eft et alis deftitutus.

Dermeftes Cardarius." Scop.

Elytris bafi fufco cinereis aut rufis.

\section{〔. 41 .}

Notae diftinctiuae partes infectorum, non vero adiectiua diftinguunt.

Notae diftinctiuae rite determinentur, rite adhibeantur, vt differentia facilior, diftinctior tradatur.

Affumfi particulas diftinguentes a Linné vfurpatas, nempe (,) ad diftinguendas partes infecti 
infecti, (:) adhibeo vbi partis fubdiuifio eft, et (.) claudo differentiam.

Scarabaeus folftitialis muticus teftaceus, thorace villofo, elytris luteo pallidis: lineis tribus parallelis. Linn.

\section{42 .}

Parenthefin differentia fpecifica nunquam admittit.

Arguit Parenthefis aut exceptionem aut defectum ordinis ideoque non admittenda.

Cerambyx eiusdem eft coloris aurei et fplendentis, fed inter tres ordinis tuberculorum (quae in hoc multo minora funt) rugulae aut carunculi apparont per dorfi longitudinem.

Papilio alba media, alis omnibus albis cum macula (feu punctum mauis dicere) leuiter nigricante in exterioribus. 


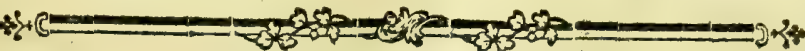

\section{ADVMBRATIONES.}

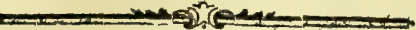

5. 1 .

Adumbrationes totam -infecti hiftoriam continent, vti Nomina, Etymologias, Metamorphofes, Claffes, Characteres, Differentias, Varietates, Synonyma, Defcriptio nes, Icones, Loca, Tempora, Oeconomias, Vfus.

Per adumbrationes perfectam infecti cognitionem acquirimus, qua fcientia amplificatur fimulque gratiffima, vtiliflima euadit.

Adumbrationibus ideo rite inftitutis infectum plane notum eft, alias non.

$$
\text { §. } 2 .
$$

Characteri generico et differentiae fpecificae nomen etiam varians, fi quod addi poteft.

Varietates vocamus infecta eiusdem fpeciei mutata a cauffa quadam naturali aut accidentali. Nomine generico et fpecifico rite impofitis perfecte quidem nominatum eft infectum, at varietates tamen cognofcere iuuat, ne in fpecierum numerum introducantur.

Inferendae ideo funt varietates euidentiores ad finem differentiae, ne confundant.

$$
\text { 5. } 3 \text {. }
$$

Sexus varietates naturales conftituit, reliquae omnes funt accidentales. 
Sexu faepius variant infecta, nec differens fexus fpeciem conftituit.

Femina plerumque maior, craflior, faepius caudata aut aculeata antennisque fimplicioribus, minoribus.

Mas plerumque minor, antennis craffioribus faepe pectinatis, interdum caudatus, nunquam aculeatus. Nentra minora, aculeata rarius occurrunt.

Cauendum, ne fexus varietatibus nouas et erroneas fpecies fingamus.

Platycerus fufcus, cornubus apice bifurcis. Geoff. mas.

- Platycerus fufcus, capite laeui. Geoif. femina.

\section{$\$ \cdot 4$.}

Varietates accidentales funt variae, vti infecta mutilata, aegrota, grauida, redintegrata, quibus accedunt frequentiffimae colóris. Varietates laeuiflimas haud curat Entomologus. Curandum tantum, vt differentia omnes comprehendat.

Infecta mutilata interdum obueniunt, in primis inter gloflata; monftra vero femper funt. Oriuntur plerumque loco nimis angufto, vt alas expandere haud valeant.

Infecta aegrota vix diftingui merentur.

Dermeftes Acaris infeftatur. Scop.

Sub tempore grauiditatis figuram faepe differentem affumere folent feminae. Abdomen tunc intumefcit.

Termes fatale.

Chryfomela Polygoni.

Infecta redintegrata vocamus, quibus partes amiflae recrefcunt, quo figura et inprimis magnitudo harum partium faepius differt.

Cancros, 
Cancros, Aftácos faepius videmus, qui alteram chelam gerunt multo minorem nuper iterum renatam.

Varietates coloris frequentiffimae iunt a loco, a climate, ab aetate aliisque cauffis accidentalibus. Difficillime tamen ad fpecies fuas reducuntur, quamdiu a coloribus differen= tias fpecificas defumere coacti fumus.

Commendo ideo Entomologis acutiffimis inprímis vaftiffima illa genera: Curculio, Ichneumon, Apis, Sphex, Aranea, Bombyx, Phalaena, Tinea aliaque, inter quorum fpecies varietates, vt credo, multae irrepfere, Has examinare, reducere non minoris eft, quam fpecies fub fuo genere collocare. Expofcit ingenium et fummam experientiam.

$$
\text { S. } 5 \text {. }
$$

Synonyma funt diuerfa Entomologorum nomina eidem infecto impofita.

Synonymiae abfolutae opus maxime neceffarium effet Entomologis.

Vnico enim auctoris nomine detecto innotefcerent mox omnium.

Omnia, quae de infecto innotuere, euolui poffent. Plura tandem nomina non amplius redderent ideam plurium infectorum.

Eft vero fynonymia perfecta opus infiniti laboris. Requirit enim cognitionem fpecierum ampliffimam et comparationem defcriptionum auctorum accuratiffimam, ne nornina adhuc magis confundantur.

$$
\text { 5. } 6 .
$$

Synonyma fecundum tempora aut fecundum fyftemata coniungantur.

Fabr. Entomi. K

Syyno= 
Synonymon optimum aut auctoris proprium aut alius felectum agmen ducat.

Secundum tempus proponuntur fynonyma, vel defcendendo $a b$ antiquiffimis ad noua, vel afcendendo a nouis ad prifca.

Synonymiae ordinem fyfternaticum recepi fynonymia felectiori contentus. Incepi a nominibus fyftematicorum praefantiflimorum Linné, Geoffroy, definens in fynonyma ichniographorum.

\section{7.}

Synonyma fingula nouam ordiantur lineam, vt eo facilius dignofcantur.

Plurimi inprimis veteres Entomologi omnia fynonyma per feriem continuatam recitare folent, quo facilius commifceantur.

Alii et nomen genericum fequers, fi idem eft cum praecedente, excludere folent. Minus tamen talis abbreuiatio placet, quim fynonymiam indiftinctiorem reddat.

$$
\text { §. } 8 \text {. }
$$

In fynonymis auctor et pagina vbique ad finem indicanda funt.

Auctoris nomen folum haud fufficit, quum idem auctor plura faepius fcripta euulgauerit. Inclaruere etiam faepius duo aut plures eiusdem nominis auctores, aut poffunt in pofterum prodire inclarefcentes, quo citatio obfcura; fallax et incerta euadit.

Opus folum pro citatione haud fufficit, quum plura iam prodiere, aut prodibunt in pofte- 
rum fub eodem nomine, quae femper anfam confufionis praeberent.

Compendiofiffima, diftinctiffima ideo citatio, fi vnico vocabulo nominetur opus et altero auctor, ne euadat dififufior attamen' euidens.

5. 9.

Synonymia abfoluta infecti primum inuentorem afterifco notare placeret.

Prodeffet hoc in Chronologia infectorum, ne quaeratur apud veteres a recentioribus detectum infectum.

Difficillime vero eruitur inuentor in plurimis fpeciebus, antequam noua et abfoluta fynonymia prodeat.

\section{10.}

Defcriptio continet infecti differentiam naturalem, quae defcribat omnes eiusdem partes externas et vifibiles.

Defcriptio continebit omnes infecti notas etiam minimas oculo armato tantum perfpicuas.

Citonia nobilis aurata, abdomine albo-punctato, ely. tris rugofis. Syft. Ent. 43. 5 .

Caput onatum, punctatum oculis prominulis.

Antennae capite breuiores feptemarticulatae: articulo primo porrecto, craffiori, vltime trilamellato, lamellis ouatis, aequalibus.

Os maxillis palpisque quatuor.

Clypeus cylindricus margine incraffatus apiceque emarginatus.

Palpi fubaequales.

anteriores filiformes, triarticulati: articulo vltimo longiori, cylindrico, maxillae dorfo inferti.

pofteriores triarticulati, fubclauati, labii bafi interiori adhaerentes. 
Mandibula porrecta, recta, cornea, acuta, inermis.

Maxilla ad inferionem palpi intus dilatata, vnidentata, apice fetofa.

Labium elongatum, cylindricum, coriaceum, apice emarginatum, palpos pofteriores tegens.

Thorax punctatus, canalicslatus, fubmarginatus, poltice rotundatus.

Scutellum rotundatum, punctatum, obtufum.

Abdomen elytris longius, prominens fegmentis fex punctatis, aequalibus.

Alae quatuor.

fuperiorescruftaceae, rugofae, bafi apiceque gibbo. fae, abdomine multo breuiores.

inferiores elytris duplo longiores, plicatae, tectae, venis duabus eleuatis longitudinalibus, diuergentibus:

Pedes fex femoribus compreffis, pilofis, tarfisque quinquearticulatis vngue duplici.

anteriores paullo breuiores : tibiis apice tridentatis. poftici quatuor longiores : tibiis apice bifpinofis.

Color aeneus, abdonine punctis aliquot albis, alae fureae.

Magnitudo fabae maioris.

Metamorphofis incompleta.

Larua hexapoda, annulata, pilofa, albida, capite paruo, corneo, rufo, abdomine apice veficllofo.

Pupa quiefcens intra glebam, abdomine apice obtufo.

\section{II.}

Defcriptio compendiofiffime, tamen perfecte, terminis tantum artis puris, fi fufficientes funt, partes depingat infecti omnes fecundum numerum, figuram, fitum et proportionem.

Defcriptio continet differentiam fpeciei naturalem, quiteodem modo conficiendä, ac character naturalis generis: admittit tantum illa notas plures accidentales onnesque poffibiles, 
quum de vnico tantum animalculo agit. Generis vero character naturalis plures comprehendens fpecies, femper aliquot notas excludit.

Partes infecti omnes primo fecundum numerum, figuram, proportionem et fitum defcribendae. Color tandem etiam, quamuis accidentalis accurate notandus, quum differentias adhuc plurimas a colore defumantur.

\section{Q. 12.}

Defcriptio ordinem a partibus primariis ad reliquas fequatur.

Praeftat ordinem certum fequi a capite ad thoracem cum fcutello, abdomen, caudam, alas, halteres, pectines, pedes.

Male ideo primum pedes, dein caput, tum cauda, demum, abdomen, tandem thorax etinftrumenta cibaria promifcue et confufe proponerentur.

Ordo eft anima fy ftematis et omnis fcientiae, ideo. que et in defcriptione conferuandus.

\section{13.}

Defcriptio diftinctas infectorum partes in diftinctis paragraphis tradat:

Ordo, perf picuitas et breuitas funt praecipuae virtutes defcriptionis bonae.

Perfpicuitas optime conferuatur, quum infecti partes diftinctis paragraphis litterisque diftinctis proponuntur. Tunc partes mox reperiuntur et omiffa et errata percipiuntur.

Exempla defcriptionis bene ordinatae fiftit Linné Mufaeum Reginae, quae partes omnes diftincte et fecundum ordinem tradit.

$$
\mathrm{K}_{3} \text { 6.14. De- }
$$




\section{§. 14 .}

Defcriptio iufto longior aut breuior vtraque mala et femper euitanda.

Iufto breuior euadit defcriptio, fi notae infecti diftinguentes et partes effentiales, vti inftrumenta cibaria, fcutellum, halteres; pedes aliaque omnino excludantur.

Iufto longior euadit defcriptio, quum colores nimis diffufe, menfura accuratiffima et ftru. ctura naturaliffima multis verbis propo. nuntur,

Taediofius nihil cogitari poteft, quam defcriptio am. pliffima, nullis paragraphis difincta et nullas differentias reales fubmininitrans,

Lucanus caraboides. Seop.

Totus punctatus carabiformis, capite, thorace, elytris. que obiter lineatis, atro-coeruleis, abdomine fupra ferrugineo, corpore fubtus atro.

Defiderantur in hac defcriptione antennarum articuli, figura, thoracis figura rotundata marginata, os, pedes, alae feutellum omnino omiffa.

Phalaena pauonia. Scop.

Long, vne, 2, et lin. 3 . lat. vne, x. et lin. 8 .

Alae anticae fupra caryophyllinae albis atomis tanquam pollini adfperfae; bafi fafcia obfcuriore, marginen craffiorem non attingente; ftria dentata ab apice vsque ad medium marginis inferioris fulminis ad inftar decurrens, ceruini coloris, Ad apicem, qui albo limbo caret, macula nigra infidens margini externo.

* - fubtus minus obfcurae, albis pilis antice atomisque fimiliter coloratis canefcentes; fafcia fulminante vt fupra.

- pofticae fupra ad bafin limbo concolores, fafciís duabus caryophyllinis; fafcia alia poftica vndata, ceruina, quam inter et limbum alae pagina caryophyllina eft. 
Alae fubtus albidis pilis atomisque canae; fafcia ad bafin caryophyllina, marginem fuperiorem non attingente, fafcia repanda poftica vt fupra, idemque color inter hanc et limbum, vt in pagina fuperiori, ibidem.

Mas antennis ferrugineis, bipectinatis, articulis $(36)$.

Defcriptio fane nimis ampla, nil nifi colores alarum diffufe defcribens. Defiderantur figura, veftitus corporis, lingua, quin ipfa alarum figura.

Incidit celeberrimus Scopoli, qui alias inter defcripto. res accuratiffimos eminet, in huius feculi ni. miam verbofitatem, quae fcientiam diffufiorem, at haud diftinctiorem tradit.

\section{\$. 15 .}

Menfura proportionalis inter infecti partes convenientiffima eft.

Menfuram infectorum fecundum fcalam geometricam et quidem accuratifimam affumferunt Scopoli, Geoffroy aliique, quafi defcriptionis effentia confifteret in menfura geometrica.

Variatio infectorum fecundum magnitudinem vnicuique in Entomologicis verfato notiffima omnino eft. Admitto ideo vix aliam menfuram nifi proportionalem feu comparatiuam inter partes eiusdem infecti diuerfas. Praeftat proportionalis haec menfúra, quum femper conftans. Antennae e. gr. femper in eadem fpecie aut capite longiores aut breviores, quamuis magnitudo corporis variat. Si vero magnitudo totius infecti addenda, comparetur cum alio quodam notiflimo, aut alia re fed notiffima, vti magnitudine Pediculi, Pulicis, Cimicis, Fabae, Pifi, Digiti.

$$
\mathrm{K}_{4} \text { \$. } 16, \mathrm{De}
$$




\section{§. 16}

Defcriptio comparationem infecti cum alio quo= cunque nunquam admittit.

Eadem eft regula defcriptionis quam differentiae. Ambae proprias infeeti notas porrigunt, illa naturales; haec effentiales.

Commendant fe breuitate, perfpicuitate, conAtantia; omne vero fimile claudicat, omne fimile tyronibus obfcurum ideoque femper euitandum.

Adnotetur tamen habitus aut talis fimilitudo, aut in initio, aut ad finem defcriptionis, vtfpecies eo melius diftinguantur: ad defcriptio= nem vero ipfam haud pertinet.

$$
\text { \$. } 17 .
$$

Ioones fe commendant fitu et figura naturaliffi$\mathrm{ma}$, accuratiflima omnium infectorum partium.

Situs naturaliffimus in iconibus femper confervandus praefertim in Gloffatis, quum plures notas a fitu alarum defumantur.

Alae patentes, reuerfae deflexae, incumbentes.

Veterum icones infectorum rudes fiftunt animalcula, quae nullo modo extricari poffunt, fitu. peruerfo et figura faepius mutata, e. gr. Mouffeti, Aldrouandi, Ionftoni.

Figurae ligneae olim vfitatae vix tam accurate, quam requiritur, icones fiftere valent, at multo minoris funt pretii.

Figurae fundamentales, vti vocantur, in Eleuteratis alisque haud contemnendae, in Gloffatis 
- fatis vero et Syneftatis, quae vix ac ne vix quidem demtis coloribus diftinguuntur, haud adhibendae; inprimis impoffibile erit, minores illas Tineas aut rufticas Noctuas absque coloribus determinare.

In nouiflimis temporibus dederunt Entomologi icones fumma arte fculptas, coloribus pulcherrimis fucatas, vt nil in arte praeftan. tius, at in luxuriam artis multiplicantur pretiofiffimae. Eminent in primis Roeffel, Drury, Sepp, Cramer, Voet, Clerk aliique.

$$
\text { 6. } 18 .
$$

Icones praeftantes omnes infecti partes licet minimas etiam oris exhibeant.

De minimis agitur animalculis, ideoque partesminimae etiam depingendae, praefertim oris, in quibus optimi characteres generici et multae differentiae fpecificae latent.

Oculi nudi vbi non fufficiunt cum armato delineandae funt partes, vt figura digna euadat.

Rauciflimas habemus icones, quae omnes exhibent partes vti Roeffel Mufca carnaria, Schaefferi Monoculus.

\section{§. 19 .}

Icones depingant etiam laruam pupamque, fi nota eft metamorphofis.

Larua, pupa et imago idem funt animalculum, ftatura et forma tantum differens.

Dignofcantur infecta in triplici hoc ftatu, vt cognitio et hiftoria eorum tandem fit abfoluta. 
Larua pupaque raro in mufeis occurrunt, raro feruari poffunt eo magis ideo iconibus depingendae, cognofcendae.

Iconographi ideo praeftantifimi etiam in Europaeis metamorphofii vti Roeffel, Merian, Sepp aliique.

$$
\text { 6. } 20 .
$$

Loca natalia comprehendunt infectorum clima, regionem et habitationem.

Loca natalia víui funt Entomologis, vt conftet, vnde infectorum fpecies defumendae pro mufeis, medicira, peconomia.

Regio tradit regna, prouincias, pagos et loca etiam fpecialiffima, ne infecta diffitarum re. gionum in vna eademque inquirantur.

Faunae fpeciales vnius cuiusque regionis hunc in finem praeftant.

Clima indicat caloris aut frigoris gradum, intra quem viuunt infecta. Diuidimus Clima in octo partes, e quibus infectorum ftationes diiudicantur.

I. indicum, continet regiones inter tropicos in Afia, Africa et America, vbi nulla hyems infeftat, nifi fit pluuia interdum dimidii anni, aqua haud congélatur et oris halitus non videtur. Summus caloris gradus 34 et frigoris 28 fupra punctum congelationis.

2. aegyptiacum, praecedenti proximum et vix fatis diftinctum. Per dimidium annum durat calor intenfus, vt oua Struthionis in Arena exclu. dantur, per alterum dimidium annum pluuiae aut diluuium Nili.

3. auftrale, ab Aethiopia ad Cap. Bon. Sp. extenditur. Aer eft temperatus inter $12-18$ fupra punctum congelationis. Huc etiam numeratur Ameri. cae auftralis pars, Brafilia, Peruuia, quae eodem caloris gradu frumtur. 
4. mediterraneum, continet regiones mari mediterraneo adiacentes vtil Gallia Narbonenfis, Italia, Lufitania, Hifpania, Armenia, Media. Incipit circa Lutetias Parifiorum et extenditur ad Tropicúm Cancri.

5. boreale, continet Europam borealem inter Lapponiam et Lutetias Parifiorum.

6. orientcale, comprehendit Afiam borealem, Sibiriam, Tartariam et Syriae partem, vbi frigus per hyemem intenfifimus.

7. occidentale, Americam borealem comprehendit, $\mathrm{Ca}$ nadam, Carolinam, Virginiam, Penfyluaniam, Marylandiam. Huc etiam numerantur Iaponia, China.

8. alpinum, omnes continet Alpes, quae fecundam aeris regionem attingunt et niue perenni obducuntur. Hyems illis eft longiflima, aeftas rariffima et aer rarior.

Habitatio infectorum differt in primis' pro cibi differentia, quo et laruae et ipfa infecta vitam fuftentant.

Mare aqua falfa, fulphurea repletum alit quaedam.
Cancer,
Pagurus,
Scyllarus.
Aftacus,
Onifcus,
Monoculus.

Lacus aquam puram continentes aliis gaudent infectis.
Dytifcus,
Elophorus,
Hydrophilus,
Naucoris,
Gyrinus.
Nepa,
Notonecta,
Sigara.
Cimex.

Praeterea laruae plurimae in illis habitant
Culicis,
Libellulae,
Phryganeae,
Agrion,
Ephemerac.
Bupreftis,
Stratiomys,
Aefhnae.
Syrphi.

Paludes humo lutof laxa et aqua ftagnante refertae, aeftate interdum ficcefcunt.

Gammarus,

Monoculus. 
In fimetis ex animalium ftercore congeftis degunt alia; vti
Scarabaeus, Hifter,
Laruae Staphylini, Mufcae.
Sphaeridium.

Cadaneribus putrefcentibus fuftentantur alia.
Dermeftes,
Silpha,
Nicrophorus.
Nitidula,
Melyris.
Larua Mufcae.
Staphylinus.

Quisquiliis delectantur haud pauca.

$\begin{array}{lll}\text { Tenebrio, } & \text { Opatrum, } & \text { Scarites. } \\ \text { Trox, } & \text { Pimelia, } & \text { Blaps. } \\ \text { Byrrhus, } & \text { Helops, } & \text { Erodius. } \\ \text { Apalus, } & \text { Forficula. } & \\ \text { Podura, } & \text { Iulus, } & \text { Scolopendra. }\end{array}$

In plantis inueniuntur plurima, et quidem infeftant radices: Truxalis, Laruae Hepialus, Melolonthae, - Mufcae.

Lignum deuorant.
Apate,
Cerambyx,
Boftrichus,
Prionus,
Ptinus,
Spondylis,
Callidium,
Anobium,
Saperda,
Rhagium,
Lymexylon.
Stenocorus.
Notoxus.
Lamia.

Tipulae.

Praeterea laruae.
Lucani,
Carabi,
Siricis,

In foliis habitant plurima.

$\begin{array}{lll}\text { Cetonia, } & \text { Melolontha, } & \text { Trichius. } \\ \text { Lucanus, } & \text { Caflida, } & \text { Crioceris. } \\ \text { Chryfomela, } & \text { Cryptocephalus, } & \text { Curculio. } \\ \text { Attelabus, } & \text { Ciftela, } & \text { Lagria. } \\ \text { Zygia, } & \text { Zonitis, } & \text { Lampyris. } \\ \text { Alurnus, } & \text { Erotylus, } & \text { Meloe. } \\ \text { Lytta, } & \text { Cerocoma, } & \text { Mylabris. } \\ \text { Mordella, } & \text { Bupretis, } & \text { Truxalis. } \\ \text { Locufta, } & \text { Gryllis, } & \text { Acrydium. }\end{array}$

Cicada, 

Cicada,
Tettigonia,
Membracis,
Cercopis.
Coccus,
Aphis,
Chermes.
Larua Gloffatorum,
Acheta,
Tenthredinis, Cynipedis.

Flores amant multa nectar pollenque eorum haurienti:

$\begin{array}{lll}\text { Anthrenus, } & \text { Nitidula, } & \text { Thrips. } \\ \text { Gloftata, } & \text { Mufca, } & \text { Syrphus. } \\ \text { Sphex, } & \text { Vefpa, } & \text { Apis. } \\ \text { Crabro, } & \text { Andrena, } & \text { Bombex } \\ \text { Nomala, } & \text { Bombylius, } & \end{array}$

Semina deualtant varia.
Curculio,
Dermeftes,
Bruchtis.

Larua Tineae.

Boletos edunt.
Tritoma,
Chryfomela,
Staphylintis.
Oxyporus, Paedorus,
Larua Mufcae.

Ex animalibus reliquisque infectis nutriuntur alia.

$\begin{array}{lll}\text { Coccinella, } & \text { Cicindela, } & \text { Cantharis. } \\ \text { Carabus, } & \text { Clerus, } & \text { Malachius. } \\ \text { Elaphrus, } & \text { Dytifcus, } & \text { Hydrophilus, } \\ \text { Mantis, } & \text { Cimex, } & \text { Acanthia. } \\ \text { Nepa, } & \text { Notonecta, } & \text { Sigara. } \\ \text { Naucoris, } & \text { Libellula, } & \text { Aeflna. } \\ \text { Agrion, } & \text { Pulex, } & \text { Hemerobius. } \\ \text { Panorpa, } & \text { Raphidia, } & \text { Fornica. } \\ \text { Mutilla, } & \text { Cancer, } & \text { Pagurus. } \\ \text { Scyllarus, } & \text { Aftacus, } & \text { Gammarus. } \\ \text { Tabanus, } & \text { Conops, } & \text { Culex. } \\ \text { Rhingia, } & \text { Afilus, } & \text { Hippobofca. } \\ \text { Stomoxys, } & \text { Empis, } & \text { Acarus. } \\ \text { Pediculus, } & \text { Phalangium, } & \text { Scorpio. } \\ \text { Aranea. } & & \\ \text { Laruae Oeftri, } & \text { Ichneumonis, } & \text { Sphegis. } \\ - & \text { Crabronis, } & \text { Myrmelionis. }\end{array}$

Rebus culinariis delectantur.

Termes,

Formica,

Blatta.

Truxalis, 
Truxalis, Dermeftes, Ptinus.

Laruae Phalaenae, Mufcae.

$$
\text { f. } 21 \text {. }
$$

Tempus comprehendit exclufionem, infantiam, adolefcentiam, aetatem.

Tempore rite obferuato nituntur calendarium et horarium faunae nondum elaborata.

Exclufio dicitur tempus, quo oua depofita excluduntur, continet ideo oui durationem in laruae prouentum.

Oua, quae autumno ponuntur, femper per hyemem integra latent, quin laruae, pupae et imagines, qui nondum fpeciem propagarunt, hybernare folent, et primo vere iterum proueniunt.

Hic de tempore aeftuo loquimur et de huius exclufione.

Hora I-2. Mufca carnaria.

Dieb. 8. Papilio Atalanta, Cardui, Pyralis viridana, Dytifcus femiftriatus.

Dieb. 12-14. Sphinx Tiliae, Euphorbiae, Bombyx Quercus, pauonia, Nepa, Crioceris merdigera.

Dieb. 14-20. Papilio Antiopa, Io, Vrticae, Bombyx Pruni, Phalaena Alniaria.

Hebdom. 3-4. Bombyx Caja, Cetonia aurata.

Hebdom. 4. Papilio Machaon, Podalirius, Sphinx ocel. lata, Truxalis, Gryllotalpa.

Menf. 6-8. Phalaena groflulariata.

\section{22.}

Infantiam vocamus tempus, quo larua exclufa edit, crefcit, vsque dum in pupam tranfit.

Infantia 
Infantia plerisque diuerfa et fingularis. Obfervanda ab Oeconomis ob culturam, ob exftirpationem.

Tempeftate ferena, calida, breuiori gaudent infantia, quam frigida et humida.

Dieb. 8. Papilio Cardui.

Dieb. 9. Mufca carnaria.

Dieb. 12 - 14. Papilio Atalanta, Paphia.

Dieb. 30. Bombyx Mori.

Menf. 6. Bombyx Pruni, Quercus, purpurata, pyramidia, Salicis.

Ann. 4. Cetonia aurata.

Ann. 5* Melolontha vulgaris.

\section{§. 23.}

Adolefcentia dicitur tempus a mutatione laruae in pupam vsque ad prouentum imaginis.

Continet tempus pupae, quae faepius contractis antennis, alis pedibusque quiefcunt.

Dieb. 9-10. Mufea carnaria.

Dieb. I4. Papilio Vrticae, polychloros, Io, C album, Atalanta, Coccinella.

Hebd. 3. Caffida viridis, Dytifcus femiftriatus, NoAtua gamma, Sirex gigas.

Hebd. 4. Cetonia aurata, variabilis, Melolontha vulgaris, Bombyx difpar, fafcelina.

Hebd. 6. Phalaena alniaria.

Hebd. 8-9. Lucanus Ceruus, Scarabaeus naficornis.

Menf. 7-8. Bombyx pationia, pudibunda.

Menf. 9. Sphinx ocellata, atropos, Tiliae.

\section{ઈ. 24 .}

Aetas dicitur tempus a mutatione pupae in imaginem vsque ad mortem aut interitum totius infecti. 
Eft tempus ipfius infecti, in quo mouetur, fpè ciem propagat et tandem moritur.

Aetas plerisque annua vix vltra propagationem fpeciei protrahitur, dum mares plerumque mox poft coitum, feminae vero poft ouo rum depofitionem pereant.

Tempus aetatis accurate determinare impoffibile, dum nunquam ante fpeciéi propagationem pereunt, et $\mathrm{f}$ in autumno nondum hunc creationis finem impleuerint; hybernant et primo vere iterum proue= niunt.

Actas breuifima. Ephemera.

- - longiflima. Aftacus, Cancèr, Scyllarus, Moñö: culus. 


\section{O E C O N O M I A.}

\section{$\circ$}

f. I.

economia infectorum dicuntur varii illi modi, quos ad fuftentationem, conferuationem et multiplicationem adhibent.

Oeconomia infectorum fingularis, admiranda, quum fpecies numerofiffimae, faepe minutiffimae plurimisque hoftibus expofitae, et tamen femper naturae miraculo proportionem certam, determinatam inter reliqua animalia conferuent.

Oeconomia infectorum examinat varia eorundem negotia, fines eorum explicat, et tandem ad leges, myfteria et oeconomiam naturae, quantum licet, penetrat.

Oeconomia naturae, homini digniffima, per generationes multiplicatas afcendendo monftrat creatorem, defcendendo per confervata naturalia offert naturam.

Sapientis vero eft cauffas examinare rerum, fcientiam augere, naturae myfteria luftrare et tandem e creatis creatorem cognofcere.

\section{2.}

Suftentationem vocamus modum, quo infecta fibi alimentum acquirere folent et diuidimus eam in fuftentationem laruae et imaginis.

Fabr. Entom. 
Larua et imago faepius diuerfifimo nutriuntur alimento, ideoque etiam fuftentatio eorum diuerfiffima.

Suftentatio pupae haud in confiderationem venit, quum pupae pleraeque nullo ntur nutrimento. Agilis vero pupae fuftentatio femper cum fuftentatione laruae conuenit, quum nutrimentum earum omnino idem.

Suftentatio continet fundamentum educationis et culturae.

\section{3.}

Suftentatio laruarum inprimis rapina viuentium faepius fingularis.

Laruae phytiphagae ad fuftentationem pauciores adhibent variationes. Excluduntur in plantis, quibus victitant, quas raro deferunt.

Per paria inaequalia lineis femper claufis migrant laruae Bombycis proceffioneae.

Per lineas parallelas difponuntur pafcentes laruae Chryfomelae Vitellinae.

Sub tentorio communi e filis contexto pafcuntur laruae Bombycis neuftriae et caftrenfis.

Neetare florum a fpadonibus collecto nutriuntur Apum laruae.

Laruae rapina viuentes faepius artificia varia adhibere folent.

Laruae obefac Coccinellarum 'et Mufcarum Aphidiuorum inrer Aphides exclufas illis victitant.

Curuatura corporis celerrime fe mouent maxillisque porreçis arcuátis rapiunt Laruae Dytifci, Hy. drophili.

Pedibus anticis elongatis, raptoriis alia infecta capiunt Mantis, Nepa.

Rependo 


$$
\text { X. O E C O N O M I A: }
$$

Rependo forficeque oris late exferendo infidias ftruint Libellulae, Agrion et Aefhnae.

In fouea in arena excauata et arena longe lateque difperfa infecta venantur Myrmeleanes.

Intra animalium viuentium corpora exeluduntur, nutriuntur Oeftri, Acarique varii.

Alia infecta intus detrorant Ichneumones, Spheges:

\section{\$. 4 .}

Suftentatio imaginis fecundum varium victum etiam varia.

Phytiphaga plantis continuo inhaerent, quibus victitant. Curculio, Chryfomela aliaque multa.

Floribus inhiant nectar haurientia Gloffata, Mufcàe, Bombylii.

Ligna finubus daedaleis penetrant Boftrichus typographus, micrographus, calcographus.

Vtenfilia fere omnia deftruunt relicta fola fuperficie Termes.

Mammalia per totum diem fequintur Tabani, Culices; Conopes, Hippobofcae.

Mammalibus continuo inhaerent Pulices, Pédiculi; Acari.

Velocitate et volatus et curfus infectis praedantur $\mathrm{C}$ cindelae, Carabi, Libellulae, Empis, Afilus.

Retibus vario modo collocatis venantur Araneae variae.

Saltu vario infecta inprimis Antliata rapiunt Araneac aliae.

Cadauera e longinquo percipiunt Dermeftes, Silphae; Nicrophori, Staphilini.

Pabulum pro tempore hyberno colligunt Apes, Formicae, Vefpae.

Cibo omnino inullo vtuntur. Eqhemerae; Borbyces Oeftri.

$$
\text { 6. } 5:
$$

Conferuationem nominamus varios modos, quibus hoftibus fe fubtrahere folent infeeta: 
Diuiditur in laruae, pupae et imaginis conferuationem.

In conferuatione infectorum valde prodiga fuit natura. Innumeros fere modos defenfionis aut cenferuationis inuenimus.

Senfibus externis hoftes appropinquantes cognofcunt. Gaudent inprimis oculis et antennis.

Oculos infectis immobiles compenfauit natura aut numero maiori fituque vario, aut compofitos illis conceflit aut pedunculo mobili finplices impofuit, vt omnia et altius et vtrinque circumfpicerent.

Antennae articulatae, mobiles, fenforiae, fenfu nobis adhuc ignoto.

Quo minora infecta, eo etiam plures illis funthoftes et vita periculofior. Compenfantur autem fertilitate immenfa et numero fere infinito.

$$
\text { \$. } 6 .
$$

\section{Laruae multoties hoftes eludunt.}

Arma funt variis varia.

pilofae, quae tactu faepius pruritum excitare folent. Dermeftides, Bombyx Caja, Plantaginis, villica, hera, fafcelina, antiqua, proceffionea. fpinofae Nicrophori, Caflidae, Papilio Vrticae, Po. puli, Antiopa. forficatae cauda forficata. Forficula. tentaculatae. Papilio Machaon, Apollo. caudatae Sphinges pleraeque, Bombyx Mori. aliae fub terra fe abfcondunt. Scarabaeus, Melolontha, Cetonia, Lucanus, Tipula, Truxalis. aliae fub aqua vrinantur. Dytifcus, Hydrophilus, Libellula, Aefhna, Agrion. aliae proprio ftercore obtectae obambulant. Caffidae. aliae 


\section{OECONOMIA.}

aliae quisquilias facile deponendas circumferunt, Reduuius perfonatus,

aliae curfu feftinant, ne laedantur. Blatta, Forfict:la.

faltu faepe altiffino fe fubtrahunt Grylli, Cercopis.

intra fpumam ano euacuatam latent Cicadae fpumariae.

fub angiportu e terra confecto migrant Termes fatale, Truxalis.

fub tentorio communi filis contexto gregatim pafcuntur Bombyx neuftria, caftrenfis, Tinea Euonymella, Padella.

vomitu hoftes pellere tentat Bombyx Coffus.

cauda longa duplici vibrant terrentque Bombyx vinula, furcula.

ratnulum arboris, cui infident, mentiuntur Phalaenae pectinicornes plurimae.

motu capitis et corporis Ichneumones fugant Gloffata.

folia contorquent filoque connectunt, intra quae latent, Pyralides.

intra cucullum mobilem a fe ipfo confeetum latitant

Tinea pellionella, trapezella, mellonella, cucullatella, Phryganeae.

cochleam animalculo mertuo intrant Pagurus, Diogenes et Bernhardus.

intra plantarum gallas nutriuntur Cynipedes.

intra alia infecta fecure iacent Ichneumones, Sphe-

ges.

mammalium corpora intrant fonticulum excitantes

Oeftri.

foetore hóftes pellunt Cimex, Acanthia, Reduuius.

intra aceruum e quisquiliis accumulatum nutriuntur Formicae.

intra fauos fexangulares polline florum conftructos educantur Apes.

$$
\text { 6. } 7 \text {. }
$$

Conferuatio puparum quiefcentium faepius fingularis. 
Pupas agiles, currentes, laruis fimillimas hic prae. tereo, quum earum conferuatio cum con feruatione laruarum omnino conueniat.

intra glebam e terra confectam intus excauatam, politam Latent Scarabaei, plexaque Eleuterata:

intra folliculum denfum e filis conftructum degunt Bombylius, Noctua,

flis hifce pilos corporis immifcent laruae hirfutae Gloffatorum.

filo apicis fe fufpendunt Papiliones varii.

filis quibusdam circa dorfum ductis fo alligant Papi= liones alii.

motu corporis celeriori hoftes in fugam vertere tentant Papiliones alii.

in gyrum celerrime fe mouet Bombyx difpar, ne vero. filum, quo fuspenditur, rumpat, mox retro movetur.

in cutem durifimam mutantur exuuiae Mufcarum, quae pupam extus obregunt.

intra folliculum apice intus elaftice aperiendum quiefcit Bombyx pauonia.

\section{8.}

Conferuatio imaginum fiue infectorum ipforum faepe diuerfifima.

alis fe in aera attollunt et vario modo effugiunt Glorfata, Syniftata, Antliata.

curfu celeriori fugam tentant Araneae, Blattae.

fub aqua fe abfcondunt Dytifcus, Hydrophilus, Gyrinus.

fub terra degunt fodientes Helops, Scarabaeus, Trua xalis.

faltu fe fubtrahunt Chryfomelae, Curculiones, Cicadae, Pulex, Podurae.

Epinis armantur Hifpa, Curculio, Lamia, Stratiomys. pilis obducuntur Bupreftis, Scarabaeus, Apis, Mufca. mortem fimulando hoftes eludit Ptinus pertinax, Byrrhus pilula, Nitidula feminulum, Noctua exoleta. 
crepitu ventris cum fumo terrefacit Carabus crepitans.

forfice caudae fe defendunt Forficula, Panorpa.

abdomine elongato, quamuis innocuo, vibrant Staphylinus, Thrips.

manibus chelatis etiam abiiciendis dimicant Cancer, Aftacus.

aculeo rigido faepius venenato laedunt Syniftata.

aculeo caudae arcuato, acuto vulnerat Scorpio.

maxillis validis arcuatis mordere conantur Cicinde. lae, Araneae.

vomitu foetidiffimo hoftes pellere tentant Silpha, $\mathrm{Ca}$ rabus.

folia imitantur obambulantes Grylli, Cicadae. Sic enim natura naturam ludit,

foetore hoftes in fugam vertunt Cimex, Acanthia, Reduuius,

pedibus anticis acutis, arcuatis vulnerat Mantis, Nepa:

oleum limpidiffimum acre per omnia corporis genicu. la exferit Meloe.

intra concharum viuentium teftas fe abfondunt Cancer minutus, pinnothores.

intra cochlearum emortuarum teftas caudam molliorem abfondunt Pagurus Diogenes et Bernhardu's.

intra folliculum cylindricum, denfum, fuperne oper. culatum latet Aranea Brown.

§. 9.

Multiplicationem vocamus omnia, quae ad propagandam fpeciem inferuiunt, vti copula, depofitio ouorum et in quibusdam educatio laruarum et puparum.

Conferuatio fpeciei per multiplicationem vltimus naturae finis videtur.

$$
64 \text { Multi- }
$$


Multiplicatio neceffaria, vt infecta negotiis fufficiant, vt naturae theatrum nitore et adolefcentia fempiterna fulgeat.

Infecta ob debilitatem hoftiumque numerum praematuro fato deftruuntur, quod vero natura fertilitate prodiga, immenfa compenfauit, ne langueat fpecies.

De imagine tantum loquimur, quum laruae et pupae fteriles fpeciem propagare haud valeant.

\section{ข. 10.}

Copula infectorum fecundum fingularem naturam et fitum partium genitalium differt.

Plerisque partes genitales in abdominis apice fitae. mares foeminis infiliunt. Eleuterata, Antliata. retro coeunt. Gloffata.

feminae comprimunt mares. Apis, Pulex, Grylli, Locuftae.

In pectore latent genitalia marum. Libellulae, Agrion, Aefhnae. Mas faeminam forcipe caudae circa collum apprehendit et fic obuolitat, vsque dum femina caudam vuluiferam ad maris peetus flectit, foecundatur.

Ad bafin abdominis penes duos gerunt Cancrorum mares, foeminae vero genitalia ad bafin pedum tertii paris.

Palpi articulo vltimo clauato, veficulofo, aranearum funt partes genitales mafculi, foemineae vero ad bafin abdominis latent. Appropinquant coeuntes circumfpectione, ne altera alterum deuoret, voraciffimae enim funt et in propriam fpeciem faeuitunt.

Stridore pedum fpinoforum contra alas Grylli alliciunt feminas.

Proprio inftrumento fub abdominis bafin latente ftrident Tettigoniae. 
Sub ligni fiftulan pulfat maremque allicit femina $\mathrm{He}$ merobii pulfatorii.

Lucem in tenebris fpargunt nuptias celebrantes Lampyris et Laternaria.

\section{II.}

In deponendis ouis fummam et maximam curam adhibent feminae, quum contra mares polygami omnino incurii.

Cura infectorum pro ouorum conferuatione naturae legibus iniuncta fumma; fingularis, admiranda.

Nunquam ouis incubant, at locum eligere ftudent, vt laruae enatae mox alimentum, quin et fecuritatem inueniant.

globum e ftercore confectum ouo foetum voluit eb terrae credit Scarabaeus vernalis, pillula- at rius.

cadauera ouis impraegnata fub terra eandem effodiendo fummo labore fepelit. Nicrophorus.

fpuma, quae calore condenfatur, indurefcit, oua obducit Mantis, Locufta.

nidum pro ouorum receptione exitu incuruo fub terra excauat Truxalis, Gryllotalpa.

caudam terrae impingit et oua deponit Gryllus, Acrydium.

pilis corporis puluerulentis oua obducit Bombyx difpar, fafcelina, antiqua, laneftris, chryforrhoea.

ramulis oua in annulum adglutinat Rombyx caftrenfis.

materia denfa tenaci glutinofa oua obuoluit bombyx Salicis, Coffus.

granis ouum adglutinat Tinea granella.

in cylindro $e$ folio conuoluto vtrinque clanfo ouum abfondit Attelabus Coryli. 
apicem abdominis fub aqua immergit et oua deponit fedens Libellula.

apicem abdominis iterum iterumque aquae imbuunt fub volatu et oua deponunt Agrion, Tipula.

aculeo ferrato ramos arborum vulnerat et vulneribus outim concredit Tenthredo.

aculeo caudae fpirali fub abdomine recondito gemmas pungit et oum imponit Cynips, quo Gallae variae oriuntur.

aculeo caudae exferto pungunt ouaque imponunt larvis pupisque, quae nuper metamorphofin fubiere, Ichneumones.

oua laruis pupisque tantum adglutinant Ichneumones aculeo deftituti.

pedibus anticis foueam fodit, in qua laruam aut ara. neam occifam fepelit cui ouum credit, orificium vero terra aut argilla claudit Sphex.

e fiftulis ligneis aggregatis nidum cylindricum petiolatum conficit Vefpa rupeftris.

folia Rofae plura materia glutinofa tenaci in cylindrum coniungit, quem florum nectare melleo implet, outum imponit et orificium folio rotundato claudit Apis centuncularis.

- polline'florum cellulas prifmatico-hexangulares Aruunt, melleque e nectare florum replent, quo laruas nutriunt, Apes.

intra acerum e quisquiliis foliisque acerofis exftructum oua conferuant Formicae.

per totum diem fupra mammalium dorfum haeret .. Oeftrus, ve inter pilos cadat ouum.

equorum anum titillat, vt ouum in inteftino recto po. nat Oeftrus haemorrhoidalis.

in facco filis contexto oua circumfert Aranea faccata.

inter pedes fpurios oua gerunt Aftaci.

inter valuulas pectorales oua conferuant Onifci.

proprio corpore oua obuoluit moriens Cocçus. 


\section{12.}

Educatio laruarum paucis tantum generibus propria, Pleraque nullam earum gerunt curam.

Infecta, vti omnia animalia fanguine frigido gaudentia, nunquam ouis incubant, nulloque parentum amore fouentur, educantur.

Quibusdam vero generibus ad commodiorem vitam et ad laruarum educationem neuera conceffit natura. Apis, Formica. Termes. Et quibusdam forte aliis. 


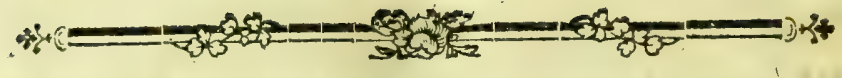

\section{XI. $\quad \mathrm{V} \quad \mathrm{S} \quad \mathrm{V} \quad \mathrm{S}$.}

Nmwer.

\section{S. I.}

fus infectorum quamuis minimorum fane magnus. Diuidimus in generalem et fpecialem.

Absque vfu nil a Creatore fapientiffimo confectum effe, iure meritoque contendimus.

Vfus eft vltimus fcientiae finis. Praeftat infectorum generalis in Philofophicis, fpecialis in Oeconomicis.

$$
\text { 6. } 2 .
$$

Vfus infectorum generalis, quem in oeconomia Naturae vniuerfali edunt, confiftit in conferuatione et multiplicatione fpeciei, in auferendis putridis, languidis, in detondendis quotannis vegetabilibus, in' humoribus animalium fuperfluis fugendis, in fervando aequilibrio inter animalium et vegetabilium fpecies et tandem aliis in alimentum cedendo.

Natura tota difcordibus conftat: quidquid alteri perit, in alterum tranfit, ne quid fuperfluum fit, vbi nil deeft.

Difcordibus hifce, bello hoc omnium contra omnes, renouatur quotannis naturae theatrum et conferuatur nitor aulae fempiternus. 
Nititur naturale femper alteri, fic animalia nituntur vegetabilibus, vegetabilia terrae, nec terra absque vegetabilibus nec vegetabilia absque animalibus exiftere valent, e quibus alimentum hauriunt.

Circulus igitur per omnia naturae regna perennis, quo ipfo florida aetas et fplendor omnium naturalium exiftentium vsque ad totius globi interitum obtinentur.

\section{§. 3 .}

Ad negotia haec varia infecta alliciuntur commodo proprio, dum e laboribus fuftentationem reportent.

Negotia infectorum propria, determinata, ne fefe aliorum negotiis immifceant illisque lucrum praeripiant.

Sub poena capitali lex haec veneni fancita eft, fenfibus ipfis infcripta, ne transgreffores excufabiles euaderent.

\section{§. 4 .}

Conferuatio et multiplicatio fpeciei neceffariae, vt negotiis propris, determinatis fufficiant.

Propagatio fpeciei vltimus finis creationis videtur. Mox poft eruptionem nuptias celebrant et breui tempore pereunt, quum contra ea, quae nondum nuptias celebrarunt, hybernent et vere rediente iterum proveniant.

Conferuationis et multiplicationis impulfores funt fames, dolor, libido.

Fames haud coercenda ad fuftentationem cogit, ne ante peractas nuptias perirent." 
Atrox dolor ad conferuationem impellit, ne adminiftratio vacaret.

Effraenata libido ad venerem incitat faepius cum vitae difpendio, vt poft parentum interitum liberi eorum officia peragerent.

\section{\$. 5 .}

Confumunt infecta putrida, languida, ftagnantia, ne odore tetro aut habitu languido confpurcetur naturae theatrum.

Naturà vt perenni femper flore rideat, putrida, acefcentia, naturae theatrum confpurcantia $\mathrm{ab}$ his naturae miniftris confumuntur, dum vegetiora in motu fertinent.

Cadauera putrefcentia, foetore aerem inplentia auferunt breui tempore Dermeftes, Silphae, Staphilini et inprimis Mufcae. Nil nifi offa nuda relinquunt, quae fenfim refoluuntur, in aera difperguntur.

Cadauera minora omnino fepeliunt, abfcondunt $\mathrm{Ni}$ crophori.

Truncos arborum putrefcentes finubus daedaleis perforant Cetoniae, Lucani, Cerambyces, Prioni aliaque plura, vt aqua plutualis intret, acefcat, qua fungi alliciuntur et breui tempore totam arborem deftructam in humo mutatam inuenimus.

Aquas ftagnantes, acefcentes, putrefcentes filtrant, purificant Culicum laruae numero infinitae.

Aquae fterquiliniorum putridum, foetidum confumunt Mufcae putris laruae.

Animalium ftercora perforant Scarabaei, Sphaeridia, ve pluuiis lixiuientur, ventis exficcentur, difpergantur.

Plantas aut a radicis laefione aut a folo peruerfo morbofas, languidas inundant, deftruunt Aphides, ne trifte fpectaculum diutius permaneret, ne viuacioribus locum praeripiant 


\section{\$. 6.}

Detondent quotannis vegetabilia inprimis laruae Gloffatorum et Coleoptera quaedam.

Pecora graminibus victitant, arbores vero altiores infectis relinquunt.

Nullam inuenimus plantam, ne venenatifimam quidem, quae haud quibusdam infectis pabulum praebeat lautum.

"Pini ramos inferiores intrat, exficcat et cadere facie Boftrichus Piniperda naturae hortulanus: Ramos vero fuperiores nunquam aggreditur, ne arbor vmbra radicis deficiente plane periret.

- Scrophulariae animalibus nullis efculentae infecta nutriunt varia, vti Curculio, Tenthredo, Anthrenus.

Vrtica dioica adultior animalibus naufeofa inprimis Papilionum laruas fuftentat.

Euphorbia fucco laeteo, acerrimo, venenatiffimo turgida tamen Sphingum laruis alimentum praebet.

Lichenes aridae nullis animalibus expetitae deuorantur a Tinea bipunctella, Lichenella.

\section{7.}

Infecta haud pauca animalium fanguinem fugunt, ne nimia plethora deftruerentur.

Animalia multa inprimis ab hominibus culta ob motus defectum et cibi abundantiam obefa, fucco copiofiori turgida perirent, nifi ab infectis ad motum incitarentur a fuccoque nimio liberarentur.

Pédiculi prole immenfa hominem animaliaque torquent.

Pulex faliens homines aliaque Mammalia vexat.

Conops calcitrans pedes pungendo calcitrationtem continuam boum equorumque efficit.

Acanthia, Culex, Tabanus, Hippobofca per totam àefta. tem animalia fequuntur, laedunt: 
Oeftrus per totam hyemem intra animalium dorfum latitat, fonticulo viuo qnafi inferuiens, quo humores fuperflui, nimis abundantes miro naturae. adminiculo eliciantur.

\section{\$. 8.}

Conferuant infecta aequilibrium inter animalium fpecies, 'ne aliae nimis propagentur et aliis locum praeripiant.

Animalia maxima vti minima infectis caftigantur, ne reliqua omnino deftruerent.

Animalia maxima mole, fortitudine reliqua fuperantia, folis infectis expofita.

Exanthemata viua, Rabies canina, Lues bouilla aliaque • plura ab infectis orta ftrages efficiunt ingentes, at clam operantur minutiffima.

Animalia mole minima, at numero, foecunditateque maxima, infinita itidem coercent, vt perennet proportio determinata.

Deftruunt laruas pupasque Ichneumones, Carabi, Cicindelae aliaque.

Imaginibus praedantur Araneae, Libellulae, Afili, Mantis, Empis.

Aphidum nimiam copiam minuunt Coccinellae, Mufcae aphidiuorae.

In propriam fpeciem faeuiunt Araneae, Cantharides.

$$
\text { §. } 9 \text { : }
$$

Conferuant infecta proportionem inter vegetabilium fpecies, dum partim propagationi inferuiunt, partim nimia copia luxuriantia deftruunt.

Propagationi inferuiunt, dum foecundationem plantarum promouent. Absque infectorum ope multa fane abortirent. 


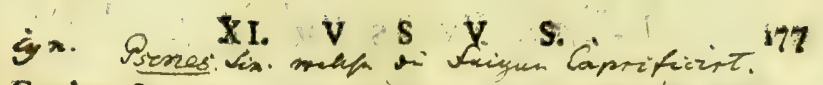

Cynips Sycomori foecundationi Ficus inferuit. Exemplum iam diu notum, diftinctiffimum.

Tipula pennicornis foecundationem Ariffolochiarum pro. mout, vti Lipfiae faepius obferuauimus.

Alias vero plantas nimia copia luxuriantes relis quasque opprimentes coercent infecta partim radices deftruentia, partim femina devorantia.

Bombyx Graminis pratorum gramina deftruit et fequent? anno prata floribus variis diuerficoloribus fplendent.

Tipulae, Truxalides; Melolonthae plantaruin radice deuorant.

Curculiones, Bruchi, Tineae, Dermeftides aliaque in: fecta varia plantarum femina exedunt, ne nimis multiplicentur:

\section{10:}

Infecta tandem omnia reliquis animalibus inprimis auibus alimento inferuiunt.

Myrmecophagae omnes formicis fultentantur.

Aues cantantes, tenuiroftres fere omnes infectis victitanit: Amphibia orninia infectis praedanttir:

Pifces omnes infectis delectantur:

\section{$\S$. ín}

Vifus infectorum fpecialis, quem in oeconomia humana praebent; eft medicus aut oeconomicus: Vterque vero a noxa fuperatur.

Eatet adhuc vfus infectorum plurimorum, quem forte pofterioris aeui diligentia deteget:

vfus infectorum medikisis. Canthärides, Meloce, Apes, Spiritus et balnetim Formicarim.

vfus infectoruth oeconomicus.

- - efculenta.i Cancer, Aftactus, Grisilus:

- - tinetoria. Cocsus, Chermes:

For zoriztom. 
. Vius. fila pracbentia. Bombyx Mori et forte plura.

- mel ceramque colligentia. Apis, Vefpa.

\section{ઈ. 12.}

Noxa infectorum in Oeconomia humana maior et huius cauffa Entomologia Oeconomis praecipue commendanda.

Infecta laedunt, deftruunt omnia. Molequidem parua clam operantur, at fertilitate numeroque immenfa valent.

Deftruunt prata. Bombyx Graminis, Truxalis, Tipulae. Laedunt agros. Mufca Frit, Thrips, Grylli, Tineae. Nocent arboribus. Papilio, Bombyx, Curculio, Chyry. fomela, Melolontha,

Deuorant plantas. Curculio, Papilio, Noctua, Phalaena. Infeftant granaria. Curculio, Tinea.

Fatigant pecora. Oeftrus, Tabanus, Conops, Myopa. Obfunt apibus. Tinea mellonella, Pyralis cereana. Exedunt vtenfilia. Tinea, Dermeftes, Termes, Ptinus. Aggrediuntur homines. Acarus, Pulex, Pediculus, Cinex.

Linne Diff. Noxa infectorum plura conquifiuit.

Magni omnino res eft rerum naturas latebras di monere. SENEC.

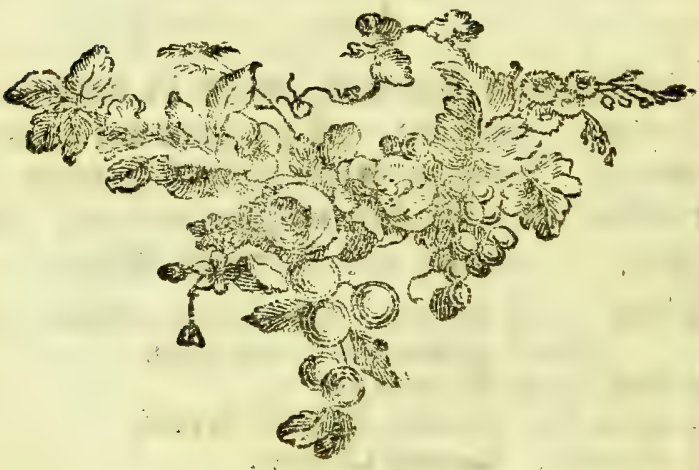







